\title{
I. Ueber den Zusammenhang zwischen den krystallographischen Eigenschaften von isomorphen Salzen und dem Atomgewicht der darin enthaltenen Metalle.
}

\author{
Eine vergleichende Untersuchung der normalen Sulfate von \\ Kalium, Rubidium und Cäsium.
}

Von

A. E. Tutton in London.

(Hierzu Tafel I und 12 Textfiguren.)

Die interessanten Beziehungen, welche aus der eingebenden Untersuchung der Kalium-, Rubidium- und Cäsiumsalze der monosymmetrischen Doppelsalze der Reihe $\mathrm{R}_{2} \mathrm{M}\left(\mathrm{SO}_{4}\right)_{2} \cdot 6 \mathrm{H}_{2} \mathrm{O}$ abgeleitet wurden (diese Zeitschr. 21, 491), machten ein ähnliches Studium der einfachen Sulfate dieser Metalle sehr wunschenswerth. Die Untersuchung ist etwas durch die Thatsache erschwert worden, dass die Winkeldifferenzen viel kleiner sind als bei den Doppelsulfaten. Wäbrend die Differenzen, welche in letzteren durch die Ersetzung des Kaliums durch Rubidium und dann des Rubidiums durch Gäsium hervorgebracht werden, sehr beträchtlich, häufig einen ganzen Grad uberschreitend, gefunden wurden, sind dagegen bei den rhombischen einfachen Sulfaten der drei genannten Metalle die Differenzen nur selten über funfzehn Minuten, und erreichen nie einen halben Grad. Daher war es besonders nöthig, nur vollkommen reine Salze und Krystalle ganz frei von Wachsthumsfehlern zu untersuchen.

Man solite glauben, dass diese drei wichtigen Salze seit Langem krystallographisch genau bearbeitet worden seien. Dieses ist aber durchaus nicht der Fall. Die krystallographischen Daten betreffend das schwefelsaure Kalium sind ganz unzulänglich für den vorliegenden Zweck, während die Angaben uber das Rubidiumsalz und das Cäsiumsalz nicht allein viel unvollständiger, sondern auch unrichtig sind. Die jetzt angenommenen Axenverbältnisse sind diejenigen für schwefelsaures Kalium von Mitscherlich vom Jahre 1830, die von Bunsen 1861 angegebenen Werthe für Rubidiumsulfat 
und diejenigen für Cäsiumsulfat von Top söe aus Messungen v on Lang's 1867 berechnet. Diese Werthe sind die folgenden, in der jetzt gewöhnlich angewandten Ordnung gesetzt :

$$
\begin{gathered}
\text { für } K_{2} \mathrm{SO}_{4} \quad a: b: c=0,5727: 1: 0,7464, \\
-\mathrm{Rb}_{2} \mathrm{SO}_{4} a: b: c=0,5723: 1: 0,7522 ; \\
-\mathrm{Cs}_{2} \mathrm{SO}_{4} \quad a: b: c=0,5805: 1: 0,7400 .
\end{gathered}
$$

Topsöe (Tidsskrift for Physik og Chemi 8, 5, 193, 321 und 9, 225) nimmt diese Axenverbältnisse in seiner beruhmlen Classificirung der isomorphen Reihen an. Man sieht sofort, dass, wenn diese Verhältnisse richtig sind, jede Idee einer Zunahme nach dem Atomgewichte des Metalles aufgegeben werden muss. In Rücksicht auf den entscheidenden Beweis, dass eine solche Zunahme bei den Salzen dieser drei Metalle in der That existirt, welcher durch die Resultale der goniometrischen Untersuchung der oben genannten Doppelsulfate geliefert wurde, war es von der höchsten Wichtigkeit, diese drei einfachen Sulfate ebenfalls einer eingehenden Untersuchung zu unterwerfen. Dass eine Ahhängigkeit vom Atomgewichte zu erwarten ist, wird ferner durch die in der letzten Zeit erschienene Arbeit von $\mathrm{Muthmann}$ über die Permanganate dieser drei Alkalimetalle angedeutet (diese Zeitschr. 22, 497).

Die Untersuchung der Doppelsulfate war auf die goniometrischen Beziehungen beschränkt. Die optischen und andere physikalischen Eigenschaften werden jetzt untersucht, und Verf. hofft in Kurzem die Resultate mitzutheilen. Es ergab sich die Nothwendigkeit, um die für die optische Arbeit nothwendigen Platten und Prismen mit grösserer Präcision als bisher herzustellen, ein neues Instrument für diesen Zweck zu construiren. Ein zweites Instrument wurde ferner erdacht, um monochromatisches Licht irgend einer Wellenlänge zu erzeugen, so dass die Beobachtungen für eine grössere Zahl von Wellenlängen als gewöhnlich, und in viel kürzerer Zeit, gemachl werden können, während zugleich das ganze Gesichtsfeld des Beobachtungsinstrumentes gleichmässig, und weit heller als durch das Benutzen von gefärbten Flammen, erleuchtet wurde. Diese zwei Instrumente sind in den Philosophical Trans. of the Royal Soc. (Serie A, 1894) beschrieben worden und eine deutsche Ausgabe dieser Beschreibung wird demnächst in dieser Zeitschrift erscheinen. Während der Ausfuhbrung dieser Instrumente sind die normalen Sulfate des Kaliums, Rubidiums und Cäsiums einer ausführlichen goniometrischen Untersuchung unterworfen worden, und da die Instrumente fertig gestellt waren, als jene vollendet wurde, hat Verf. die Arbeit über diese drei Salze durch ein ebenso ausfuhrliches Studium der optischen und anderen physikalischen Eigenschaften vervollständigt.

Die reinen angewandten Sulfate bildeten einen Theil des Ausgangsmaterials, welches fur die Darstellung der Doppelsulfate beschafft worden 
war. Analysen der drei Salze wurden in der vorher erwähnten Mittheilung (S. 492) gegeben. Diese Analysen nebst spectroskopischer Prüfung deuten einen hohen Grad von Reinheit an. Die Salze sind seitdem häufig wieder theilweise umkrystallisirt worden, um die Sicherheit für ihre Reinheit zu erhöhen.

Die spectroskopische Prüfung wurde mit besonderer Sorgfalt vorgenommen. E $\mathbf{r d m}$ an hat in der letzten Zeit gezeigt (Archiv der Pharmacie 232, 1, 10), dass man kleine Spuren des Kaliums in Rubidiumsalzen mit Gewissheit durch Beobachtung der Linien im Roth des Spectrums entdecken kann. Die zwei nahe zusammenliegenden rothen Linien des Kaliums besitzen die Wellenlängen (nach Kayser und $\mathrm{R}$ unge) 766,56 und $769,93 m_{\mu}$. Die zwei rothen Rubidiumlinien haben die Wellenlängen 781,1 und 795 $m_{\mu}$. Ein 1-2\% Kalium enthaltendes Hubidiumsalz zeigt, nach Erdmann, die doppelte Kaliumlinie sehr stark und die Rubidiumlinie 781 nur schwach, während die andere Rubidiumlinie ganz fehlt. Ein analytisch reines Salz zeigt die beiden Rubidiumlinien, aber die Kaliumlinie herrscht noch vor. Annähernd reine Rubidiumsalze zeigen vorherrschende Rubidiumlinien, jedoch ist die Kaliumlinie noch sichtbar, wäbrend ein absolut reines Rubidiumsalz natürlich keine Spur der Kaliumlinie giebt. Das in dieser Untersuchung angewandte schwefelsaure Rubidium zeigte die zwei erwähnten rothen Linien mit grosser Intensität, aber keine Kaliumlinie. Das schwefelsaure Gäsium gab weder Kalium-, noch Rubidiumlinien, die ganze Reihe der Cäsiumlinien aber war sehr hell.

\section{Löslichkeit der drei Sulfate.}

Die drei Salze weichen hinsichtlich ihrer Löslichkeit sebr von einander ab. Schwefelsaures Kalium ist, wie wohl bekannt, ein schwer lösliches Salz. $\mathrm{Mulder}$ fand, dass $100 \mathrm{ccm}$ einer bei $10^{0}$ gesättigten Lösung nur $9,7 \mathrm{~g} \mathrm{~K}_{2} \mathrm{SO}_{4}$ enthielten und die Bestimmungen von Buns en stimmen mit diesem Resultate überein. Schwefelsaures Rubidium ist viel löslicher. Erdmann (loc. cit.) fand in $100 \mathrm{ccm}$ einer bei gewöhnlicher Temperatur gesättigten Lösung 34,4 g $\mathrm{Rb}_{2} \mathrm{SO}_{4}$; Bunsen (Ann. der Chemie 119, 110) giebt an, dass es sich in der 2,4 fachen Menge seines Gewichtes Wasser bei $7^{0}$ auflöst. Verf. fand, dass bei $17,5100 \mathrm{~cm}$ Wasser $44,7 \mathrm{~g}$ reines $R b_{2} S O_{4}$ auflösen, und $100 \mathrm{ccm}$ einer bei dieser Temperatur gesättigten Lösung $44 \mathrm{~g}$ des Salzes nach dem Verdunsten zurücklassen. Schwefelsaures Cäsium ist ein sehr lösliches Salz. Bunsen (l. c.) giebt an, dass bei $2^{0}$ nur 0,63 seines Gewichtes Wasser zur Lösung gebraucht wird. Verf. beobachtete, dass $100 \mathrm{ccm}$ Wasser bei 17,0ّ lösen 163,5 g des reinen Salzes, einer Löslichkeit in 0,61 seines Gewichtes Wasser entsprechend, ein Resultat, welches gut mit demjenigen von Bunsen ubereinstimmt. Nach dem Verdunsten einer bei dieser Temperatur gesättigten Lösung hleibt eine Menge $\mathrm{Cs}_{2} \mathrm{SO}_{4}$ zurück, welche $131 \mathrm{~g} \mathrm{Salz} \mathrm{per} 100 \mathrm{ccm}$ 
Lösung entspricht. Das Volum der gesältigten Lösung ist beinahe genau ein Viertel grösser als dasjenige des für die Lösung gebrauchten Wassers.

Die Löslichkeiten sind grösser bei höheren Temperaturen, jedoch ist schwefelsaures Kalium selbst bei $100^{\circ}$ nur schwach löslich. Cäsiumsulfat löst sich bei $100^{\circ}$ in einer sehr grossen Menge auf, um eine sehr schwere Flüssigkeit zu bilden, auch schwefelsaures Rubidium ist mehr löslich als bei der gewöhnlichen Temperatur, behält aber noch seine mitılere Stellung. Was die Löslichkeit der Salze betrifft, kann man daher die folgende Schlussfolgerung ziehen :

Die Löslichkeilen der normalen Sulfate von Kalinm, Rubidium und Cäsium sind sebr verschieden; schwefelsaures Kalium ist schwer, schwefelsaures Rubidium ziemlich und schwefelsaures Cäsium sehr löslich in Wasser. $100 \mathrm{ccm}$ Wasser bei der gewöhnlichen Temperatur lösen $10 \mathrm{~g} \mathrm{~K}_{2} \mathrm{SO}_{4}$, $44 \mathrm{~g} R b_{2} \mathrm{SO}_{4}$ und $163 \mathrm{~g} \mathrm{Cs}_{2} \mathrm{SO}_{4}$ auf. Die Löslichkeiten sind grösser bei höheren Temperaturen, aber die mittlere Stellung des Rubidiumsalzes wird bewahrt.

\section{Goniometrische Untersuchung.}

Der Isomorphismus der rhombischen Normalsulfale von Kalium, Rubidium und Cäsium ist ein sehr vollkommener. Dieselben Formen sind an den Krystallen aller drei Salze entwickelt; zwar werden Verschiedenbeiten in der relativen Ausbildung der Flächen beobachtet, so dass jedes Salz durch

Fig. 1.

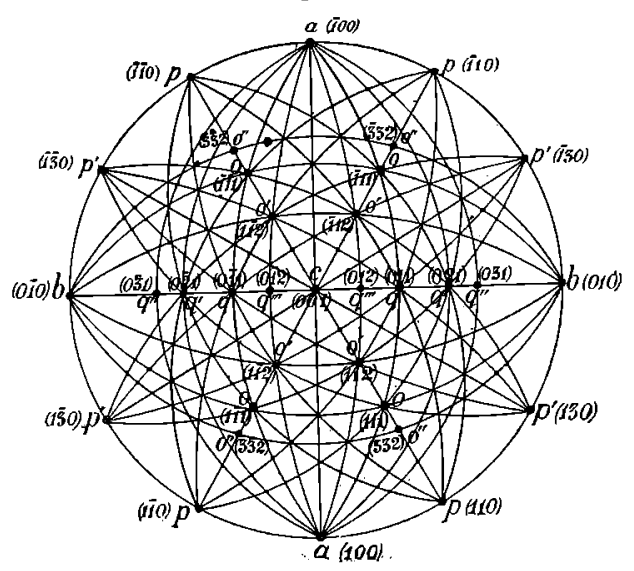
besondere Eigenthumlichkeiten des Habitus charakterisirt ist, doch ist der Unterschied nicht so scharf, als bei den Doppelsulfaten.

Die allgemeine Symmetrie der drei Sulfate ist in der spbärischen Projection, Fig. 1, dargestellt.

Die Winkelunterschiede sind so klein, dass eine sphärische Projection in dem gegebenen Maassstabe alle drei Salze genau repräsentirt. Man bemerkt sofort als Hauptzug der Symmetrie

die Annäherung an hexagonale Symmetrie. Die Winkel $a p, p p^{\prime}$ und $p^{\prime} b$ sind beinahe genau $30^{\circ}$; der Winkel $a p$ ist $12^{\prime}-16^{\prime}$ weniger als $30^{\circ}$ und 
Ueber den Zusammenlang zwischen den krystallographischen Eigenschaften etc. 5

der Winkel $p^{\prime} b$ grösser als $30^{0}$ um denselben Betrag, während der Winkel $p p^{\prime}$ bei jedem Salze genau $30^{\circ}$ gefunden worden ist.

\section{Schwefelsaures Kalium, $\mathrm{K}_{2} \mathrm{SO}_{4}$.}

Mehrere besonders vortreffliche und passende Krystallisationen dieses Salzes, welche aus sehr glänzenden, ungestreiften und ungekrúmmten Individuen bestanden, wurden durch die Methode der langsamen Krystallisation aus kalten Lösungen erhalten. Um diese Lösungen gegen plötzliche Temperaturänderungen und störende atmosphärische Einflüsse zu schützen, wurden sie unter eine grosse Glasglocke gebracht, und die kleinen mit ebenen Böden versehenen Bechergläser, worin die Lösungen enthalten waren, auf schlecht wärmeleitende Stoffe gestellt und mit denselben umgeben. Das langsame Verdunsten geschah bei gewöhnlichem Drucke und wurde durch das Wasseranziehen concentrirter Schwefelsäure hervorgebracht, welche ebenfalls unter der Glocke eingeschlossen wurde.

Elf der am besten ausgebildeten flächenreichen Krystalle von bequemer kleiner Grösse wurden aus drei dieser vortrefflichen Krystallisationen ausgewählt und mit grosser Ausfuhrlichkeit gemessen, welche durch die Winkeltabelle angedeutet ist.

Das Axenverbältniss, aus den Messungen berechnet, ist:

$$
a: b: c=0,5727: 1: 0,7418 \text {. }
$$

Der Werth des von Mitscherlich angegebenen Verbältnisses ist 0,5727: $1: 0,7464$.

Die be obachteten Formen schliessen alle die in der sphärischen Projection angegebenen Formen ein, mit Ausnabme des Brachydomas $q^{\prime \prime \prime}\{012\} . \quad$ Es sind: $a=\{100\} \infty \bar{P} \infty, b=\{010\} \infty \breve{P}_{\infty}, c=\{001\} 0 P$, $p=\{110\} \infty P, p^{\prime}=\{130\} \infty \breve{P} 3, q=\{011\} \breve{P} \infty, q^{\prime}=\{021\} 2 \breve{P} \infty, q^{\prime \prime}=$ $\{031\} 3 \breve{P} \infty, \quad o=\{111\} P, \quad o^{\prime}=$ $\{112\} \frac{1}{2} P, o^{\prime \prime}=\{332\} \frac{3}{2} P$.

Fig. 2.

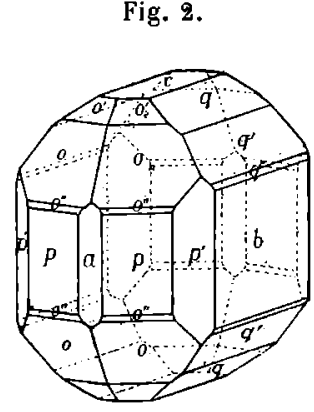

Fig. 3.

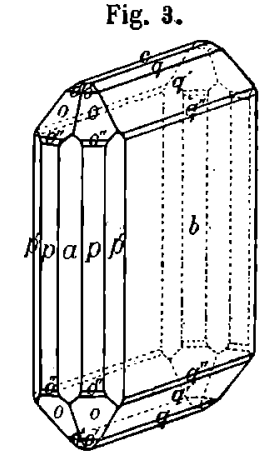
, in Fig. 2, 3, 4 u. 5 dargestellten Typen des Habitus hervorgebracht wurden. Diese vier Typen charakterisirten auch alle anderen erhaltenen Krystallisationen. 
Die Krystalle des ersten Typus zeigen einen kurzprismalischen Habitus, wie er in Fig. 2 dargestellt ist. Die Prismen werden gebildet durch die Flächen des Brachypinakoids $b\{010\}$, welche gewöhnlich sehr vorherrschen,

Fig. 4.

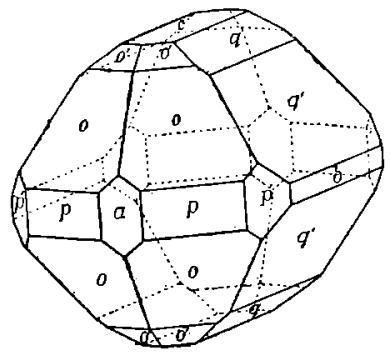

Fig. 5.

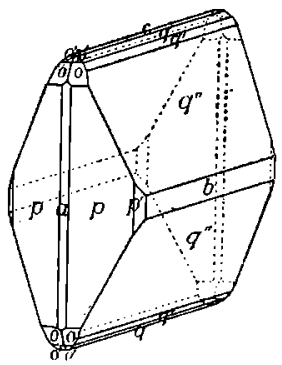
daruach folgen an Wichtigkeit zunächst jene des Brachydomas $q^{\prime}\{021\}$, ferner des Brachydomas $q\{011\}$ und der Basis $c\{001\}$, welch' letztere zwei Formen gewöhnlich viel schmäler sind. Die Endflächen bestehen aus schmalen Flächen des Makropinakoids a $\{100\}$ und breiteren Flächen des primären Prismas $p\{110\}$ und der prismatischen Form $p^{\prime}\{130\}$. Von diesen beiden prismatischen Formen herrschen in der Regel die Flächen des primären Prismas vor, doch ist es häufig auch der Fall, dass beide ungefähr gleich gross entwickelt sind. Von den pyramidalen Formen sind die Flächen der primären Pyramide $o\{111\}$ immer gut entwickelt; diejenigen der Pyramide $o^{\prime}\{112\}$ sind gewöhnlich kleiner, aber immer glänzend und eben. Die Entwickelung des Brachydomas $q^{\prime \prime}\{031\}$ ist gelegentlich eine gute, während die pyramidale Form $o^{\prime \prime}\{332\}$ nur selten beobachtet wird und dann immer nur klein und etwas matt ist.

Bei den Krystallen des zweiten, in Fig. 3 repräsentirten Typus herrscht das Brachypinakoid $b\{010\}$ so stark vor, dass der Habitus ein tafelförmiger ist. Die Krystalle dieses Typus bestehen aus dunnen viereckigen Platten, deren Kanten durch die eben erwähnten prismatischen und brachydomatischen Formen abgestumpft und deren Ecken durch dieselben pyramidalen Formen modificirt sind.

Die Krystalle des dritten Typus unterscheiden sich von den eben genannten durch das Vorherrschen der Flächen des Brachydomas $q^{\prime}\{021\}$, während jene des Brachypinakoids nur in ganz schmalen Streifen, wie in Fig. 4 dargestellt ausgebildet sind. Die Flächen der primären Pyramide $o\{111\}$ sind relativ sebr gross entwickelt, wäbrend jene des primären Prismas $p\{110\}$ und des Prismas $p^{\prime}\{130\}$ zu den relativen Dimensionen herabgehen, welche in der Zeichnung angedeutet sind.

Mehrere der grösseren Krystalle gewisser Krystallisationen zeigten eine ausserordentliche Ausbildung des Brachydomas $q^{\prime \prime}\{031\}$, wie dies in Fig. 5 dargestellt ist. Diese Krystalle besassen die Gestalt flacher Doppelkeile, häufig verlängert parallel den Keilkanten; ihre Enden wurden hauptsächlich durch die Flächen des primären Prismas $p\{110\}$ gebildet, während die Ecken nur unbedeutend durch kleine Flächen der Pyramide of111\} und 
$o^{\prime}\{112\}$ modificirt wurden. Die Flächen der prismatischen Form $p^{\prime}\{130\}$ und der anderen Brachydomen $q\{011\}$ und $q^{\prime}\{021\}$ waren alle relativ sehr klein.

Zahlreiche, hexagonalen Pyramiden ähnliche Drillings- oder Zwillingskrystalle wurden ebenfalls beobachtet, deren Zwillingsebene nabezu senkrecht zur Fläche des primären Prismas oder des Prismas $p^{\prime}\{130\}$ stand, wie dies bereits Mitscherlich und Scacchi beschrieben haben.

Mit Ausnahme der Flächen des Brachydomas $q^{\prime}\{021\}$ reflectirten die Flächen aller oben beschriebenen, gewöhnlich auftretenden Formen vortreffliche, meistens einfache, sehr helle und vollkommen definirte Signalbilder. Sehr häufig lieferten auch die $q^{\prime}$-Flächen ganz tadellose einfache Reflexe, und in solchen Fällen stimmten die gemessenen Winkel in einer zufriedenstellenden Weise mit den berechneten Werthen uberein. In anderen Fällen waren diese Flächen etwas gestreift und verzerrt, jedoch wurden dann nur jene Werthe angenommen, deren Unsicherheit ganz unbed eutend war.

Die Resultate der Messungen sind in der folgenden Tabelle zusammengestellt.

Zahl der

Messungen :

\{

$\left\{\begin{array}{l}3 \\ 2\end{array}\right.$

$\left\{\begin{array}{l}p p^{\prime} \\ p^{\prime} b\end{array}\right.$

$\left\{\begin{array}{l}c q=(001):(011) \\ q q^{\prime}=(011):(021) \\ c q^{\prime}=(001):(021) \\ q^{\prime} q^{\prime \prime}=(021):(031) \\ q^{\prime \prime} b=(031):(010) \\ q^{\prime} b=(021):(010)\end{array}\right.$

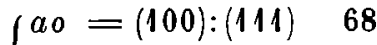

$\{\circ q=(111):(011) \quad 58$

$\left\{a o^{\prime}=(100):(112) \quad 27\right.$

$\left\{o^{\prime} o^{\prime}=(112):(112) \quad 7\right.$

$f_{0}=(010):(111) \quad 73$

$\{00=(111):(1 T 1) \quad 33$

$\left\{b o^{\prime}=(010):(112) \quad 25\right.$

$\left\{o^{\prime} o^{\prime}=(112):(1 \overline{1} 2)\right.$

$\left\{\begin{array}{lr}c o^{\prime}=(001):(112) & 35 \\ o^{\prime} o=(112):(111) & 37 \\ c o=(001):(111) & 80 \\ o o^{\prime \prime}=(111):(332) & 1 \\ o^{\prime \prime} p=(332):(110) & 1 \\ o p=(111):(110) & 84\end{array}\right.$
Grenzen :

$29045^{\prime}-29052^{\prime}$

$2955-30 \quad 4$

$308-30 \quad 15$

$3631-3641$

$1920-1931$

$5555-569$

$940-955$

$24 \quad 7-24 \quad 19$

$3352-34 \quad 5$

$4345-440$

$46 \quad 4-46 \quad 15$

$\begin{array}{llll}58 & 38-58 & 47\end{array}$

$6230-6238$

$6532-6541$

$48 \quad 40-4852$

$7238-7248$

$3431-3441$

$3638-3651$

$19 \quad 16-1933$

$\begin{array}{llll}56 & 6-56 & 17\end{array}$

$33 \quad 42-3357$
Mittel

beobachtet: $29048^{\prime}$

$30 \quad 0$

$30 \quad 11$

$36 \quad 36$

1926

$56 \quad 2$

944

2413

$\begin{array}{ll}33 & 59\end{array}$

4352

468

$58 \quad 44$

$62 \quad 34$

6536

$48 \quad 47$

7242

$34 \quad 36$

$36 \quad 45$

1926

$56 \quad 11$

$\begin{array}{lll}9 & 49\end{array}$

248

$\begin{array}{ll}33 & 49\end{array}$
Berechnet: Diff.:

$29048^{\prime} \quad 0^{\prime}$

$\begin{array}{lll}30 & 0 & 0\end{array}$

$\begin{array}{lll}30 & 12 & 1\end{array}$

$\begin{array}{lll}36 & 34 & 2\end{array}$

$\begin{array}{lll}19 & 27 & 1\end{array}$

$\begin{array}{lll}56 & 1 & 1\end{array}$

$\begin{array}{lll}9 & 47 & 3\end{array}$

$24 \quad 12 \quad 1$

$\begin{array}{lll}33 & 59 & 0\end{array}$

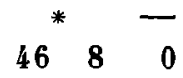

$\begin{array}{lll}58 & 44 & 0\end{array}$

$\begin{array}{lll}62 & 32 & 2\end{array}$

$\begin{array}{lll}65 & 37 & 1\end{array}$

$48 \quad 46 \quad 1$

$\begin{array}{lll}72 & 42 & 0\end{array}$

$3436 \quad 0$

$\begin{array}{lll}36 & 44 & 1\end{array}$

$1927 \quad 1$

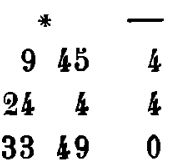


A. E. Tutton.

\begin{tabular}{|c|c|c|c|c|c|c|}
\hline & $\begin{array}{l}\text { Zahl der } \\
\text { ssungen }\end{array}$ & & Grenzen: & $\begin{array}{c}\text { Millel } \\
\text { beobachtet: }\end{array}$ & Berechnet: & Diff.: \\
\hline$\left(p_{0}=(110):(1 T 1)\right.$ & 55 & $60^{0}$ & $2^{\prime}-65^{01} 3^{\prime}$ & $65^{0} 9^{\prime}$ & $65^{0} \quad 8^{\prime}$ & $1^{\prime}$ \\
\hline$o q^{\prime}=(1 \bar{T} \mid):(0 \overline{2} 1)$ & 45 & 49 & $6-49 \quad 15$ & $49 \quad 11$ & $49 \quad 12$ & 1 \\
\hline$q^{\prime} p=(0 \overline{2} 1):(\bar{T} T 0)$ & 49 & 65 & $32-6550$ & 6540 & $6 \breve{~} 40$ & 0 \\
\hline$\left(p o^{\prime}=(110):\left(1 T^{\top} 2\right)\right.$ & 21 & 72 & $19-72 \quad 27$ & $72 \quad 23$ & $72 \quad 23$ & 0 \\
\hline$o^{\prime} q=\left(1 \top^{\top} 2\right):\left(0 \top^{\top} 1\right)$ & 15 & 34 & $49-3457$ & $34 \quad 52$ & 3450 & 9 \\
\hline$q p=(0 \mathbb{T} 1):(\mathbb{T} T 0)$ & 23 & 72 & $43-7252$ & 7246 & 7247 & 1 \\
\hline$\left(p^{\prime} 0=(130):(111)\right.$ & 46 & 43 & $54-446$ & 4359 & 4359 & 0 \\
\hline$O o^{\prime}=(111):(112)$ & 23 & 45 & $44-4552$ & $45 \quad 47$ & $45 \quad 47$ & 0 \\
\hline$o^{\prime} q^{\prime}=\left(1 T^{\prime} 2\right):(0 \overline{2} 1)$ & 20 & 45 & $53-46$ & 460 & $46 \quad 1$ & 1 \\
\hline$o q^{\prime}=(111):(0 \overline{2} 1)$ & 39 & 91 & $38-9155$ & $91 \quad 47$ & 9148 & 1 \\
\hline$\left(q^{\prime} p^{\prime}=(0 \overline{2} 1):(\overline{1} \overline{3} 0)\right.$ & 42 & 44 & $5-4423$ & $44 \quad 13$ & $44 \quad 13$ & 0 \\
\hline$\left(p^{\prime} o^{\prime}=(130):(112)\right.$ & 19 & 58 & $43-5853$ & $58 \quad 48$ & 5848 & 0 \\
\hline$o^{\prime} q=(112):(0 T 1)$ & 12 & 62 & $10-6218$ & 6214 & 6212 & 2 \\
\hline$q p^{\prime}=(0 \mathrm{~T} 1):(\bar{\top} \overline{3} 0)$ & 18 & 58 & $55-59 \quad 1$ & 5858 & $\begin{array}{ll}59 & 0\end{array}$ & 2 \\
\hline
\end{tabular}

Gesammtzahl der Messungen: 1160.

Ber merkw.üdige Grad der Uehereinstimmung zwischen den Mitteln 'der beobachteten und den berechneten Werthen rechtfertigt völlig die Ausfuhrlichkeit, womit die goniometrische Untersuchung ausgefuhrt worden ist. Die ausserordentliche Zahl der Messungen wurde besonders nöthig erachtet in Rưcksicht auf die kleinen Winkeldifferenzen, welche zwischen den drei Sulfaten erwartet wurden.

\section{Schwefelsaures Rubidium, $\mathrm{Rb}_{2} \mathrm{SO}_{4}$.}

Das schwefelsaure Rubidium kann man in guten einfachen Krystallen nur aus kaltgesättigten Lösungen erhalten; aus warmen Lösungen krystallisirt es gewöhnlich in federartigen Aggregaten. Fün Krystallisationen besonders gut ausgebildeter und gunstigerweise einfacher Krystalle wurden unter anderen erhalten durch sehr langsames Verdunsten kaltgesättigter Lösungen in der beim schwefelsauren Kalium erwähnten Weise, und hieraus wurden zehn vortrefflich ausgebildete Individuen ausgewählt und zum Messen benutzt.

Das Axenverhältniss, aus den Messungen berechnet, ist:

$$
a: b: c=0,5723: 1: 0,7485 \text {. }
$$

Das von Bunsen 1861 angegebene Verhältniss ist $0,5723: 1: 0,7522$ (Annalen 119, 110).

Die beobachteten Formen umfassen alle in der sphärischen Projection eingezeichneten Formen mit Ausnabme von $o^{\prime \prime}\{332\}$ und $q^{\prime \prime}\{031\}$. Es sind: $a=\{100\} \infty \bar{P} \infty, b=\{010\} \infty \breve{P}_{\infty}, c=\{001\} 0 P, p=\{110\} \infty P$, $p^{\prime}=\{130\} \infty \breve{P} 3, \quad q=\{011\} \breve{P} \infty, \quad q^{\prime}=\{021\} 2 \breve{P} \infty, \quad q^{\prime \prime \prime}=\{012\} \frac{1}{2} \breve{P} \infty$, $o=\{111\} P, o^{\prime}=\{112\} \frac{1}{2} P$. 
Der Habitus der Krystalle des schwefelsauren Rubidiums weicht beträchtlich von demjenigen der in Figg. 2 und 3 repräsentirten Krystalle des schwefelsauren Kaliums ab und nähert sich mehr demjenigen, welcher in Fig. 4 dargestellt ist. Die Flächen des Brachypinakoids $b\{010\}$ sind nämlich gewöhnlich recht schmal, wie in Fig. 6 dargestellt, während diejenigen des Brachydomas $q^{\prime}\{021\}$ so stark vorherrschen, dass sie den Krystallen einen prismatischen Habitus verleihen.

Fig. 6.

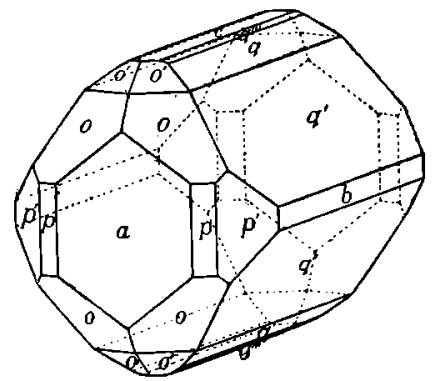

Fig. 8.

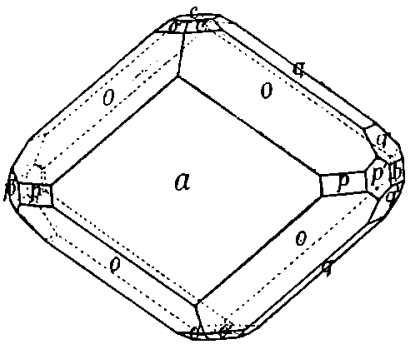

Fig. 7.

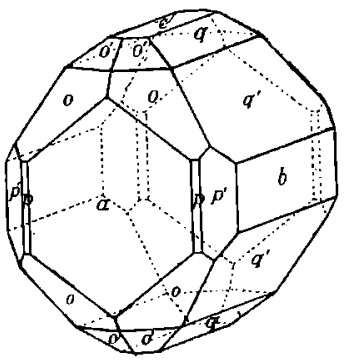

Fig. 9.

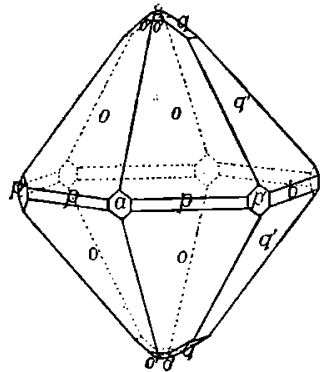

Die Enden der Prismen werden durch relativ grosse Flächen des Makropinakoids $a\{100\}$ und kleinere Flächen des Prismas $p^{\prime}\{130\}$ und der Pyramiden $o\{111\}$ und $o^{\prime}\{112\}$ gebildet. Das primäre Prisma $p\{110\}$ ist nur selten entwickelt; es wurde gut ausgebildet nur an zwei der gemessenen Krystalle gefunden. Die primäre Pyramide $o\{111\}$ war immer eine wichtige Form, doch waren auch die Flächen der zweiten Pyramide ó $\left.o^{\prime} 12\right\}$ häufig eben so gross und gelegentlich sie noch ubertreffend. Die Basis $c\{001\}$ war in der Regel nur schmal, und die Kanten $c q^{\prime}$ wurden in der Regel durch gleich schmale Flächen des primären Brachydomas $q\{011\}$ modificirt. An einem Krystalle wurde eine gute Fläche des selten vorhandenen Brachydomas $q^{\prime \prime \prime}\{012\}$ beobachtet.

Bei gewissen Krystallisationen waren die Flächen des Brachypinakoids $b\{010\}$ beträchtlich breiter wie in Fig. 7 dargestellt ist. Eine charakteristische 
Form des schwefelsauren Rubidiums ist auch in Fig. 8 abgebildet; der Habitus ist derjenige einer flachen Pyramide, auf einer breiten Basis parallel zum Makropinakoid $a\{100\}$ aufgebaut. Wegen der Hinderung durch die Oberfläche des Krystallisationsgefässes wurde das Wachsthum des Krystalles nach unten verzögert, so dass die Pyramidenflächen $0\{111\}$ und $o^{\prime}\{112\}$ entweder nur an einem Ende der Axe $a$ ausgebildet sind, oder wenigstens nur an diesem eine beträchtliche Entwickelung zeigen. Die Spitze der Pyramide ist gewöhnlich durch eine ziemlich breite Makropinakoidfläche abgestumpft. Gelegentlich trifft man äbnliche flache Pyramiden an, deren Grundflächen aber parallel dem Brachypinakoid $b\{010\}$ oder der Basis $e\{001\}$ sind.

Krystalle des schwefelsauren Rubidiums von noch einem anderen Typus wurden häufig beobachtet. Sie waren anscheinend hexagonale Pyramiden, wie in Fig. 9 gezeichnet ist, und die ausserordentliche Annäherung der Winkel der Prismenzone an $30^{\circ}$ nebst der fast ubereinstimmenden Grösse der Winkel $p o$ und $b q^{\prime}$ machte es schwer, sie von wahren hexagonalen Pyramiden zu unterscheiden. Diese Gestalt verdanken dieselben der beinahe gleichen Entwickelung der Flächen der primären Pyramide $o\{111\}$ und des Brachydomas $q^{\prime}\{021\}$, während die $o^{\prime}-$ und $q$-Flächen relativ sehr klein sind.

Ausserdem wurden noch Drillingskrystalle beobachtet, ähnlich denen des schwefelsauren Kaliums, deren Zwillingsebene beinahe senkrecht zur primären Prismenfläche war. Häufig bildeten sie vollkommene hexagonale Pyramiden, und die einfachen Krystalle des zuletzt beschriebenen Typus sind sehr schwer von ihnen zu unterscheiden. Messungen der Winkel $p o$ und $b q^{\prime}$ bestimmen die Verschiedenheit, denn die Winkelwerthe weichen $8^{\prime}$ ab, während bei den Drillingskrystallen die entsprechenden Winkelwerthe (in beiden Fällen $=p: o$ ) naturlich identisch sind. Bei den Drillingskrystallen sind auch die Flächen nicht eben; gewöhnlich zeigen sie eine Grenzlinie längs der Mitte, und die Hälften an verschiedenen Seiten der Verbindungslinie geben verschiedene Signalbilder, da der primäre Prismenwinkel nicht genau $60^{\circ}$ ist.

Die Flächen aller oben beschriebenen Formen mit Ausnahme derjenigen des vorherrschenden Brachydomas $q^{\prime}\{021\}$, dieselbe Form, welche auch beim schwefelsauren Kalium häufig etwas unvollkommen gefunden wurde, gaben meistens vortreffliche, einzelne helle Signalbilder. Die $q^{\prime}-$ Flächen waren gewöhnlich mehr oder weniger gestreift und lieferten, als sie für die Zone $[c q b]$ justirt wurden, ein Bundel naheliegender Bilder. An mehreren der ausgewählten Krystalle aber waren ganz ebene $q^{\prime}$-Flächen vorbanden; diese gaben gute einfache Reflexe und die daraus erhaltenen Winkelwerthe stimmten mit den berechneten und mit dem Mittel aller beobachteten Werthe gut uiberein. 
Ueber den Zusammenhang zwischen den krysta!lographischen Eigenschaften elc. 11.

Die folgende Tabelle enthält die Resultate der Messungen.

ZahI der

Messungen :

\section{Grenzen:}$$
\text { (cq }
$$$$
\left\{\begin{array}{l}
a \\
0
\end{array}\right.
$$$$
\left\{\begin{array}{lr}
a o^{\prime}=(100):(112) & 39 \\
o^{\prime} q^{\prime \prime \prime}=(112):(012) & 1 \\
o^{\prime} o^{\prime}=(112):(112) & 12
\end{array}\right.
$$$$
\begin{cases}b_{0}=(010):(111) & 38 \\ 00 & =(111):(1 T 1)\end{cases}
$$$$
\left\{\begin{array}{l}
b o^{\prime}=(010):(112) \\
o^{\prime} o^{\prime}=(112):(112)
\end{array}\right.
$$$$
\left\{\begin{array}{lr}
c o^{\prime}=(001):(112) & 51 \\
o^{\prime}=(112):(111) & 42 \\
c o=(001):(111) & 62 \\
o p=(111):(110) & 7 \\
o o=(111):(11 \overline{1}) & 22
\end{array}\right.
$$$$
\left\{\begin{array}{lr}
p o=(110):(1 \bar{T} 1) & 5 \\
o q^{\prime}=(1 \bar{T} 1):(0 \overline{\mathrm{A}} 1) & 19 \\
q^{\prime} p=(0 \overline{2} 1):(\bar{\top} \bar{T} 0) & 5
\end{array}\right.
$$$$
\left\{\begin{array}{l}
p o^{\prime}=(110):(1 \bar{T} 2) \\
o^{\prime} q=(1 \bar{T} 2):(0 \bar{T}) \\
q p=(0 \bar{T}):(\bar{T} 0)
\end{array}\right.
$$

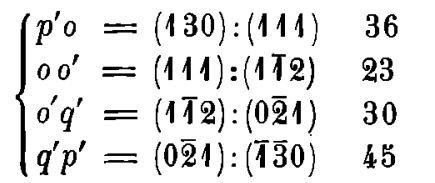$$
\left\{\begin{array}{l}
a p=(100):(110) \\
p p^{\prime}=(110):(130)
\end{array}\right.
$$$$
\begin{aligned}
& 29045^{\prime}-299^{4} 46^{\prime} \\
& 30 \quad 0-30
\end{aligned}
$$$$
30-30-3
$$$$
59 \quad 43-59 \quad 54
$$$$
\begin{array}{llll}
30 & 10-30 & 17
\end{array}
$$$$
\left(\begin{array}{l}
c q^{\prime \prime \prime}=(001):(012) \\
q^{\prime \prime \prime} q=(012):(011)
\end{array}\right.
$$$$
c q=(001):(011) \quad 18 \quad 36 \quad 44-36 \quad 55
$$$$
q q^{\prime}=(011):(021) \quad 16
$$$$
\begin{array}{ll}
c q^{\prime}=(001):(021) & 29 \\
q^{\prime} b=(021):(010) & 28
\end{array}
$$$$
1921-1931
$$$$
56 \quad 8-5625
$$$$
3333-3353
$$$$
a o=(100):(111) \quad 64 \quad 4333-4348
$$$$
\log =(111):(011) \quad 43
$$$$
46 \quad 10-46 \quad 24
$$$$
58 \quad 25-58 \quad 34
$$$$
6256-632
$$$$
65 \quad 28-6538
$$$$
48 \quad 48-49 \quad 2
$$$$
\text { 72 } 32-7242
$$$$
34 \quad 42-3452
$$$$
\begin{array}{lll}
36 & 52-37 \quad 6
\end{array}
$$$$
1919-1931
$$$$
\begin{array}{llll}
56 & 19-56 & 33
\end{array}
$$$$
\begin{array}{lll}
33 & 28-33 & 38
\end{array}
$$$$
67 \quad 1-67 \quad 14
$$$$
64 \cdot 59-65 \quad 5
$$$$
\begin{array}{lll}
49 & 18-49 & 27
\end{array}
$$$$
6532-6537
$$$$
72 \quad 12-72 \quad 19
$$$$
35 \quad 2-35 \quad \%
$$$$
7235-7241
$$$$
43 \quad 44-4355
$$$$
4551-461
$$$$
46 \quad 6-46 \quad 16
$$$$
4359-448
$$

Mittel

beobachtet: Berechnet: Diff.:

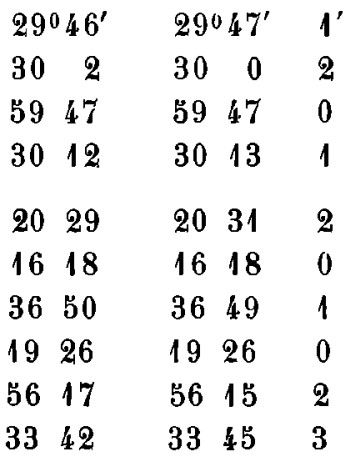

\section{$43 \quad 41$}

$46 \quad 19$

$58 \quad 30$

3134

6259

$46 \quad \begin{array}{ll}* & -\end{array}$

$\begin{array}{lll}65 & 33\end{array}$

4854

$58 \quad 31 \quad 1$

$31 \quad 29 \quad 5$

$6258 \quad 1$

7237

3447

$\begin{array}{lll}65 & 33 & 0\end{array}$

48 54 0

$\begin{array}{lllll}37 & 0 & 37 & 0 & 0\end{array}$

1926

19260

$\begin{array}{lll}56 & 26\end{array}$

$33 \quad 34$

$33^{*} 34 \quad 0$

$\begin{array}{ll}67 & 8\end{array}$

$\begin{array}{lll}67 & 8 & 0\end{array}$

$\begin{array}{lllll}65 & 3 & 65 & 2 & 1\end{array}$

$\begin{array}{lllll}49 & 22 & 49 & 22 & 0\end{array}$

$\begin{array}{lllll}65 & 35 & 65 & 36 & 1\end{array}$

$\begin{array}{lllll}72 & 15 & 72 & 15 & 0\end{array}$

$\begin{array}{lllll}35 & 5 & 35 & 4 & 1\end{array}$

$\begin{array}{lllll}72 & 38 & 72 & 41 & 3\end{array}$

$\begin{array}{lllll}43 & 48 & 43 & 49 & 1\end{array}$

$45 \quad 57 \quad 45 \quad 55 \quad 2$

$\begin{array}{lllll}46 & 11 & 46 & 12 & 1\end{array}$

$\begin{array}{lllll}44 & 3 & 44 & 4 & 1\end{array}$




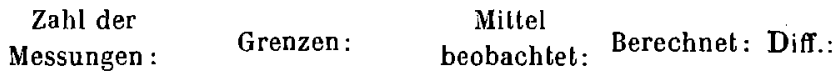

$$
\begin{aligned}
& \left\{\begin{array}{llllll}
p^{\prime} o^{\prime}=(130):(112) & 30 & 58^{0} 31^{\prime}-58^{0} 40^{\prime} & 58^{0} 35^{\prime} & 58^{0} 35^{\prime} & 0^{\prime} \\
o^{\prime} q=(112):(0 \top 1) & 15 & 6235-6241 & 6238 & 6236 & 2 \\
q p^{\prime}=(0 T 1):(1 \overline{3} 0) & 22 & 5845-5852 & 5847 & 5849 & 2
\end{array}\right.
\end{aligned}
$$

Gesammtzahl der Messungen: 820.

Dieselben Bemerkungen betreffs der günstigen Uebereinstimmung der im Mittel beobachtelen und der berechneten Werthe gelten fur schwefelsaures Rubidium ganz so wie fur das Kaliumsalz.

\section{Schwefelsaures Cäsium, $\mathrm{Cs}_{2} \mathrm{SO}_{4}$.}

Es hat keine Schwierigkeit, scheinbar vortreffliche einzelne Krystalle von schwefelsaurem Cäsium zu erhalten; verzweigte Aggregate wie beim Rubidiumsalze bilden sich gewöhnlich nicht. Die Krystalle wachsen zu einer beträchtlichen Grösse, wenn man sie einige Tage in der Mutterlauge ungestört lässt.

Bei der spectroskopischen Prufung lassen sich, wie früher erwähnt wurde, keine Spuren von Verunreinigungen entdecken; um über die Reinheit noch grössere Sicherheit zu erhalten, wurden Krystalle für die Messungen nur aus Krystallisationen gewählt, welche mehrfach fractionirt krystallisirt worden waren.

Elf aus füf solchen verschiedenen Krystallisationen stammende Krystalle wurden in derselben ausfübrlichen Weise untersucht, wie es bei dem Kaliumsalze der Fall war. Die verhältnissmässig kleinere Gesammtzahl der Messungen an den Krystallen des schwefelsauren Cäsiums ist eine Folge der Thatsache, dass dieselben nicht so flächenreich, wie diejenigen der Sulfale von Kalium und Rubidium sind. Die Gesammtzahl der Messungen ist verhältnissmässig ebenso gross fur die vorhandenen Flächen wie bei den zwei anderen Salzen.

Das Axenverhältniss, aus den Messungen berechnet, ist:

$$
a: b: c=0,5712: 1: 0,7531 \text {. }
$$

Das aus von Lang's Messungen berechnete Verhältniss, durch Topsöe (loc. cit.) citirt, ist: $0,5805: 1: 0,7400$.

Die beobachteten Formen sind nicht so zahlreich wie an den Krystallen der Sulfate von Kalium und Rubidium. Die Brachydomen $q^{\prime \prime}\{031\}$ und $q^{\prime \prime \prime}\{012\}$ und die Pyramide $o^{\prime \prime}\{332\}$ wurden an keinem der elf Krystalle entdeckt. Die vorhandenen Formen sind: $a=\{100\} \infty \bar{P} \infty, b=\left\{\begin{array}{ll}0 & 0\end{array}\right\}$ $\infty \breve{P} \infty, c=\{001\} 0 P, p=\{110\} \infty P, p^{\prime}=\{130\} \infty \breve{P} 3, q=\{011\} \breve{P}_{\infty}$, $q^{\prime}=\{021\} 2 \breve{P} \infty, o=\{111\} P, o^{\prime}=\{112\} \frac{1}{2} P$.

Die Krystalle des schwefelsauren Cäsiums zeigen gewöhnlich eine viel grössere Ausbildung der Basis $c\{001\}$ als die Krystalle der zwei anderen 
Salze. Sie bilden, wie in Fig. 10 dargestellt ist, dicke, rechtwinklige, durch die Flächen der Pinakoide $a\{100\}$ und $b\{010\}$ und der Basis $c\{001\}$ begrenzte Parallelepipede, und die zuletzt erwähnte Form herrscht in

Fig. 10.

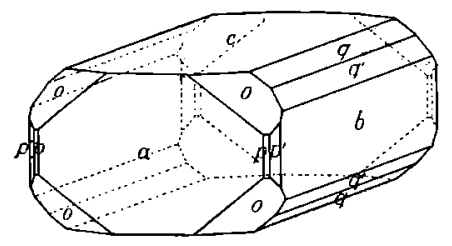

Fig. 11.

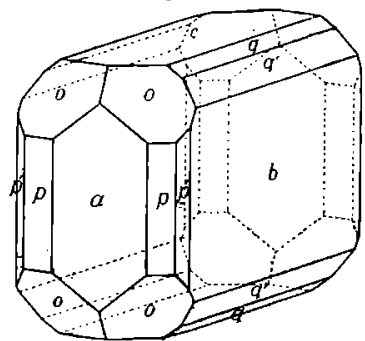

der Regel mehr oder weniger vor, so dass die Krystalle tafelförmig darnach erscheinen. Die Kanten $b c$ sind gewöhnlich durch die Brachydomen $q\{011\}$ und $q^{\prime}\{021\}$ modificirt, deren Flächen ungefähr gleich gross und in der durch die Figur angedeuteten Weite entwickelt sind. Von den beiden prismatischen Formen $p\{110\}$ und $p^{\prime}\{130\}$ war die letztgenannte beinahe immer durch einige ihrer vier Flächen repräsentirt, während die Flächen des primären Prismas entweder sehr klein waren oder ganz fehlten. Die primären Pyramidenflächen $o\{111\}$ waren die grössten nach den drei oben erwähnten vorherrschenden Ebenen, und modificirten die Ecken der rechtwinkligen Tafeln beträchtlich. Die Krystalle des Cäsiumsalzes unterscheiden sich von denjenigen der zwei anderen Sulfate dadurch, dass sie selten die Flächen der Pyramide o' $\{112\}$ zeigen. Eine kleine Fläche dieser Form wurde jedoch an einem der gemessenen Krystalle entdeckt.

Bei gewissen Krystallisationen wurden Krystalle beobachtet, wofür Fig. 11 typisch ist, und woran die Flächen des Brachypinakoids $b\{010\}$ über diejenigen der Basis $c\{001\}$ vorherrschten, so dass sie einen tafelförmigen Habitus nach einer beim eben beschriebenen gewöhnlichen Falle senkrechten Richtung zeigten. Doch waren die Basis $c\{001\}$ und das Makropinakoid $a\{100\}$ immer wichtige Ebenen, und sehr selten trat die erste Form so stark zurück wie bei den Krystallen der beiden anderen Sulfate.

Wohl definirte Zwillings- oder Drillingskrystalle wurden nicht beobachtet, obgleich zablreiche Fälle zusammengewachsener Krystalle untersucht wurden.

Die von den kleineren Flächen des Gäsiumsalzes reflectirten Signalbilder waren gewöhnlich nicht so hell und scharf als bei den beiden anderen Salzen, ibrer schlecht spiegelnden Beschaffenheit wegen. Die Zahl der guten und vollkommen zuverlässigen Werthe, welche fur mehrere der durch diese Flächen gebildeten Winkel erhalten wurden, ist also kleiner als bei schwefelsaurem Kalium und Rubidium. Die angenommenen Werthe wurden nur von gewissen gut spiegelnden Flächen der ausgewählten ausnahmweise gut 
ausgebildeten Krystallen geliefert und sind ganz frei von Ungewissheit. Die grösseren Flächen gaben in der Regel vortreflliche einfache Reflexe.

Die Resultate der Messungen sind unten tabellarisch zusammengestellt.

Zahl der

Messungen :$$
\left\{\begin{array}{l}
a p \\
p p
\end{array}\right.
$$$$
\left\{\begin{array}{l}
a p^{\prime}=(100):(130) \quad 15 \\
p^{\prime} b=(130):(010)
\end{array}\right.
$$$$
\begin{cases}c q=(001):(011) & 33 \\ q q^{\prime}=(011):(021) & 18 \\ c q^{\prime}=(001):(021) & 22 \\ q^{\prime} b=(021):(010) & 25\end{cases}
$$$$
\left\{\begin{array}{l}
a o=(100):(111) \quad 67 \\
o q=(111):(011) \quad 59
\end{array}\right.
$$$$
\left\{\begin{array}{l}
a o^{\prime}=(100):(112)- \\
o^{\prime} o^{\prime}=(112):(112)-
\end{array}\right.
$$$$
\left\{\begin{array}{l}
b_{0}=(010):(111) \quad 51 \\
0 o=(111):(111)
\end{array}\right.
$$$$
\left\{\begin{array}{l}
b o^{\prime}=(010):(112)- \\
o^{\prime} o^{\prime}=(112):(1 T 2)-
\end{array}\right.
$$$$
\left\{\begin{array}{lr}
c o^{\prime}=(001):(112) & 1 \\
o^{\prime} o=(112):(111) & 1 \\
c o=(001):(111) & 73 \\
o p=(111):(110) & 20 \\
o o=(111):(11 \pi) & 33
\end{array}\right.
$$$$
\left\{\begin{array}{lr}
p o=(110):(1 \overline{1} 1) & 6 \\
o q^{\prime}=(1 T 1):(0 \overline{2} 1) & 13
\end{array}\right.
$$$$
q^{\prime} p=(0 \overline{2} 1):(\bar{T} T 0) \quad 4
$$$$
\left\{\begin{array}{l}
p o^{\prime}=(110):(1 \bar{T} 2)- \\
o^{\prime} q=(1 T 2):(0 \bar{T} 1)- \\
q p=(0 \bar{T} 1):(T \bar{T} 0)
\end{array}\right.
$$$$
\left\{\begin{array}{l}
p^{\prime} 0=(130):(111) \\
o o^{\prime}=(111):(112)
\end{array}\right.
$$$$
\left\{\begin{array}{l}
o o^{\prime}=(111):(1 \bar{T} 2)- \\
o^{\prime} q^{\prime}=(1 \bar{T} 2):(0 \overline{2} 1)-
\end{array}\right.
$$$$
\begin{array}{lr}
o q^{\prime}=(111):(0 \overline{2} 1) & 8 \\
q^{\prime} p^{\prime}=(0 \overline{2} 1):(\overline{1} \overline{3} 0) & 10
\end{array}
$$$$
\left\{\begin{array}{l}
p^{\prime} o^{\prime}=(130):(112)- \\
o^{\prime} q=(112):(0 \overline{1})- \\
q p^{\prime}=(0 \bar{T} 1):(\overline{1} \overline{3} 0) \quad 7
\end{array}\right.
$$

Mittel

beobachtet: Berechnet: Diff.:

$29^{\circ} 42^{\prime}-29^{\circ} 49^{\prime}$

$2956-30 \quad 3$

$59 \quad 39-5953$

$30 \quad 10-3018$

$36 \quad 50-37 \quad 10$

$1914-1938$

วั6 $20-5630$

$3321-3341$

$4324-4336$

$4623-4635$

$65 \quad 27-6539$

$4851-493$

$56 \quad 27-56 \quad 49$

$33 \quad 10-3328$

$6634-6653$

64. $48-6458$

$4926-4935$

$6534-6542$$$
7
$$

$7235-7241$

$4332-4346$

$29^{0} 45^{\prime}$

$29044^{\prime} \quad 1^{\prime}$

$\begin{array}{ll}30 & 0\end{array}$

$59 \quad 45$

3015 -

$\begin{array}{lll}30 & 0 & 0\end{array}$

30

$36 \quad 59$

1925

5625

$33 \quad 34$

4331

$46 \quad 28$

$\begin{array}{lll}59 & 44 & 1\end{array}$

$\begin{array}{lll}30 & 16 & 1\end{array}$

$\begin{array}{lll}36 & 59 & 0\end{array}$

$1926 \quad 1$

56250

33351
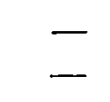

6531

4857

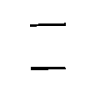

$37 \quad 10$

1920

5638

3321

$\begin{array}{ll}66 & 44\end{array}$

6452

4930

6536

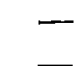

7238

$43 \quad 39$

-
$9217-92 \quad 26$
$4355-448$

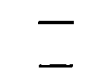

$92 \quad 22$

441

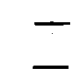

$58 \quad 40-58 \quad 46$

$58 \quad 43$

$58 \quad 43$

Gesammtzahl der Messungen : 528 . 
Der Grad der Uebereinstimmung zwischen den mittleren beobachteten und den berechneten Werthen ist wieder zufriedenstellend, und man darf daher mit Vertrauen zu einer Vergleichung der analogen Winkel der drei Sulfate übergehen.

\section{Vergleichung der Grössen der Winkel der drei Salze.}

In der folgenden Tabelle sind die respectiven Werthe analoger Winkel der drei Salze verglichen.

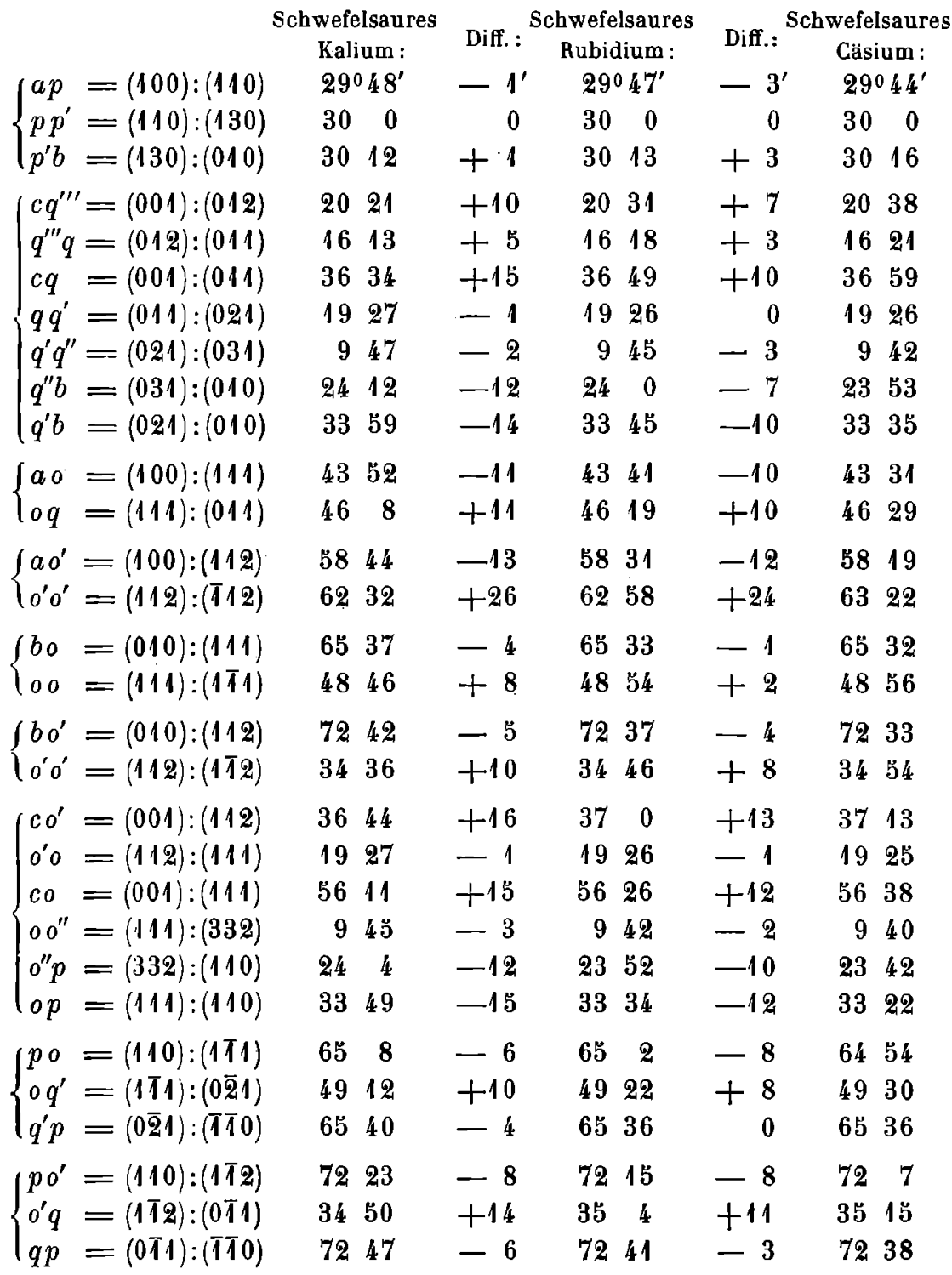


A. E. Tulton.

\begin{tabular}{|c|c|c|c|c|c|}
\hline & $\begin{array}{c}\text { Schwefelsaures } \\
\text { Kalium: }\end{array}$ & Diff.: & $\begin{array}{c}\text { Schwefelsaures } \\
\text { Rubidium : }\end{array}$ & Diff.: & $\begin{array}{c}\text { Schwefelsaures } \\
\text { Cäsium: }\end{array}$ \\
\hline$p^{\prime} 0=(130):(111)$ & $43^{0} 59^{\prime}$ & $-10^{\prime}$ & $43^{0} 49^{\prime}$ & $-9^{\prime}$ & $43040^{\prime}$ \\
\hline $0 o^{\prime}=(111):(172)$ & $45 \quad 47$ & +8 & 4555 & +6 & $46 \quad 1$ \\
\hline$o^{\prime} q^{\prime}=\left(1 T^{\prime} 2\right):(0 \overline{2} 1)$ & 461 & +11 & $46 \quad 12$ & +8 & 4620 \\
\hline$q^{\prime} p^{\prime}=(0 \overline{\mathbf{2}} 1):(\mathrm{T} \overline{3} 0)$ & $44 \quad 13$ & -9 & 444 & -5 & 4359 \\
\hline$\left(p^{\prime} o^{\prime}=(130):(112)\right.$ & $58 \quad 48$ & -13 & 5835 & -10 & 5825 \\
\hline$o^{\prime} q=(112):(0 \overline{1} 1)$ & $62 \quad 12$ & +24 & 6236 & +17 & 6253 \\
\hline$\left(q p^{\prime}=(0 \bar{T} 1):(\bar{T} \overline{3} 0)\right.$ & $59 \quad 0$ & -11 & $58 \quad 49$ & -7 & $58 \quad 42$ \\
\hline
\end{tabular}

Hieraus ergeben sich die folgenden interessanten Thatsachen:

Die Werthe aller Winkel des Rubidiumsalzes liegen ohne Ausnahme zwischen den Werthen der analogen Winkel des Kalium-und des Cäsiumsalzes.

Die Differenzen zwischen den Grössen analoger Winkel bei diesendrei rhombischen normalen Sulfaten sind viel kleiner als diejenigen, welche bei den Kalium resp. Rubidium und Cäsium enthaltenden Doppelsulfaten beobachtet worden sind. Die Differenzen sind zu klein, um einen definitiven Schluss zu gestatten uber die Beziehung der Differenzen $z$ wischen dem Kaliumsalz und dem Rubidiumsalzeinerseits und zwiscben dem Rubidiumsalz und dem Gäsiumsalzandererseits; die Werthe beim Rubidiumsalze scheinen im Durchschnitte aber năher dem Mittel derjenigen der zwei anderen Salze zu liegen, als es bei den Doppelsulfaten beobachtet wurde.

Es wird also eine Zunahme in den Grössen der Winkel der Krystalle der normalen Sulfate von Kalium, Rubidium und Cäsium, entsprechend der Zunahme im Atomgewichte des darin enthaltenden Metalles, durch die Ersetzung des Kaliums durch Rubidium und dann des Rubidiums durch Cäsium hervorgebracht.

\section{Vergleichung der Axenverhältnisse.}

Die aus den Messungen berechneten Axenverhältnisse sind folgende:

$$
\begin{array}{ccc}
\text { für } \mathrm{K}_{2} \mathrm{SO}_{4} & a: b: c=0,5727: 1: 0,7418 \\
\text { - } & \mathrm{Rb}_{2} \mathrm{SO}_{4} & a: b: c=0,5723: 1: 0,7485 \\
- & \mathrm{Cs}_{2} \mathrm{SO}_{4} & a: b: c=0,5712: 1: 0,7531 .
\end{array}
$$

Daraus folgt:

Die Axenverhälnisse für Rubidiumsulfat liegen zwischen denjenigen für Kaliumsulfat und resp. Cäsiumsulfat. 
Das Verhältniss der Länge der Axe $a$ zu derjenigen der Axe $b$ nimmtab, aber nur sehr wenig, wenn Kalium durch Rubidium oder Rubidium dureh Cäsium ersetzt wird, während das Verhältniss der Vertical axe $c$ zur Axe $b$ beträchtlich zunimmt.

Es giebt also eine wahre Zunahme in den Axenverhältnissen, welche ammeisten hervortritt beidem Verhältnisse $\frac{c}{b}$, und welche der Zunahme im Atomgewichte des in dem Salze enthaltenen Metalles entspricht.

\section{Beziehungen des Habitus.}

Obgleich die Krystalle der drei Sulfate so ähnlich sind, dass man von jedem der Salze Individuen finden kann, welche allen durch die Figuren repräsentirten Arten der Entwickelung entsprechen, so wird doch jedes der drei Salze durch vorherrschende Eigenthumlichkeiten des Habitus charakterisirt. Zum Beispiel : Kaliumsulfat ist durch die relativ grosse Entwickelung des Brachypinakoids $b\{010\}$ und das verhältnissmässige Zurucktreten des Makropinakoids $a\{100\}$ und der Basis $c\{001\}$ charakterisirt, wie durch den sebr häufig vorkommenden in Fig. 3 dargestellten Typus erläutert wird. Dem Rubidiumsulfat ist eigenthumlich, dass es eine viel grössere Enlwickelung des Makropinakoids, eine etwas grössere der Basis und eine viel kleinere Ausbildung des Brachypinakoids als schwefelsaures Kalium zeigt. Die relativ kleine Grösse der Basis und des Brachypinakoids verursacht eine entsprechende Zunahme der brachydomatischen Formen, insbesondere von $q^{\prime}\{021\}$. Diese Eigenthümlichkeit ist klar aus Fig. 7 ersichtlich. Cäsiumsulfat ist durch die ausnahmsweise Entwickelung der Basis charakterisirt, wie aus Fig. 10 hervorgeht, sowie durch die grosse Ausbildung des Makropinakoids.

Es sind also die drei Salze durch die relative Entwickelung der Basis und des Makropinakoids charakterisirt. Beim Kaliumsalz ist die erste sehr klein, beim Rubidiumsulfat ist sie etwas grösser und beim Cäsiumsalz ist die Basis vorherrschend. Beim Kaliumsulfat ist das Makropinakoid sehr schmal, beim Rubidiumsalz ist es die charakterisirende Form, aber durch die grosse Entwickelung der Pyramidenflächen etwas verringert und beim Cäsiumsulfat, bei welchem die letztgenannten Flächen ganz unbedeutend sind, bildet das Makropinakoid das breite Ende des Krystalles. Ausserdem ist die mittlere Stellung des Rubidiumsalzes klar durch die Thatsache angedeutet, dass, während bei den Sulfaten des Kaliums und des Cäsiums ein mehr oder weniger tafelförmiger Habitus sich entwickelt, in Folge des Vorherrschens des Brachypinakoids beim ersten und der Basis beim letzten Salz, diese Formen beim Rubidiumsalı gewöhnlich relativ unbedeutend werden, und durch die grosse Entwickelung des Brachydomas $q^{\prime}\{021\}$ ein domatisch-prismatischer Habitus bedingt wird. In Rücksicht also auf die relative Ausbildung der 
Basis und des Makropinakoids ist es augenscheinlich, dass ein regelmässiges Fortschreiten vom Kalium- zum Rubidiumsalz und vom Rubidium- zum Cäsiumsalz beobachtet wird. Diese Beobachtungen kann man wie folgt zusammenfassen:

Die Krystalle der rhombischeo Sulfatevon Kalium, Rubidium und Gasium nähern sich im Habilus einander mehr als die der Doppelsulfate. Die vorherrschenden relativen Beträge der Entwickelung der primären Flächen aber deuten ein Fortschreiten von dem Kalium-durch das Rubidium-zum Casiumsalz an, d. h. dem Fortschreiten des Atomgewichtes des darinenthaltenen Metalles entsprechend.

Es mag hier bemerkt werden, und später wird sich dies als eine wichtige Thatsache erweisen, dass keine anderen Flächen in der Zone, welche die Basis und das Makropinakoid enthält, ausser jenen Flächen selbst, je entdeckt worden sind.

\section{Veränderung der Winkel durch Temperaturerhöhung.}

Eine Reihe von Messungen sind bei gewöhnlicher Temperatur (180-200) und bei $120^{\circ}$ nach einander ausgefuhrt worden, um ganz gewiss zu sein, dass die aus der goniometrischen Untersuchung gezogenen Schlussfolger . ungen nicht von dem Umstande abhängig sind, dass die Beobachtungen bei gewöhnlicher Temperalur gemacht wurden. Zu diesen Beobachtungen wurde das Fuess'sche Goniomeler Modell Nr. 1 benutzt und dazu solche Krystalle der drei Sulfate ausgewählt, welche vortreffliche einfache Signalbilder von den Flächen $a\{100\}$ und $p\{110\}$, oder $p\{110\}$ und $b\{010\}$ lieferten, welche den Winkel $a p$ oder $b p$ und folglich das Verhältniss $a: b$ bestimmen. Auf gleiche Weise wurde der Winkel $c q$ mit Hulfe vortrefflicher Flächen der Basis $c\{001\}$ und des Brachydomas $q\{011\}$ bestimmt, um das Verhältniss $c: b$ zu liefern.

Die in diesen Winkeln durch ungleiche Ausdehnung des Krystalles längs der krystallographischen Axen hervorgebrachten Veränderungen sind äusserst klein, entschieden grösser aber für den Winkel $c q$ als für den Winkel $a p$. Die Veränderung irgend eines Winkels geschieht bei allen Salzen in derselben Richtung, die beiden Winkel ap und $c q$ nehmen zu, wenn ein Krystall derselben erwärmt wird, so dass die beiden Verhältnisse $a: b$ und $c: b$ entsprechend zunehmen. Der Betrag der Zunahme des Winkels $a p$, wenn der Krystall von $20^{\circ}$ auf $120^{\circ}$ erhitzt wird, ist weniger als eine Minute und ungefähr 45", einer Zunahme des Verhältnisses $a: b$ von nicht mehr als drei Einheiten der vierten Decimale entsprechend. Die Zunahme des Winkels $c q$ unter gleichen Umständen ist beträchtlicher und beträgt ungefähr 1,'5, einer Zunahme des Verhältnisses $c: b$ von ungefähr 0,0007 entsplechend. Die Differenzen zwischen den Beträgen der Verän- 
derung für die drei Salze fallen innerbalb der Fehlergrenzen, denn sie sind geringer als die Differenzen, welche sich für einen und denselben Winkel ergeben, wenn er an verschiedenen Krystallen beobachtet wird. Aus diesen Thatsachen kann man wie folgt schliessen:

Die Schlussfolgerungen aus der Vergleichung der Grössen der Winkel und der Axenverhältnisse der Krystalle dieser drei Sulfate sind vonder Temperaturganzunabhängig, denn diekleinen Veränderungen, welche durch Temperaturänderungen hervorgebracht werden, geschehen in derselben Richtung bei jedem Salze. Die Wirkung einer Temperaturerhöhung von 1000 auf die Axenverhaltnisse besteht bei allen Salzen in einer Zunahmedes Verhältnisses $a: b$ um nicht mehr als 0,0003 und des Verhältnisses $c: b$ um ungefähr 0,0007 ; die Beziehungen zwischen den drei Salzen bleiben also unverandert.

\section{Die Spaltbarkeit der drei Sulfate.}

Schwefelsaures Kalium besitzt, wie seit Langem bekannt ist, zwei Spaltungsrichtungen, parallel zum Brachypinakoid $b\{010\}$ und zur Basis $c\{001\}$, welche als "nicht vollkommen " angegeben werden. Eine grosse Zahl von Krystallen der Sulfate des Rubidiums und Cäsiums sind im Laufe dieser Arbeit auf ibre Spaltbarkeit untersucht und die Thatsache festgestellt worden, dass dieselben zwei Spaltungsrichtungen den drei Salzen gemeinschaftlich sind. Unter keinen Umständen wurde ein Bruch parallel dem Makropinakoid oder den prismatischen, domatischen oder pyramidalen Formen erhalten. Die Spaltbarkeit in der Richtung des Brachypinakoids ist entschieden vollkommener als diejenige in der Richtung der Basis; die Krystalle spalten indessen ziemlich leicht in beiden Richtungen, während sie grossen Widerstand parallel zum Makropinakoid darbieten und eventuell nach einer unebenen Fläche brechen.

Daher kann man sagen:

Die Spaltungsrichtungen der drei Sulfatesindidentisch, nämlich parallel dem Brachypinakoid und der Basis. Keine der Spaltbarkeiten ist sehrvollkommen, doch entsteht diejenige parallel dem Brachypiuakoid am leichtesten vonbeiden.

\section{Untersuchung über die Volumbeziehungen.}

Die specifischen Gewichte der drei Sulfate.

Das specifische Gewicht des schwefelsauren Kaliums ist häufig Gegenstand der Untersuchung gewesen. Unter den fruberen Bestimmungen sind diejenigen von Joule und Playfair, Schiff, Karsten, Filhol, Spring 
und Schröder zu nennen. In den Jahren 1872 und $18 \% 6$ hal Petterssou eine umfassende Untersuchung der Molekularvolumina vieler schwefelsaurer und selensaurer Salze ausgeführt (Nova Acta R. Soc. Scient. Upsaliensis $1873[3], 9$, fasc. 1 und $1876[3], 10$, fasc. 2); unter anderen wurden die Volumina der Sulfate von Kalium, Rubidium und Cäsium bestimmt, und die Werthe von Pettersson sind jetzt allgemein angenommen. Die Hauptresultate Pettersson's wurden auch in den Berichten der deutsch. chem. Ges. (1876, 9, 1559) mitgetheilt; die ausfuhrliche Beschreibung ist aber nur in den obengenannten Upsala Nova Acta zu finden. Arzruni, in seiner vortrefflichen, in der letzten Zeit herausgegebenen Abhandlung uber die "Physikalische Chemie der Krystalle ", sagt, dass er letztere nicht bekommen konnte und legt natürlich sämmtlichen Pettersson'schen Zahlen denselben Werth bei. Verf. hat in der Bibliothek des »British Museum « Dessen Originalmittheilungen gefunden und darin die folgenden Worte Pettersson's, betreffend die Bestimmung des spec. Gew. des schwefelsauren Cäsiums: „Das schwefelsaure Cäsium war nicht vollkommen rein, denn bei der spectroskopischen Prüfung zeigte sich auch eine schwache Rubidiumlinie. Die ausserordentlich geringe Menge des Materials machte es unmöglich, dasselbe vorher zu reinigen und gestattete nur eine Bestimmung des specifischen Gewichtes. " Ausserdem wurden nur zwei Bestimmungen des specifischen Gewichtes des schwefelsauren Rubidiums gemacht und mit so kleiner Menge Material (1,9926 und 1,1628 g), dass genaue Resultate kaum erbalten werden konnten. Es war daher sehr nöthig, die specifischen Gewichte dieser Salze wieder zu bestimmen. Der Verf. führte deshalb eine Reihe solcher Bestimmungen aus, und zog auch das schwefelsaure Kalium in die Untersuchung, um die drei specifischen Gewichte streng vergleichbar zu machen. Retgers hat in der letzten Zeit für das specifische Gewicht des schwefelsauren Kaliums den Werth 2,666 erhalten, ein Resultat, welches ziemlich gut mit den Peltersson'schen Werthen 2,667, 2,669 und 2,660 ubereinstimmt; einige frühere Beobachter aber hatten niedrigere Werthe erhalten, z. B. Spring 2,656, Wi se 2,653 und Schröder 2,658. Aus einer anderen Bestimmung hat Spring den Werth 2,660 erhalten.

Die Bestimmungen sind mit zwei Arten von Pyknometern ausgefuhrt worden: Das-eine war-eine modifieirte Form des gewöhnlichen Pyknometers von ungefähr $10 \mathrm{ccm}$ Inhalt. Diese Art Pyknometer verdankt der Verf. seinem geehrten Collegen, Herrn Chapman Jones, welchem für seine gütige Erlaubniss dasselbe zu gebrauchen und seinen geschätzten Rath Verf. besten Dank sagt. Der Rand des Halses wurde bis zur Zone der vollkommenen Berührung mit dem Stöpsel abgeschliffen, dann wurde er schräg geschliffen und eine Glaskappe über beide, Stöpsel und Hals, angepassı und auf dem schrägen Rande des letzteren zur vollkommenen Beruhrung geschliffen. Um die Kappe in Berührung mit dem Halse zu erhalten, wurde 
ein kleines Gestell aus Messingdraht construirt. Der Draht wurde erstens schneckenförmig in zwei naheliegende Ringe gebogen, den niedrigeren Ring konnte man auf die Wagschale setzen, während der obere die Kugel des Pyknomelers stützte; der Draht wurde dann vertical aufwärts gebogen únd ein wenig unter der Höhe des oberen Stöpselendes wurde er zu einer horizontalen Schlinge gebogen, um auf den Stöpsel wie eine Springfeder zu dricken und denselben dicht an das Pyknometer anliegend zu erhalten und also alles Verdunsten entweder durch die Capillare des Stöpsels oder durch den Hals zu verhindern. Wenn der Draht gut lackirt ist, so bleibt das Gewicht eines solchen Standes für lange Zeit unverändert. Die Bestimmungen wurden doppelt, mit zwei ähnlichen Pyknometern, bei der Temperatur von $20^{\circ}$ gemacht. Ein drittes grösseres Pyknometer, von $30 \mathrm{ccm}$ Inhalt, wurde zur Bestimmung des specifischen Gewichtes der angewandten Flüssigkeit benutzt. Die grösste Vorsicht wurde angewendet, um die Temperatur von $20^{\circ}$ genau durch ein geschitztes Wasserbad zu erreichen und alle Wägungen unter gleichen Oberflächenbedingungen zu machen; die Wägungen wurden natürlich für verdrängte Luft corrigirt.

Die andere Form des Pyknometers ist die von Muthmann ersonnene. Die Beschreibung seines Pyknomelers wurde dem Verf. von Herrn Dr. Muthma n n privalim mitgetheilt nebst sämmtlichen Einzelheiten seiner Arbeitsmethode. Das Wesentliche der Methode, welches Verf. durch die Gefälligkeit und auf Wunsch des Herrn Dr. Muthmann in den Stand gesetzt ist mitzutheilen, ist, dass der durchbohrte Stöpsel zu einem zweimal gebogenen Capillarrohre verlängert wird, wovon das Ende unter der Oberflache einer kleinen Menge der in den Bestimmungen angewandten Flüssigkeit bis zur Zeit des Wägens eingetaucht wird.

Die angewandte Flüssigkeit war Tetrachlorkohlenstoff, von welchem Muthma n gefunden hat, dass es die anorganischen Salze am wenigsten von allen anwendbaren Flüssigkeiten auflöst und auch sehr bequem ist seiner hohen Dichtigkeit wegen. Das schwere Jodmethylen wurde auch für die zwei schwereren Salze benutzt, aber nicht passend gefunden, da es eine kleine Auflösungswirkung ausübte, und ungefähr ein Procent zu hohe Zahlen erhalten wurden. Terpentinöl wurde lúr eine Reihe von Bestimmungen gebraucht, welche, wie später zu beschreiben ist, bei einer höheren Temperatur wiederholt wurden, weil dieses mit Tetrachlorkohlenstoff seines niedrigen Siedepunktes wegen unmöglich ist. Das Salz wurde in jedem Falle im Zustande feinsten Pulvers benutzt, erbalten durch Zerreiben der durchsichtigsten Krystalle in einem Achatmörser. Um alle Spuren von Feuchtigkeit auszutreiben, welche durch kleine Einschlüsse der Mutterlauge verursacht waren, wurde das Pulver während einiger Stunden in einem Luftbade auf $110^{0}-120^{0}$ erhitzt, eine Vorsicht, welche sehr nothwendig ist. Die eingeschlossene Luft wurde extrahirt, nachdem das Salz im Pyknometer mit 
Flüssigkeit bedeckl war, durch Evacuiren mil einer Sprengelpumpe und sanftes Klopfen entfernt. Der Inhalt der Pyknometer wurde vorher mit grösster Vorsicht durch wiederholte Wägung mit reinem gasfreien Wasser bestimmt.

Die Resultate der Bestimmungen sind unten zusammengestellt. Die bei verschiedenen Bestimmungen benutzten Proben gehörten verschiedenen Krystallisationen an. Die erste nach der Methode von $\mathbf{M}$ th mann ausgefuhrte Reihe wurde bei 14,75 gemacht, weil eine niedrige Temperatur vortheilhaft bei dieser Methode ist. Die Resultate für diese Reihe wurden auf $20^{\circ}$ corrigirt durch Benutzen der später anzugebenden Ausdehnungscoëfficienten.

Specifisches Gewicht von schwefelsaurem Kalium bei $20^{\circ}$.

$\begin{array}{cccr}\text { Angewandte } & \text { Gebrauchte } & \text { Menge des } & \text { Spec. Gew. } \\ \text { Methode: } & \text { Flüssigkeil: } & \text { Salzes }(\mathrm{g}): & \text { bei } 200 \\ \text { nomet. mit Kappe } & \text { Tetrachlorkohlenst. } & \mathbf{4 , 4 5 1 6} & \mathbf{2 , 6 6 5 9} \\ \text { - } & - & 5,2624 & 2,6609 \\ \text { - } & \left(\begin{array}{c}\text { grossem } \\ \text { Inhalt }\end{array}\right) \text { Telpentinöl } & 19,1356 & 2,6660\end{array}$

Methode von Muthm. Tetrachlorkohlenst. 7,2834 2,6648 bei 14,75 2,6630

$$
\begin{array}{lllr}
- & - & 6,31472,6640 & 2,6622 \\
- & - & 7,6748 & 2,6617 \\
- & - & 6,5019 & 2,6631
\end{array}
$$

Mittel von 7 Bestimmungen des spec. Gewichtes $K_{2} S O_{4}$ bei $\frac{20^{0}}{\mathrm{aq} 4^{0}} \quad 2,6633$

Specifisches Gewicht von schwefelsaurem Rubidium bei $20^{\circ}$.

$\begin{array}{cccr}\text { Angewandte } & \text { Gebrauchte } & \text { Menge des } & \text { Spec. Gew. } \\ \text { Methode: } & \text { Flüssigkeit: } & \text { Salzes (g): } & \text { bei } 200 \\ \text { nomet. mit Kappe } & \text { Tetrachlorkohlenst. } 6,9676 & 3,6150 \\ \text { - } & - & 7,4668 & 3,6094 \\ \text { - } & \text { Terpentinöl } & 10,7690 & 3,6128\end{array}$

Methode von Muthm. Tetrachlorkohlenst. 7, 1384 3,6155 bei 14,75 3,6132

$\begin{array}{llll}- & - & 7,23373,6094 & 3,6071 \\ - & - & 6,2758 & 3,6144 \\ - & - & 7,0490 & 3,6073\end{array}$

Mittel von 7 Bestimmungen des spec. Gewichtes $\mathrm{Rb}_{2} \mathrm{SO}_{4}$ bei $\frac{20^{0}}{\mathrm{aq} 4^{0}} \quad 3,6113$

Specifisches Gewicht von schwefelsaurem Cäsium bei $20^{\circ}$.

$\begin{array}{cccr}\text { Angewandte } & \text { Gebrauchte } & \text { Menge des } & \text { Spec. Gew. } \\ \text { Methode: } & \text { Flüssigkeit: } & \text { Salzes }(\mathrm{g}): & \text { bei } 200 \\ \text { nomet. mit Kappe } & \text { Tetrachlorkohlenst. } & \mathbf{9 , 5 7 4 9} & 4,2411 \\ \text { - } & - & 5,5173 & 4,2458 \\ - & \text { Terpentinöl } & 12,4937 & 4,2433\end{array}$




$\begin{array}{lllr}\text { Angewandle } & \text { Gebrauchte } & \text { Menge des } & \text { Spec. Gew } \\ \text { Nethode: } & \text { Flussigkeil: } & \text { Salzes }(g): & \text { bei } 20^{\circ}\end{array}$

Methode von Muthm. Tetrachlorkohlensl. 9,5117 4,2487 bei $14,75 \quad 4,2459$

$$
\begin{array}{llll}
- & - & 8,07684,2460 & 4,2432 \\
- & - & 4,5809 & 4,2412
\end{array}
$$

Mittel von 6 Bestimmungen des spec. Gewichtes $\mathrm{Cs}_{2} \mathrm{SO}_{4}$ bei $\frac{20^{0}}{\text { aq } 4^{0}} \quad 4,2434$

Das Resultat für $\mathrm{K}_{2} \mathrm{SO}_{4}$ ist ungefähr das Mittel der von anderen Beobachtern erhaltenen Werthe. Der Werth für $\mathrm{Rb}_{2} \mathrm{SO}_{4}$ ist beträchtlich niedriger als die Zahlen (3,638 und 3,640 auf $20^{\circ}$ corrigirt), welche Pettersson mit 1,16 und $1,99 \mathrm{~g}$ Material erhielt. Der Werth für $\mathrm{Cs}_{2} \mathrm{SO}_{4}$ ist viel höher als derjenige $(4,105$ bei 19,2$)$ von Pettersson, welcher mit nur 1,0925 g unreinen Materials, wie vorher erwahnt, erhalten wurde.

\section{Kubische Ausdehnungscoëfficienten der drei Salze.}

Um die specifischen Gewichte bei höheren Temperaturen berechnen zu können, sind eine Reihe Bestimmungen bei $60^{\circ}$ ausgefuhrt worden, und zwar ist Terpentinöl als die bequemste Flussigkeit zu diesem Zwecke gefunden worden, wie Joule und Playfair (Quart. Journ. Chem. Soc. 1, 121) auch seit Langem beobachtet haben. Da die Resultate der bei $20^{\circ}$ mit Terpentinöl ausgefuhrten Bestimmungen so gut mit den mit Tetrachlorkohlensloff erbaltenen Wertben ubbereinstimmen, kann irgend eine wahrnehmbare Wirkung auf die Salze nicht ausgeubt worden sein. Des hohen Siedepunktes wegen, $158^{\circ}-160^{\circ}$, ist es sehr bequem für Bestimmungen bei höheren als gewöhnlichen Temperaturen. Eine doppelte Bestimmung seiner Dichligkeit bei $60^{\circ}$ war vorher ausgefubrt worden. Die folgenden Resultate wurden erhalten :

$\begin{array}{lcccc} & \begin{array}{c}\text { Spec. Gew. } \\ \text { bei } 20^{0} / 4^{0}\end{array} & \begin{array}{c}\text { Spec. Gew. } \\ \text { bei } 600 / 4^{0}\end{array} & \begin{array}{c}\text { Differenz für } \\ \text { Kub. Ausdehnungscoëffic. }\end{array} & \begin{array}{c}400 \\ \text { für } 40^{\circ}\end{array} \\ \mathrm{K}_{2} \mathrm{SO}_{4} & 2,6660 & 2,6521 & 0,0139 & 0,0053 \\ \mathrm{Rb}_{2} \mathrm{SO}_{4} & 3,6128 & 3,5943 & 0,0185 & 0,0052 \\ \mathrm{Cs}_{2} \mathrm{SO}_{4} & 4,2433 & 4,2218 & 0,0245 & 0,0051\end{array}$

Die Ausdehnungscoëfficienten scheinen also praktisch identisch zu sein, denn die Differenz 0,0002 ist ungefähr die Fehlergrenze. Die vortreffliche Methode von Fize a und Benoi $\mathrm{u}$, die linearen Ausdehnungscoëfficienten zu bestimmen, ist hier nicht anwendbar der relativ grossen und dicken dazu nothwendigen Krystallplatten wegen. Die mikroskopische von S ch r a u f bescbriebene Methode (diese Zeitschr. 9, 433 und 12, 321) wurde mit Hulfe eines ähnlichen Fuess'schen Mikroskops versucht; es betrugen aber die äusserst kleinen Differenzen weniger als die Messungsfehler, wenn ein Tischerhitzungsapparat gebraucht wurde. 
Aus den durch die Messungen der Winkelabweichungen bei $120^{\circ}$ und den Bestimmungen der kubischen Ausdehnungscoëfficienten gelieferten Daten, vorausgesetzt dass die Krystalle innerhalb der Fehlergrenzen sich gleich ausdehnen, ist es möglich, die lineare Ausdehnung parallel den Richtungen der drei krystallographischen Axen zu berechnen.

Die kubische Ausdebnung $e$ (alle Glieder von höherer als erster Ordnung ausgeschlossen) ist:

$$
e=\lambda_{a}+\lambda_{b}+\lambda_{c}
$$

Der Werth von $e$ für $100^{\circ}$, aus dem Miltelwerthe $(0,0052)$ für $40^{\circ}$ berechnet, ist 0,0130. Joule und $\mathrm{Pla}$ y fair fanden 0,0107 für $\mathrm{K}_{2} \mathrm{SO}_{4}$, aber sie brauchten kleine Krystalle anstalt Krystallpulver und ihr Werth für das specifische Gewicht war viel niedriger, 2,656 bei $4^{0}$, als der vom Verf. erbaltene.

Es ist gezeigt worden, dass eine Temperalurerhöhung von $100^{\circ}$ eine Zunahme des Verhältnisses $a: b$ von nicht mehr als 0,0003 bewirkt und eine ähnliche Veränderung des Verhältnisses $c: b$ von ungefähr $0,000 \%$. Daher sind die Differenzen der Ausdehnungen :

$$
\begin{aligned}
& \lambda_{a}-\lambda_{b}=\frac{0,0003}{0,5727}=0,00052 \\
& \lambda_{c}-\lambda_{b}=\frac{0,0007}{0,7418}=0,00094
\end{aligned}
$$

wenn die Axenverhältnisse des Kaliumsalzes benutzt werden. Identische Werthe werden erhalten, wenn die Zahlen für das Rubidiumsalz gebraucht werden, und die Werthe weichen nur um 0,00001 ab, wenn die Verhältnisse des Căsiumsalzes angewandt werden.

Aus den drei Gleichungen:

$$
\begin{aligned}
\lambda_{a}+\lambda_{b}+\lambda_{c} & =0,0130 \\
\lambda_{a}-\lambda_{b} & =0,00052 \\
\lambda_{c}-\lambda_{b} & =0,00094
\end{aligned}
$$

werden die mittleren Linearausdehnungen der drei Salze wie folgt gefunden:

$$
\begin{aligned}
& \lambda_{a}=0,00437 \\
& \lambda_{b}=0,00385 \\
& \lambda_{c}=0,00479 .
\end{aligned}
$$

Es scheint daher, dass die Krystalle der drei Salze sich durch Erhitzen am meisten längs der Verticalaxe $c$ ausdehnen, und am wenigsten in der Richtung der Makrodiagonalaxe $b$. Es ist wahrscheinlich, dass die Ausdehnungen längs der Axen $a$ und $b$ noch näher gleich sind als durch die obigen Zahlen dargestellt ist; denn die Veränderung des Verhältnisses $a: b$ war wahrscheinlich niedriger als 0,0003 . 
Die Thatsache, dass die Krystalle sich so viel mehr längs der Verticalaxe als in der Bichtung der zwei seitlichen Axen ausdehnen, wird sich später als in inniger Beziehung zu der durch Temperaturerhöhung bewirkten Veränderung der optischen Elasticität stehend erweisen. Denn die grösste Zunahme der optischen Elasticität findet ebenfalls in der Richtung derVerticalaxe statt, und die kleineren Veränderungen längs der zwei anderen Axen sind nahezu gleich. Es geht aus den festgestellten Beziehungen der optischen Elasticität hervor, dass, wenn man die thermischen Ausdehnungen der drei Salze auch mit Genauigkeit bestimmen könnte, sie aller Wahrscheinlichkeit nach ebenfalls ein ähnliches Fortschreiten nach der Ordnung des Atomgewichtes des in dem Salze enthaltenen Metalles darstellen würden.

Nach der Beendigung dieser Untersuchung wurde die Aufmerksamkeit des Verfs. auf eine Mittheilung Spring's über die Ausdehnung der Sulfate des Kaliums und Rubidiums gelenkt. Spring hat eine Reihe sorgfältiger Bestimmungen dieser Constanten bis $100^{\circ}$ ausgefuhrt mittelst eines Gewichtsthermometers und mit Olivenöl als Flussigkeit. Sein Werth für die kubische Ausdehnung des schwefelsauren Kaliums für $100^{\circ}$ ist 0,0126 , sehr nahe der oben gegebenen Zahl. Sein Werth für schwefelsaures Rubidium aber ist etwas niedriger, 0,0111 und sein Werth des specifischen Gewichtes dieses Salzes bei $20^{\circ}$ ist 3,6367, etwas höher als das des Verfs. Betreffend der Reinheit des angewandten Salzes sind keine Data gegeben. Verf. hat die Absicht, eine weitere Reihe der Bestimmungen für das grössere Intervall von $100^{0}$ nach der Spring'sche Methode auszuführen.

\section{Die Molekularvolumina der drei Sulfate.}

Die Molekularvolumina $\frac{M}{d}$ der drei Salze, aus den specifischen Gewichten bei $20^{\circ}$ berechnet, sind die folgenden:

$$
\begin{aligned}
& \text { fur } \mathrm{K}_{2} \mathrm{SO}_{4} \frac{M}{d}=\frac{174}{2,6633}=65,33 \\
& \text { für } R b_{2} S O_{4} \frac{M}{d}=\frac{266,4}{3,6113}=73,77 \quad \text { Differenz } 8,44 \\
& \text { für } \mathrm{Cs}_{2} \mathrm{SO}_{4} \frac{M}{d}=\frac{361,4}{4,2434}=85,17
\end{aligned}
$$

Die von Pettersson gegebenen Molekularvolumina waren 65,37, 73,27 und 88,1. Der Irrthum bei seiner Bestimmung des specifischen Gewichtes des schwefelsauren Căsiums führt also einen Fehler von drei Einheiten im Molekularvolum ein. Die von Petterss on angedeutete Thatsache, dass die Ersetzung von Rubidium durch Cäsium von einer viel grösseren Volumveränderung begleitet wird, als wenn Kalium durch Rubidium ersetzt wird, 
ist ganz richlig; der Belrag der Differenz aber ist nicht so gross wie von Petters son angegeben, denn das Verhältniss ist 8,4 zu 11,4 anstatt 7,9 zu 14,8 .

Die hauptsächlichen, dio Volumina der Salze betreffenden Schlussfolgerungen kann man wie folgt zusammenstellen :

Die specifischen Gewichte der normalen Sulfate von Kalium, Rubidium und Gäsium, bei $20^{\circ}$ mit Wasser von $4^{0}$ verglichen, sind 2,6633 resp. 3,6113 und 4,2434.

Die Molekularvolumina der drei Salze sind 65,33 resp. 73,77 und 85,17. Eine grössere Volumzunahme begleitet die Erselzung des Rubidiums durch Cäsium, als siebeobachtet wird, wenn Kalium durch Rubidium ersetzt wird, und das Verhält$n$ is der respectiven Veränderungen ist 11,4 zu 8,4.

Die Dichtigkeiten der drei Sulfate nehmen im Verhältniss ihrer numerischen Werthe ab, wenn man ihre Temperatur erhöht. Bei $60^{\circ}$ sind die specifischen Gewichte, mit Wasser bei $4^{0}$ verglichen, 2,6521 resp. 3,5943 und 4,2218; die Differenzen für $40^{\circ}$ Temperaturerhöhung sind 0,0139 resp. 0,0185 und 0,0215. Die aus diesen Dalen berechneten kubischen Ausdehnungcoëficienten fur $100^{\circ}$ sind beinahe identisch, 0,0133 resp. 0,0130 und 0,0128; diesekleinen Differenzen abersind ungefäbr die Fehlergrenzen.

Die Coëficienten der linearen Ausdehnung längs der drei Axenrichtungen sind auch sonaheidentisch, dass die Unterschiede zwischen denjenigen längs analoger Richtungen bei irgend zwei Salzen innerhalb der Fehlergrenzen fallen. Es ist jedoch festgestellt, dass bei jedem Salzediegrösste Ausdehnung in die Richtung der Verticalaxe $c$ fällt.

\section{Relative Grösse und Natur des Krystallelementes.}

Eine wichtige Mittheilung ist in der letzten Zeit von Muthmann publicirt worden (diese Zeitschr. 22, 497). Es wurde darin gezeigt, dass die Molekularvolumina einer Reihe krystallisirter Substanzen von ähnlicher Zusammensetzung nur die relativen Volumina der chemischen Molekule repräsentiren können, wenn 1) die physikalischen Molekïle, aus denen die Krystalle aufgebaut sind, aus gleich vielen chemischen Molekülen bestehen, 2) die Zwischenräume, welche sich zwischen den chemischen Molekülen im Krystallbausteine befinden, in dem gleichen Verbältnisse zu einander stehen, wie die Volumina der chemischen Molekule selbst, und 3) wenn dasselbe fur die Zwischenräume zwischen den Krystallbausteinen im Krystalle gilt. Die erste Bedingung wird augenscheinlich durch streng isomorphe Substanzen, wie die Normalsulfate von Kalium, Rubidium und 
Cäsium und die diese Metalle enthaltenden Doppelsulfale erfüllt. Die Molekularvolumina liefern daher, obgleich sie wahrscheinlich nicht die relativen Volumina der physikalischen Moleküle darstellen, unserer Unwissenheit uber die Bedingungen 2) und 3) wegen, relalive Maasse des Volums des Elementarparallelepipeds von Bravais und Sohncke, welches durch Verbindung der Mittelpunkte anliegender Kryslallelemente (Krystallbausteine) gebildet wird. Ausserdem werden die Seiten und die Hơhe dieses Elementarparallelepipeds im Verhältniss der Axen des Krystallelements sein, d. h. in dem gewöhnlichen krystallographischen Axenverhältnisse stehen. Folglich kann man durch Verbindung der Molekularvolumina mit den Axenverhällnissen die relativen Enlfernungen der Krystallelemente längs der drei Axenrichtungen direct berechnen. Fedorow hat bewiesen, wie Muthmann bemerkt, dass die Symmetrieebenen der Krystalle immer Netzebenen in den Raumgittern entsprechen und mithin sind die Axen beim rhombischen Systeme immer mit Punkten besetzte Richtungen. Ein rechtwinkliges Parallelepiped, dessen Seiten im Verhältnisse der krystallographischen Axen stehen und dessen Inhalt bei den verschiedenen Gliedern der Reihe dem Molekularvolum proportional ist, wird also das Elementarparallelepiped der Krystallstructur repräsentiren.

Einige Monate vor dem Erscheinen der Mittheilung von Muthmann und kurz nach der Herausgabe der Arbeit des Verfs. über die Doppelsulfate ist die Idee der Verbindung der Axenverhältnisse mit den Molekularvolumina, um relative Maasse der wahren Axenverhältnisse des Krystallelemente zu erhalten, dem Verf. in einem freundlichen Briefe von Herrn Prof. Becke in Prag mitgelheilt worden. Darnach ist, wenn $V$ das Volum des Elementarparallelepipeds, $p$ das Molekulargewicht des Salzes, $s$ sein specifsches Gewicht und $a_{0}, b_{0}, c_{0}$ die Länge der Kanten repräsentiren:

$$
V=\frac{p}{s}=a_{0} \cdot b_{0} \cdot c_{0} \sin \beta,
$$

wenn das Parallelepiped monokline Symmetrie besitzt, wie im Falle der Doppelsulfate.

Ferner :

$$
a_{0}: b_{0}: c_{0}=a: 1: c \text { (das gewöhnliche Axenverhältniss). }
$$

Dividirt man die erste Gleichung durch $b_{0}{ }^{3}$, so hat man:

$$
\frac{V}{b_{0}^{3}}=\frac{a_{0}}{b_{0}} \cdot \frac{b_{0}}{b_{0}} \cdot \frac{c_{0}}{b_{0}} \cdot \sin \beta=a c \sin \beta, \text { weil } \frac{a_{0}}{b_{0}}=a \text { und } \frac{c_{0}}{b_{0}}=c \text {. }
$$

Daher ist :

$$
\begin{aligned}
& b_{0}=\sqrt[3]{\frac{V}{a c \sin \beta}} \\
& a_{0}=a b_{0}=\sqrt[3]{\frac{a^{2} V}{c \sin \beta}}
\end{aligned}
$$




$$
c_{0}=c b_{0}={\sqrt[3]{\frac{c^{2} V}{a \sin \beta}}}^{-}
$$

Die Werthe von $a_{0}, b_{0}$ und $c_{0}$ fur die verschiedenen Salze der isomorphen Reihe werden naturlich verschieden sein, und diese verschiedenen Werthe werden die Axenverhältnisse der Krystallelemente der Salze repräsentiren.

Wenn man diese Formeln der rechtwinkligen Natur der rhombischen Symmetrie anpasst, so hat man :

$$
a_{0}=\sqrt[3]{\frac{a^{2} V}{c}}, \quad b_{0}=\sqrt[3]{\frac{V}{a c}} \text { und } c_{0}=\sqrt[3]{\frac{c^{2} V}{a}} .
$$

Diese Ausdrucke für die elementaren Axenverhältnisse sind mit denjenigen von Muthmann aus anderen Betrachlungen abgeleiteten identisch. Muthmann benutzt die drei letzten Buchstaben des griechischen Alphabets $\chi, \psi, \omega$ anstatt $a_{0}, b_{0}, c_{0}$, und nennt die drei Werthe das top ische Axenverhält nis der Substanz.

Wenn man die topischen Axenverhältnisse der Sulfate von Kalium, Rubidium und Gäsium aus den vorher gegebenen Axenverhältnissen und Molekularvolumina berechnet, so erhält man die folgenden Werthe:

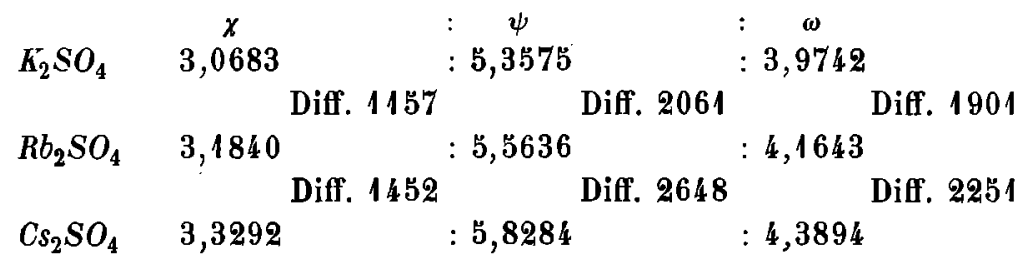

Es gebt direct aus diesen Werthen hervor, dass die Entfernungen von Mittelpunkt zu Mittelpunkt anliegender Krystallelemente längs der Axenrichtungen des Rubidiumsalzes zwischen denjenigen anliegender physikalischer Molekule der Salze von Kalium und Cäsium liegen. Die obigen

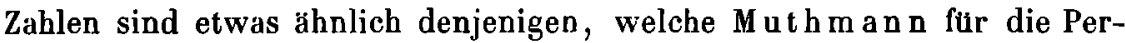
manganate derselben drei Metalle gefunden hat; die Ordnung der Differenzen aber ist verschieden, der verschiedenen Natur der Salze wegen. Der grösste Betrag der Aenderung in den Entfernungen der Krystallelemente findet längs der Richtung der $b$-Axe statt, und diejenige längs der $c$-Axe ist nur wenig niedriger, während es viel weniger Zunahme des Betrags der Entfernung in der Richtung der Axe $a$ giebt.

Verf. kann keine Ursache sehen, warum die obigen topischen Axenverhältnisse nicht in ihrer einfachsten Form ausgedruckt werden sollen, und zieht daher vor, mit dem Werthe von $\psi$ für das Kaliumsalz zu dividiren. Die topischen Verhältnisse des Kaliumsalzes sind dann mit den krystallographischen Axenverhältnissen identisch, und die Beziehungen aller so er- 
haltenen Zablen sind genau dieselben wie die durch die grösseren Zahlen ausgedrückten. Die so erhaltenen topischen Axenverhältnisse sind :

\begin{tabular}{|c|c|c|c|c|c|}
\hline \multirow{3}{*}{$\mathrm{K}_{2} \mathrm{SO}_{4}$} & $x$ & & & & $\omega$ \\
\hline & 0,5727 & & \multicolumn{2}{|l|}{$: 1$} & $: 0,7418$ \\
\hline & \multicolumn{3}{|c|}{ Diff. 216} & Diff. 385 & Diff. $\mathbf{3 5 5}$ \\
\hline \multirow[t]{2}{*}{$\mathrm{Rb}_{2} \mathrm{SO}_{4}$} & 0,5943 & & $: 1,0385$ & & $: 0,7773$ \\
\hline & & Diff. 271 & & Diff. 494 & Diff. 420 \\
\hline $\mathrm{Cs}_{2} \mathrm{SO}_{4}$ & 0,6214 & & $: 1,0879$ & & $: 0,8193$ \\
\hline
\end{tabular}

Die folgende Schlussfolgerung kann man jetzt uber die topischen Axenverhältnisse ziehen:

Die topischen Axenverhältnisse der normalen Sulfate von Kalium, Rubidium und Cäsium deuten an, dass die Ersetzung des Kaliums durch Rubidium und des Rubidiums durch Cäsium miteiner Zunahmeder Entfernung der Krystallelemente längs jeder der Axenrichtungen begleitetist, der Zunahme des Molekularvolums entsprechend, und diese Zunahme ist relativ viel grösser, wenn Rubidium durch Cäsium ersetzt wird, als wenn Kalium durch Rubidium ersetztwird. Der Betrag der Zunahme variirt in dendrei Hauptrichtungen; er ist am grössten in der Richtung der b-Axe und amkleinsten längs der $a$-Axe, während der Betrag der Zunahme in der Richtung der Verticalaxe $c$ beinahe gleich dem Maximum längs der Axe $b$ ist.

Es wird später gezeigt werden, bei der Vergleichung dieser Veränderungen mit den Aenderungen der optischen Elasticität, dass die Zunahme längs der Axen $a$ und $b$ beinahe genau im Verbältnisse der Längen jener Axen steht, während die Zunahme längs der $c$-Axe sehr viel grösser im Verhältniss zu deren Länge isl.

Die Fragen nach der Natur des Elementarparallelepipeds der Reihe und der Structur des Krystallelements können jetzt betrachtet werden. Die erste kann man mit grosser Wahrscheinlichkeit mit Rucksicht auf die Spaltbarkeit und den relativen Inhalt der primären Flächen beantworten. Denn die Lehre der Bravais-Sohncke' schen Theorie ist, wie Muthmann andeutet, dass die Spaltungsebenen diejenigen von grösster Punktdichtigkeit und daher diejenigen sind, worin die Elementarparallelogramme den kleinsten Inhalt besitzen, und auch dass Flächen am leichtesten parallel zu Ebenen von grösster Punktdichtigkeit entwickelt werden. Die Spaltungsrichtungen der drei Sulfate von Kalium, Rubidium und Cäsium sind parallel dem Brachypinakoid $b\{010\}$ und der Basis $c\{001\}$ und diejenige parallel der ersten Richtung ist die vollkommenste. Daher würde man erwarten, dass der Inhalt des Brachypinakoids am kleinsten und derjenige der Basis nur 
etwas grösser gefunden werden wurde; dieses isl genau der Fall. Der Inhalt des Brachypinakoids ist $a c=0,57 \times 0,74$; derjenige der Basis ist $a b=0,57 \times 1,0$, etwas grösser ạls derjenige des Brachypinakoids, während das Makropinakoid, parallel welchem keine Spaltbarkeit beobachtet wurde, den noch grösseren Inhalt $0,74 \times 1,0$ besitzt. Ausserdem zeigt das primäre Prisma $p\{110\}$, dessen Flächen dio Seiten des Elementarparallelepipeds sein wiurden, wenn das rhombische Raumgittersystem gilt, den grössten Inhalt $\sqrt{a^{2}+b^{2}} \times c=1,125 \times 0,74$. Demnach ist eine weit grössere Wahrscheinlichkeit dafur vorhanden, dass das Raumgittersystem der Normalsulfate von Kalium, Rubidium und Cäsium dasjenige des rechtwinkligen rhombischen Prismas ist, als dasjenige des Prismas mit rhombischer Basis. Es ist interessant für die Theorie, dass keine Flächen in der Zone des Makropinakoids $a$ und der Basis $c$, die Ebenen von grösstem und mittlerem Inhalt, ausser jenen Flächen selbst, je entdeckt worden sind.

Muthmann geht noch einen Schritt weiter; er vermuthet, dass das Krystallelement (der Krystallbaustein) dieselbe Symmetrie wie der Krystall selbst besitzt. Diese Annahme hat ohne Zweifel sehr viel Wahrscheinliches für sich. Wenn sie richtig ist, würde sie natürlich eine Raumgitterstructur bedingen, denn die Krystallelemente wurden alle parallel zu einander und symmetrisch nach derselben Axenrichtung geordnet sein. Es ist gewiss von Bedeutung, dass die Ersetzung eines Alkalimetalles durch ein anderes bei den vorliegenden Sulfaten immer Veränderungen in denselben besonderen Richtungen verursacht. Es ist gezeigt worden, dass die $b$ - und $c$-Axen beinabe dieselben Veränderungen erleiden, von viel grösserem Betrage als die Veränderung in der Richtung der $a$-Axe. Es ist aber schwer zu verstehen, warum diese örtliche (localisirte) Veränderung vorkommt, wenn es nicht ist, weil die in den chemischen Molekülen erhaltenen metallischen Atome den zwei Axen näher stehen, welche die grösste Veränderung erleiden. Bei den Permanganaten schliesst Muthman n, dass die Veränderungen der topischen Axenverhältnisse am besten durch die Voraussetzung erklärt werden, dass jedes physikalische Molekull aus vier chemischen Molekülen aufgebaut wird. Wenn die Voraussetzung Muthmann's richtig ist, dann muss eine ähnliche Voraussetzung fur die Sulfate gelten. In diesem Falle giebt es zwei metallische Atome im chemischen Molekül und die topischen Verhältnisse fừ zwei Axen zeigen beträchtliche Veränderung. Die genaue Nalur dieser Veränderungen kann man durch die Annahme erklären, dass eines der zwei Atome jedes chemischen Molekuls in der Ebene $a b$ und näher zu $b$, und das andere in der Ebene $b c$ und näher zu $c$ gelagert ist. Eine solche Orientirung würde mit der Thatsache übereinstimmen, dass die grösste Veränderung in der Richtung der $b$-Axe, eine etwas kleinere, aber noch relativ grosse Veränderung längs der $c$-Axe und eine verhältnissmässig kleine, aber noch bemerkbare in der Richtung der $a$-Axe vorkommt. Wenn 
nun das Krystallelement rhombische Symmetrie betreffs der Anordnung der darin enthaltenden chemischen Molekule wie der Krystall selbst besitzt, eine Voraussetzung, welche weiter unterstutzt wird durch noch später in dieser Mittheilung anzustellende optische Betrachtungen, muss jedes von diesen zwei Atomen viermal, rhombischer Symmetrie zufolge, wiederholt werden. Daher muss das physikalische Molekül aus vier chemischen Molekülen, symmetrisch in Bezug auf die drei Symmetrieebenen, aufgebaut sein.

Die Untersuchung der Volumbeziehungen kann jetzt mit der folgenden Darlegung beschlossen werden :

Die Spaltungsrichtungen, die Ebenen von kleinstem Inbalt, sowie die Häufigkeit der an den Krystallen beobachteten Formen deuten an, dass das Elementarparallelepiped der Reibe ein rechtwinkliges rhombisches Prisma ist. Wennes wahrist, das die Anordnung der in dem physikalischen Molekul enthaltenen chemischen Moleküle dieselbe Symmelrie, wie der Krystall selbst besitzt, sokann die Veränderung der topischen Axenverhältnisse völlig aus der Voraussetzung erklärt werden, dass das Krystallelement der Reihe aus vier chemischen Molekulen aufgebaut wird, wovon die Atome oder Gruppen symmetrisch in Bezug auf die drei Ebenen der rhombischen Symmetrie angeordnet sind.

\section{Optische Untersuchung.}

Die optischen Constanten des schwefelsauren Kaliums sind fruher von Topsöe und Ghristiansen bestimmt worden (Ann. Ghim. Phys. 1874 [5], 1,46). Diejenigen der Sulfate von Rubidium und Cäsium fehlen ganz, denn es existiren nur Angaben über die Orientirung der optischen Axen und die Natur der Doppelbrechung, welche von Lang mitgetheilt hat (Sitzungsber. der Wien. Akad. 55, 2, 415) und welche für das schwefelsaure Rubidium mit den Resultaten des Verfs. nicht ganz im Einklange sind.

Der Charakter der vorliegenden optischen Untersuchung unterscheidel sich von den bisherigen durch die viel verbesserte Methode, die nothwendigen Schnittplatten und Prismen herzustellen, welche durch die Anwendung des genauen Schleifapparates geleistet wird, welchen Verf. in der letzten Zeit beschrieben hat (Phil. Trans. Royal Society 1894, Serie A). Durch die Benutzung des neuen Apparates, welcher ein genaues Goniomeler mit einem Schleif- und Polirapparat vereinigt, kann man Platten oder Prismen in den gewünschten Richtungen schleifen mit einer Genauigkeit der Orientirung innerhalb 10'; daher kann man immer die Regel befolgen, Prismen zu benutzen, deren Flächen symmetrisch zu den optischen Hauptschnitten sind und deren Kanten parailel einer Hauptschwingungsrichtung liegen. Bei optisch-zweiaxigen Krystallen werden bekanntlich alle drei 
Brechungsexponenten durch die Benutzung zweier solcher Prismen bestimmt, und einer davon doppelt. Ausserdem sind die so hergestellten Oberflächen so genau eben und so hoch polirt, dass Deckgläser gewöhnlich ganz unnöthig sind. Die durch diese Oberflächen gelieferten Bilder des Goniometer- oder Spectrometerspaltes sind immer hell und einfach. Durch eine empfindliche Vorrichtung wurde auch dafur gesorgt, dass der Druck des Krystalles auf die Schleifscheibe während der Arbeit geändert werden konnte, so dass ein Krystall sehr selten zerbricht. Es ist ferner auch ein Mittel beigegeben, um eine zweite Oberläche genau parallel zur ersten zu schleifen, wodurch man eine planparallele Schnittplatte erhalten kann genau senkrecht zu einer Mittellinie, sodass die durch solche Schnittplatten gesehenen Interferenzfiguren immer genau symmetrisch zum Centrum des Gesichtsfeldes erscheinen.

Die Beobachtungen sind für mehr Wellenlängen als gewöhnlich ausgeführt worden. Dieses ist durch die Benutzung des neuen "Apparat zur Erzeugung des monochromatischen Lichtes ", welcher ebenfalls in einer demnächst erscheinenden Mittheilung in den Philosophical Transactions of the Royal Society 1894, Serie A beschrieben worden ist, erreicht worden. Mit diesem Apparate kann man das ganze Gesichtsfeld des Axenwinkelapparates gleichförmig hell erleuchten mit Lichtstrahlen von nur sebr wenig verschiedener Wellenlänge. Das durch brennendes Sauerstoffleuchtgas erzeugte Kalklicht wurde bei dieser Untersuchung als Lichtquelle gebraucht, um sehr enge Spalte anwenden zu können, so dass der Monochromatismus ein sehr angenähert vollkommener war. Den Wechsel von einer Wellenlänge zu einer anderen kann man so leicht und schnell ausfuhren, dass man Beobachtungen für sechs Wellenlängen in sehr kurzer Zeit vollenden kann, was besonders bequem ist bei Beobacbtungen in höheren Temperaturen, wo es schwer ist, die Temperatur während langer Zeit constant zu erhalten. Der Apparat liefert viel bessere Hesultate als diejenigen, welche durch die Benutzung gefärbter Flammen erhalten werden; die Beleuchtung des Gesichtsfeldes des Polariskops, wenn man die Interferenzfiguren im convergenten Lichte studirt, und des Bildes des Websky'schen Spaltes, wenn man Brechungsexponenten mit Prismen bestimmt, ist viel heller und ermöglicht, dass man genauere Einstellungen der Hyperbeln der ersten oder des engen mittleren Theiles der letzten auf das Fadenkreuz erlangen kann.

Die Krystalle der Sulfate des Kaliums, Rubidiums und Cäsiums zeigen nur sehr schwache Doppelbrechung, so dass relativ dicke Platten nöthig sind, um gut definirte Interferenzcurven im convergenten Lichte zu erhalten. Bei den Sulfaten des Kaliums und Cäsiums sind Platten von wenigstens $2 \mathrm{~mm}$ Dicke nothwendig, um kleine Ringe um die optischen Axen hervorzubringen, während vom schwefelsauren Rubidium eine Platte von nur wenig unter einem Centimeter Dicke unentbehrlich ist für die 
Erzeugung einer ähnlich gut definirten Figur. Die optischen Eigenschaften des schwefelsauren Rubidiums sind zwar scheinbar ungewöhnlich und ganz verschieden von denjenigen der zwei anderen Sulfate, und es war nur durch beträchtliche Fortschritte in der optischen Untersuchung möglich, die Ursache davon zu entdecken und die interessante Thatsache festzustellen, dass diese Eigenthümlichkeiten Bedingungen einer gesetzmässigen Abhängigkeit der optischen Eigenschaften von den Atomgewichten der in den Salzen enthaltenen Metalle sind.

Es sollen nun zunächst die Resultate der ausführlichen optischen Untersuchung des schwefelsauren Kaliums und Cäsiums und nachber diejenigen des schwefelsauren Rubidiums beschrieben werden.

\section{Optische Eigenschaften des schwefelsauren Kaliums.}

Die Ebene der optischen Axen ist, wie seit langem bekannt, das Makropinakoid $a\{100\}$. Die erste Mittellinie ist die krystallographische Axe $c$. Die Axen und die sie umgebenden Ringe und Lemniscaten werden durch eine $2 \mathrm{~mm}$ dicke Platte parallel der Basis $c\{001\}$ beobachtet. Die Doppelbrechung ist positiv. Also ist die Axe $c$ (erste Mittellinie) die Axe c der kleinsten optischen Elasticität; die $\operatorname{Axe} b$ (zweite Mittellinie) ist die Axe a die der grössten Elasticilăt; und die Axe $a$ die Axe $\mathfrak{b}$ der mittleren Elasticität, nach dem Schema von Topsöe und Ghristiansen, wobei $\mathfrak{a}, \mathfrak{b}, \mathfrak{c}$ die optischen Elasticitătsaxen repräsentiren, wenn $\mathfrak{a}>\mathfrak{b}>\mathfrak{c}$.

Best immungen der Brechungsexponenten. Die drei Brechungsexponenten $\alpha, \beta, \gamma$ (wo $\alpha<\beta<\gamma$ ) sind bestimmt worden mittelst vortrefflicher Prismen, welche genau in den theoretisch wunschenswerthen Richtungen mit dem neuen Apparate geschliffen und polirt wurden. Jedes Prisma war durch ebene Flächen, genau symmetrisch zu einem optischen Hauptschnitte, gebildet, und die brechende Kante war einer optischen Elasticitätsaxe genau parallel. Elf solche Prismen, mit der grössten Vorsicht hergestellt, wurden ungedeckt benutzt. Die polirten Flächen reflectirten helle und einfache Bilder des Spaltes und in jedem Falle wurden ein Paar heller und scharf definirter, gebrochener Bilder, den zwei Brechungsexponenten entsprechend, erhalten. Die elf Prismen waren aus funf verschiedenen gut ausgebildeten, mehreren Krystallisationen entnommenen Krystallen geschliffen, welche etwas grösser waren, als die bei der goniometrischen Untersuchung angewandten Krystalle. Ein paar Prismen (in einem Falle drei Prismen) wurden aus demselben Krystalle in solchen Richtungen geschliffen, dass alle drei Brechungsexponenten mittelst derselben bestimmt wurden, und einer davon naturlich doppelt, weil eine Schwingungsrichtung zweien Prismen gemėinschaftlich war. Also sind fün vollkommen unabhängige Reihen Brechungsexponenten erhalten worden, deren Mittelwerthe wabrscheinlich so nahe der Wahrheit sind, wie experimentell 
erreichbar ist. Die Messungen der Prismenwinke], welche sehr nahe $60^{\circ}$ waren, und die Bestimmungen der Minimalablenkung mit Hülfe des neuen Apparates fur monochromatisches Licht sind genau so ausgeführt worden, wie in der vorher erwähnten Mittheilung über den genannten Apparat und seinen Gebrauch beschrieben ist.

Die Resultate sind nebenstehend tabellarisch zusammengestellt.

Allgemeine Formel furdie Brechungsexponenten des schwefelsauren Kaliums. Die Brechungsexponenten der Krystalle des schwefelsauren Kaliums mögen durch die folgende Formel ausgedrükt werden. Sie ist erhalten worden durch Verbindung der drei Gleichungen, welche durch Einsetzung der beobachteten Werthe der Brechungsexponenten und der entsprechenden Wellenlängen für rothes Licht der $C$-Linie, gelbes der $D$ Linie und Licht derselben Wellenlänge wie diejenige der grunen Thalliumlinie in die Formel von Cauchy gebildet worden sind. Benutzt wurden die Indices $\beta$ und gefunden, dass $\alpha$ und $\gamma$ gleich gut durch die Formel ausgedrückt werden, wenn die Constante $A$ um 0,0012 vermindert und um 0,0026 vermehrt wird. Bei der Berechnung der Constanten sind die Mittel der beobachtelen Werthe fur die Luftbrechung corrigirt worden, indem man zum beobachteten Wertbe 0,0004 hinzufugte, so dass die Formel die wahren Brechungsexponenten im Vacuum ausdruckt; ausserdem sind nur die in Betracht kommenden ganzen Zahlen der Wellenlängen, 6562, 5892 und 5348 , gebraucht worden.

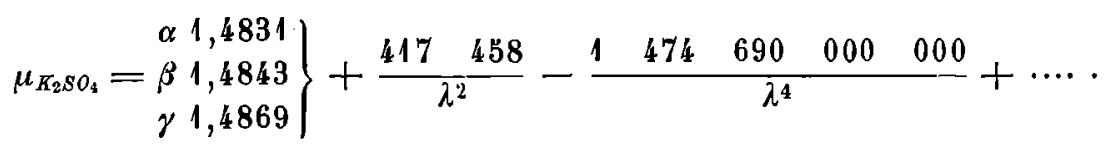

Die Formel reproducirt die beobachteten Werthe mit grosser Genauigkeit; die berechneten Werthe fur $G$-Licht sind nur 4-6 Einheiten in der vierten Decimalstelle von den beobachteten entfernt $(+0,0004$ für Vacuumcorrection), und diejenigen fur den beller leuchtenden Theil des Spectrums werden ganz genau wiedergegeben.

Bestimmungen der Brechungsexponenten bei höheren Temperaturen. Eine Reihe von Bestimmungen der Brechungsexponenten sind fur Temperaturintervalle von $40^{\circ}$ bis zu $180^{\circ}$ ausgefubrt worden. Hierzu wurde das grosse Goniometer, Nr. 1, mit dem zugehörigen Erhitzungsapparate gebraucht. Solche Untersuchungen werden durch den neuen Apparat fur monochromatisches Licht sehr erleichtert, denn man kann eine Reihe von Bestimmungen init funf Wellenlängen nebst Messungen des Prismenwinkels in wenigen Minuten ausfuhren, während welcher Zeit es nicht schwer ist die Temperatur constant zu erhalten. Die Bestimmungen wurden mit zwei der besten Prismen gemacht. Die Werthe fur G-Licht 
Ueber den Zusammenhang zwischen den krystallographischen Eigenschaften etc. 35

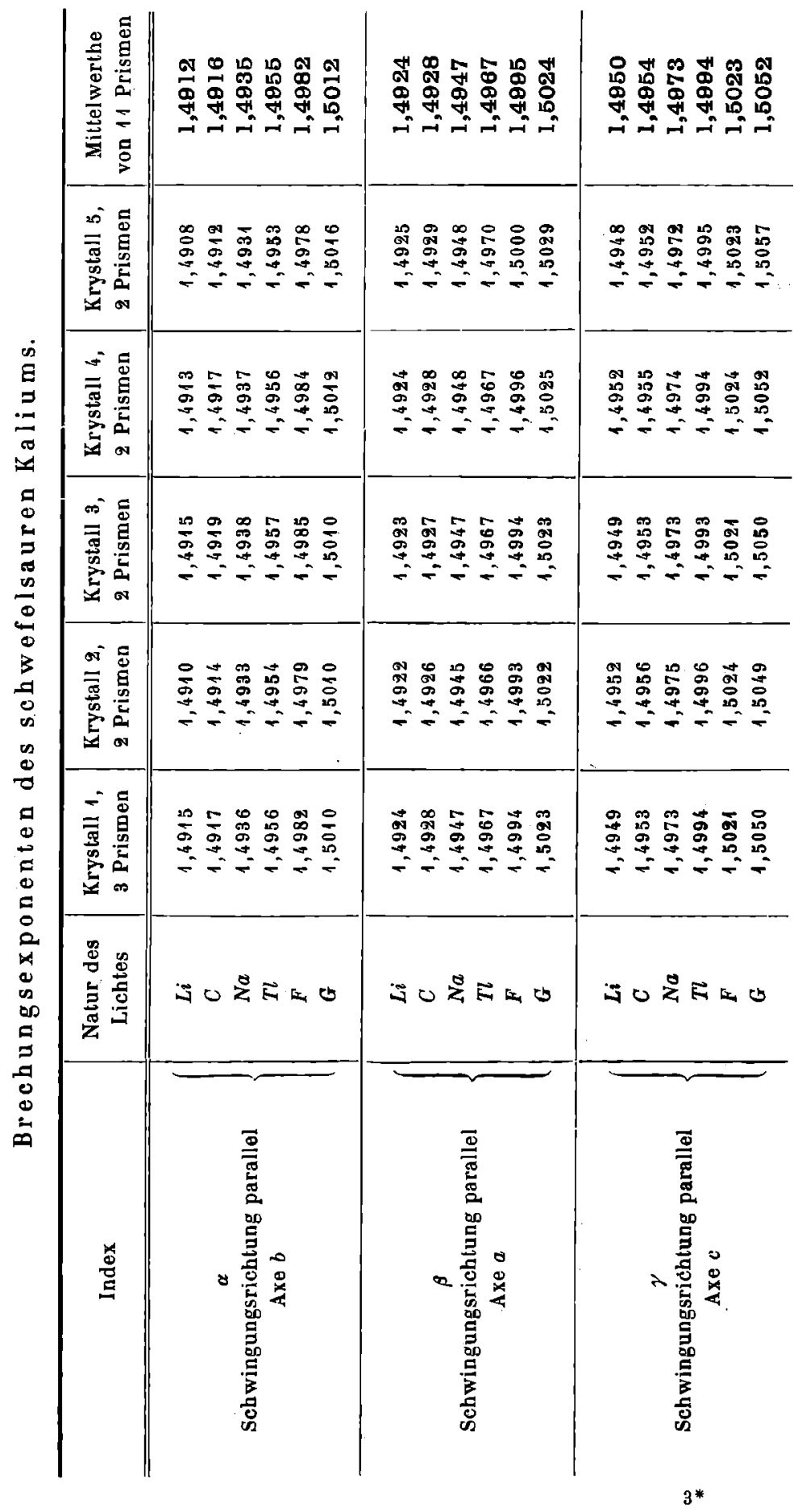


wurden nicht beobachtet wegen der schwächenden Wirkung der Glasfenster des Erhitzungsapparates.

Die folgende Tabelle stellt die Resultate für die verschiedenen Temperaturen dar; die Werthe für die gewöhnliche Temperatur sind aus der vorher gegebenen Tabelle genommen.

Refraction des scbwefelsauren Kaliums bei verschiedenen Temperaturen.

\begin{tabular}{|c|c|c|c|c|c|c|}
\hline Index & $\begin{array}{c}\text { Natur des } \\
\text { Lichtes }\end{array}$ & $\begin{array}{c}\text { Bei gewöhnl. } \\
\text { Temperatur } \\
\left(18^{0}-20^{0}\right)\end{array}$ & Bei $60^{\circ}$ & Bei $100^{\circ}$ & Bei $140^{\circ}$ & Bei $180^{\circ}$ \\
\hline \multirow{5}{*}{$\begin{array}{c}\alpha \\
\text { Schwingungs- } \\
\text { richtung parallel } \\
\text { Axe } b\end{array}$} & $L i$ & 1,4912 & 1,4902 & 1,4890 & 1,4876 & 1,4855 \\
\hline & $C$ & 1,4916 & 1,4906 & 1,4894 & 1,4880 & 1,4859 \\
\hline & $\mathrm{Na}$ & 1,4935 & 1,4925 & 1,4911 & 1,4896 & 1,4878 \\
\hline & $T l$ & 1,4955 & 1,4945 & 1,4931 & 1,4917 & 1,4899 \\
\hline & $F$ & 1,4982 & 1,4972 & 1,4960 & 1,4946 & 1,4926 \\
\hline \multirow{5}{*}{$\begin{array}{c}\beta \\
\text { Schwingungs- } \\
\text { richtung paralle] } \\
\text { Axe } a\end{array}$} & $L i$ & 1,4924 & 1,4914 & 1,4901 & 1,4886 & 1,4869 \\
\hline & $C$ & 1,4928 & 1,4918 & 1,4905 & 1,4890 & 1,4873 \\
\hline & $N a$ & 1,4947 & 1,4936 & 1,4921 & 1,4909 & 1,4890 \\
\hline & $T l$ & 1,4967 & 1,4955 & 1,4944 & 1,4928 & 1,4910 \\
\hline & $F$ & 1,4995 & 1,4984 & 1,4972 & 1,4956 & 1,4936 \\
\hline \multirow{5}{*}{$\begin{array}{c}\gamma \\
\text { Schwingungs- } \\
\text { richtung parallel } \\
\text { Axe } c\end{array}$} & $\mathrm{Li}$ & 1,4950 & 1,4938 & 1,4924 & 1,4905 & 1,4883 \\
\hline & $C$ & 1,4954 & 1,4942 & 1,4928 & 1,4909 & 1,4887 \\
\hline & $\mathrm{Na}$ & 1,4973 & 1,4963 & 1,4948 & 1,4929 & 1,4906 \\
\hline & $\pi$ & 1,4994 & 1,4983 & 1,4968 & 1,4949 & 1,4927 \\
\hline & $\boldsymbol{F}$ & 1,5023 & 1,5010 & 1,4995 & 1,4978 & 1,4954 \\
\hline
\end{tabular}

Man beobachtet: 1) Das Brechungsvermögen nimmt regelmässig bei steigender Temperatur ab. 2) Die Veränderung ist am grössten bei dem Exponenten $\gamma$, den parallel der Verticalaxe $c$ schwingenden Strahlen entsprechend, wobei der Unterschied für $160^{\circ}$ Erhöhung der Temperatur 0,0067 beträgt. 3) Die Veränderung bei den Exponenten $\alpha$ und $\beta$, den Axen $b$ und $a$ entsprechend, ist ungefähr gleich und beträgt circa 0,0057 .

Optische Elasticitätsaxen des schwefelsauren Kaliums. Die aus den Reciproken der Brechungsexponenten berechneten Elasticitätsaxen sind für die gewöhnliche Temperatur die folgenden:

$$
a: b: c=0,9992: 1: 0,9975 \text {. }
$$

Identische Werthe werden erhalten, ob man die Berechnungen fur die Wasserstofflinie $C$, die Natriumlinie $D$ oder für die Thalliumlinie macht.

Die Brechungsexponenten vom schwefelsauren Kalium sind von Topsöe und Ghristiansen (l. c.) fur die Spectrumlinien $C, D$ und $F$ bestimmt worden; ibre Lichtquellen waren ein Geiss ler'sches Wasserstoffrohr und 
eine mit Kochsalz gesättigte Spirituslampe. Sechs Prismen wurden angewandt, wovon zwei durch vorhandene Flächen der Krystalle gebildet wurden und die anderen vier mil der Hand geschliffen und mit Deckgläsern bedeckt wurden. Fünf dieser sechs Prismen aber lieferten nur einen einzigen Brechungsexponenten, weil sie nicht symmetrisch zu einem optischen Hauptschnitte waren. Die erhaltenen Werthe der Brechungsexponenten sind ziemlich nahe den in dieser Mittheilung gegebenen; der grösste Unterschied fur irgend einen Exponenten beträgt 0,0007. Das aus ihren Werthen berechnete Verhältniss der Elasticitätsaxen ist :

$$
a: b: c=0,9991: 1: 0,9968 \text {. }
$$

Die Orientirung der optischen Elasticitätsaxen nach dem Schema von Topsöe und Christiansen ist $\mathfrak{b} \mathfrak{a} \mathfrak{c}$.

Die optischen Elasticitätsaxen, aus den Brechungsexponenten bei $180^{\circ}$ berechnet, sind :

$$
a: b: c=0,9992: 1: 0,9981 \text {. }
$$

Das Verhăltniss $a: b$ ist identisch mit und dasjenige fưr $c: b$ nicht weit entfernt von demjenigen für die gewöhnliche Temperatur, und die Ordnung ist dieselbe.

Bestimmungendes optischen Axenwinkels vom schwefelsauren Kalium. Experimentelle Bestimmungen des optischen Axenwinkels sind von viel grösserer Genauigkeit, besonders in den Fällen schwach doppeltbrechender Substanzen, als die Werthe, welche aus den Brechungsexponenten durch die Formel $\cos V=\sqrt{\frac{\frac{1}{\beta^{2}}-\frac{1}{\gamma^{2}}}{\frac{1}{\alpha^{2}}-\frac{1}{\gamma^{2}}}}$ berechnet werden. Denn die Differenzen zwischen den Reciproken der Quadrate der Brechungsexponenten sind so klein, dass eine Veränderung von 0,0001 bei den letztgenannten häufig genugt, um den berechneten Werth des optischen Axenwinkels um zwei Grad zu verändern. Selbst bei den so sorgfältig bestimmten Brechungsexponenten dieser Untersuchung ist es möglich, dass die Fehler 0,0002 erreichen, daher bei diesen schwach doppeltbrechenden Sulfaten nur Messungen des optischen Axenwinkels allein von irgend einer Zuverlässigkeit sind.

Drei Paar Platten senkrecht zur ersten und zweiten Mittellinie wurden mit Hülfe des neuen Instrumentes geschliffen. Die Platten mússen, wie schon erwähnt, sehr dick sein, um der niedrigen Doppelbrechung wegen gut definirte Interferenzfiguren zu zeigen. Die drei zur Bestimmung von $2 E$ und $2 H_{a}$ angewandten Platten parallel zur Basis variirten von zwei bis uber vier Millimeter in der Dicke; die letztgenannte Dicke ist besonders bequem. Um solche Platten zu erhalten, sind elwas grössere Kry- 
stalle nöthig, da die Krystalle in genannter Richtung gewöhnlich nur schmal sind. Wegen der grösseren Entwickelung der Krystalle in der Richtung des Brachypinakoids wurden drei vortreffliche grosse und genúgend dicke Platten senkrecht zur zweiten Mittellinie hergestellt, wodurch $2 \mathrm{H}_{0}$ in $\alpha$-Monobromnaphtalin gut zu beobachten war. Die vortreffliche Politur, welche die Oberflächen nach fünf Minuten durch die Benutzung des Polirapparates des Instrumentes erhielten, ermöglichte es, dass die sämmtlichen Messungen ohne Deckgläser ausgeführt werden konnten. Die Messungen wurden mit Hulfe des grossen Axenwinkelapparates von Fuess ausgefuhrt und zur Beleuchtung der neue Apparat für monochromatisches Licht benutzt, wie dies in der diesen Apparat betreffenden Mittheilung (l. c.) beschrieben worden ist. Fưr jede Wellenlänge wurden drei Einstellungen jeder Hyperbel auf das Fadenkreuz gemacht und das Mittel der Ablesungen wurde als wahre Einstellung betrachtet.

Die Interferenzfigur von schwefelsaurem Kalium in Luft $2 E$ zeigt sehr kleine Dispersion der optischen Axen, so klein, dass man gar keine Farben an den Grenzen der Hyperbeln bei weissem Lichte bemerken kann. Obgleich die angewandten dicken Platten sehr scharfe Hyperbeln lieferten, konnte man keinen Unterschied grösser als die Einstellungsfehler entdecken zwischen den Axenwinkeln für die beiden Enden des Spectrums. Topsöe und Christiansen geben fur $2 E 111^{0} 19^{\prime}$. Des Cloizeaux hatte vorber $107^{0}-109^{\circ}$ gefunden und in einer späteren Mittheilung (Mém. des Savants Étrangers 18, 608) gab er $110^{\circ} 15^{\prime}$ und $110^{\circ} 26^{\prime}$ furr Roth und resp. Blau an.

Eine grosse Zahl von Messungen von $2 E$ wurden für Licht von den Wellenlängen der rothen Lithiumlinie und der grunlichblauen Wasserstofflinie $F$ mit den drei Platten ausgefuhrt; die erhaltenen Winkelwerthe zeigen aber Differenzen für dieselbe Wellenlänge grösser als die Grenzen der Werthe von Des Gloizeaux. Verf. zieht daher vor, dass Mittel aller erhaltenen Wertbe zu geben in Berucksichtigung der Thatsache, dass die Dispersion sebr gering ist. Der Mittelwerth ist :

$$
2 E=111^{\circ} 0^{\prime} \text {. }
$$

Die Grenzen der einzelnen Werthe liegen beinahe $30^{\prime}$ auf jeder Seite dieses Mittelwerthes.

Die Bestimmungen von $2 H_{a}$ und $2 H_{o}$ in Bromnaphtalin boten keine Schwierigkeiten dar. Die Hyperbeln waren vortrefflich definirt und die Dispersion ganz klar. Mit Hülfe des neuen Apparates für monochromatisches Licht kann man eine geringe Dispersion sehr leicht bemerken; wenn man den Prismenkreis schnell umdreht und so eine schnelle Verănderung der beleuchtenden Farbe hervorbringt, kann man die Hyperbel von einer Stellung zu einer anderen in Bezug auf das Fadenkreuz sich bewegen sehen. Die folgende Tabelle stellt die Resultate der Messungen an den sechs Platten dar. 
Ueber den Zusammenhang zwischen den kryslallographischen Eigenschaften elc. $\mathbf{3} 9$

Optische Axenwinkel des schwefelsauren Kaliums.

\begin{tabular}{|c|c|c|c|c|c|c|}
\hline $\begin{array}{c}\text { Natur } \\
\text { des } \\
\text { Lichtes: }\end{array}$ & $\begin{array}{c}\text { Nr. der } \\
\text { Platte } \\
\text { senkrecht } \\
\text { zur ersten } \\
\text { Mittellinie: }\end{array}$ & $\begin{array}{c}\text { Beobachtet } \\
2 H_{a}\end{array}$ & $\begin{array}{c}\text { Nr. der } \\
\text { Platte } \\
\text { senkrecht } \\
\text { zur zweiten } \\
\text { Mittellinie: }\end{array}$ & $\begin{array}{c}\text { Beobachtet } \\
2 H_{o}\end{array}$ & $\begin{array}{c}\text { Berechnet } \\
2 V_{a}\end{array}$ & $\begin{array}{c}\text { Miltel } \\
2 V_{a}\end{array}$ \\
\hline \multirow{3}{*}{$L i$} & 1 & $60^{0} \quad 5^{\prime}$ & $1 a$ & $97016^{\prime}$ & $670^{\circ} 25^{\prime}$ & \multirow{3}{*}{$67^{0} 25^{\prime}$} \\
\hline & 2 & 6030 & $2 a$ & $97 \quad 48$ & $6732\}$ & \\
\hline & 3 & $\begin{array}{ll}60 & 3\end{array}$ & $3 a$ & $97 \quad 28$ & $\begin{array}{ll}67 & 18\end{array}$ & \\
\hline \multirow{3}{*}{$C$} & 1 & $60 \quad 2$ & $1 \dot{a}$ & $97 \quad 12$ & 6724 & \multirow{3}{*}{6724} \\
\hline & 2 & $60 \quad 23$ & $2 a$ & 9736 & $6731\}$ & \\
\hline & 3 & $59 \quad 57$ & $3 a$ & 9723 & $67 \quad 16$ & \\
\hline \multirow{3}{*}{$N a$} & 1 & 5953 & $1 a$ & $97 \quad 2$ & 6721 & \multirow{3}{*}{6720} \\
\hline & 2 & 5959 & $2 a$ & 9658 & 6727 & \\
\hline & 3 & $59 \quad 44$ & $3 a$ & 976 & $67 \quad 12$ & \\
\hline \multirow{3}{*}{$T l$} & 1 & 5930 & $1 a$ & 9628 & $67 \quad 16$ & \multirow{3}{*}{6715} \\
\hline & 2 & 5933 & $2 a$ & $96 \quad 18$ & 6723 & \\
\hline & 3 & $59 \quad 12$ & $3 a$ & $96 \quad 17$ & $67 \quad 61$ & \\
\hline \multirow{3}{*}{$F$} & 1 & $\begin{array}{ll}59 & 0\end{array}$ & $1 a$ & $95 \quad 44$ & 6710 & \multirow{3}{*}{67} \\
\hline & 2 & 5854 & $2 a$ & 9535 & $\left.\begin{array}{ll}67 & 9\end{array}\right\}$ & \\
\hline & 3 & $58 \quad 49$ & $3 a$ & $95 \quad 42$ & 67 & \\
\hline
\end{tabular}

Die Messungen von $2 H_{a}$ und $2 H_{o}$ mit jedem Paar in derselben horizontalen Linie der Tabelle stehender Platten, welche zusammen die Berechnung des wahren Axenwinkels $2 V_{a}$ durch die Formel tang $V_{a}=\frac{\sin H_{a}}{\sin H_{o}}$ ermöglichen, wurden direct nach einander ausgeführt, so dass keine Veränderung der Brechung des Bromnaphtalins möglich war. Beobachtungen mit $G$-Licht sind nicht so zuverlässig wegen des durch die Absorption des Bromnaphtalins hervorgebrachten Lichtverlustes.

Der Werth von $2 V_{a}$ für Natriumlicht, aus den beobachteten Brechungsexponenten berechnet, ist $67^{\circ} \mathbf{3 8}^{\prime}$. Diese vortreffliche Uebereinstimmung aber ist ganz zufällig, denn ein Unterschied von 0,0001 bei irgend einem der Brechungsexponenten würde eine sehr grosse Differenz verursachen. Zum Beispiel wenn man den Werth des Exponenten $\alpha$ 1,4936 anstatt 1,4935 annimmt, wird das berechnete $2 V_{a}=6^{\circ} 6^{\prime}$, ein Unterschied von anderthalb Grad. Da der mögliche Fehler der Bestimmungen der Brechungsexponenten etwa 0,0002 beträgt, so sieht man, dass die Uebereinstimmung des beobachteten und berechneten Axenwinkels rein zufällig ist.

Der optische Axenwinkel $2 V_{a}$ fur $N a$-Licht wurde von Topsöe und $\mathrm{Ch}$ ristiansen bei zwei Bestimmungen $66^{\circ} 40^{\prime}$ resp. $67{ }^{\prime} 28^{\prime}$ gefunden.

Wirkung von Temperaturerhöhung auf den optischen 
Axenwinkel. Beobachtungen bei höheren Temperaturen sind bereits fruher von Des Cloizeaux (Nouv. Rech.) und Mallard (diese Zeitschr. 9, 402) ausgefuhrt worden. Der erste Beobachter fand, dass eine Temperaturerhöhung von $140^{\circ}$ von einer Zunahme von $2 E$ um ungefähr $10^{\circ}$ begleitet wurde. Diese Beobachtung ist in Uebereinstimmung mit derjenigen des Verfs. und stimmt mit den Angaben für die Veränderungen der Brechungsexponenten. Bei $116^{0}$ wurden die Hyperbeln schwach roth an der Innenseite und blau an der Aussenseite gefärbt. Messungen bei dieser Temperatur mit Hülfe des dem grösseren Axenwinkelapparate beigegebenen Erhitzungsapparates gaben die folgenden Werthe:

$$
\begin{aligned}
& 2 E \text { bei } 116^{0} \text { für } L i \text {-Licht }=118^{\circ} 55^{\prime} \\
& \mathrm{Na}-\mathrm{C}=11840 \\
& F-\quad-=11830
\end{aligned}
$$

Fưr $100^{\circ}$ Temperaturerhöhung nimmt also $2 E$ um beinahe $70 \mathrm{zu}$. Verf. erhitzte die Krystallplatte nicht weiter, um nicht den vortrefflichen Messungsapparat zu beschädigen. Für den Zweck der Vergleichung ist dieses völlig genugend, wie späler bewiesen werden wird. Mit Hulfe eines weniger theuren Instrumentes hat Mall a rd die Erscheinungen bei schwefelsaurem Kalium bis zu sehr hohen Temperaturen verfolgt und gezeigt, dass die Zunahme des Winkels fortfährt, bis bei ungefähr $380^{\circ}$ die Axen sich in $\operatorname{der} \operatorname{Axe} b$ verbinden und dann sich in der Ebene $\{001\}$ senkrecht zu ihrer vorherigen Ebene wieder trennen, und dass bei noch höheren Temperaturen weitere ähnliche Veränderungen beobachtet sind, bis zwischen $600^{\circ}$ und $650^{\circ}$ eine plötzliche Umwandlung in eine wabre hexagonale Form mit negativer Doppelbrechung erfolgt. Diese Beobachtungen von Mallard sind von besonderem Interesse für den Zweck dieser Mittheilung, denn es wird später gezeigt werden, dass schwefelsaures Rubidium ähnliche, aber noch complicirtere Phänomena zeigt bei Temperaturen, welche nur wenig uber der gewöhnlichen liegen.

\section{Optische Eigenschaften des schwefelsauren Cäsiums.}

Das schwefelsaure Cäsium ist dem schwefelsauren Kalium sehr ähnlich hinsichtlich seiner geringen Doppelbrechung, aber es weicht dadureh ab, dass das Zeichen derselben negativ und die Dispersion der Axen grösser ist. Die erste Mittellinie ist die Verticalaxe $c$ und die Interferenzfigur im convergenten Lichte wird durch die breit ausgebildete Basis gut gesehen; ein Krystall von 2-3 mm Dicke zeigt sie scharf definirt. Die optische Axenebene ist das Brachypinakoid $b\{010\}$. Die Orientirung der optischen Axen ist also $\mathfrak{c} \mathfrak{b} \mathfrak{a}$, wie von Lang angegeben hat.

Brechungsexponentendes schwefelsauren Cäsiums. Vierzehn Prismen wurden in ähnlicher Weise, wie vom schwefelsauren Kalium, 
aus Krystallen von fünf verschied enen Krystallisationen hergestellt. Ihre Flächen wurden in jedem Falle sym metrisch zu bekannten Symmetrieebenen der Krystalle und so, dass ihre bre chenden Kanten parallel einer optischen Elasticitätsaxe waren, geschliffen und polirt. Es gab also jedes Prisma zwei Brechungsexponented. Aus den Krystallen 1 und 2 wurden nicht weniger als vier Prismen aus jedem Krystalle geschliffen, nänlich je ein Paar gleichartiger von den Enden jeder der beiden krystallographischen Axen. Mit einem guten Krystalle, 4-5 mm im Durchmesser, gelingt es ohne Schwierigkeit dieses mit Hüle des neuen Instrumentes auszuführen, man erhält so zwei der Brechungsexponenten zweimal und den anderen viermal an einem und demselben Krystalle.

Die von jedem Krystalle erhaltenen Mittelwerthe nebst den Endmittelwerthen sind in der Tabelle auf $\mathrm{S}$. 42 zusammengestellt.

Die Refraction des schwefelsauren Cäsiums für irgend eine Wellenlänge, für das Vacuum corrigirt, wird genau durch die folgende allgemeine Formel ausgedruckt. Die Constanten sind durch Verbindung der Gauchyschen Gleichungen, worin die beobachteten Werthe für $\mathrm{C}$-, $\mathrm{Na}$ - und $\mathrm{Tl}$-Licht eingesetzt wurden, nebst Vacuumcorrection $(0,0004)$ erhalten worden.

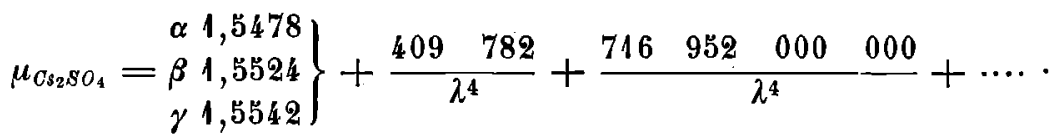

Die aus der Formel berechneten Werthe, nach Subtraction der Vacuumcorrection, sind in beinahe allen Fällen identisch mit den beobachteten Mittelwerthen oder nur 0,0001 von denselben en Ifernt. Man wird bemerken, dass die $\beta$-Werthe sich mehr den $\gamma$-als den $\alpha$-Werthen nähern, was das negative Zeichen der Doppelbrechung beweist. Dies wurde unabhängig davon durch die Anwendung einer Viertelundulationsglimmerplatte bestätigt. Der Werth der Constante $A$ fur $\alpha$ ergiebt sich durch Subtrahirung von 0,0046 von der wirklich berechneten Constante für $\beta$, und derjenige für $\gamma$ durch Hinzufügung von 0,0018 .

B rechung des schwefelsauren Cäsiums bei höheren Temperaturen. Eine Reibe Bestimmungen der Brechungsexponenten mit einem vortrefflichen Paar Prismen, bei regelmässigen Temperaturintervallen, sind auch bei diesem Salze ausgefuhrt worden. Die Resultate sind in der Tabelle auf $\mathrm{S} .43$ angegeben.

Es ist interessant zu bemerken, dass, wie bei dem schwefelsauren Kalium, 1) eine regelmässige Verminderung im Brechungsvermögen mit steigender Temperalur stattfindet; 2) die grösste Veränderung bei dem der Verticalaxe $c$ entsprechenden Brechungsexponenten vorkommt, wobei der Unterschied für $160^{\circ}$ ungefähr 0,0065 beträgt, und 3) die Veränderungen der den Axen $a$ und $b$ entsprechenden Exponenten ungefähr gleich sind 
A. E. Tutton.

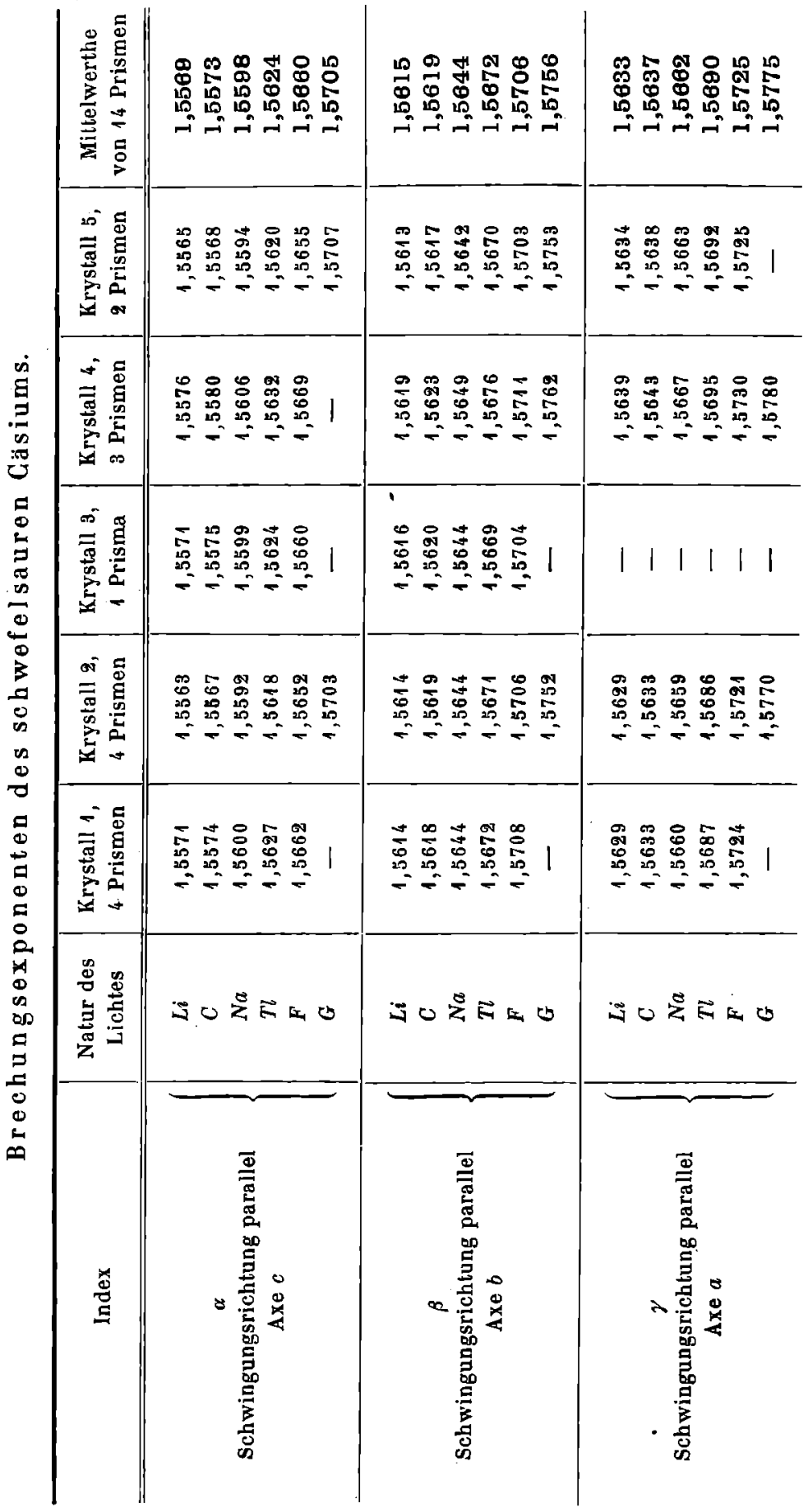


Jeber den Zusammenhang zwischen den kryslallographischen Eigenschaften etc, 43

Refraction des schwefelsauren Cäsiums bei verschiedenen Temperaturen.

\begin{tabular}{|c|c|c|c|c|c|c|}
\hline Index & $\begin{array}{c}\text { Natur des } \\
\text { Lichtes }\end{array}$ & $\begin{array}{c}\text { Bei gewöhnl. } \\
\text { Temperatur } \\
\left(18^{0}-20^{\circ}\right)\end{array}$ & Bei $60^{\circ}$ & Bei 1000 & Bei $140^{\circ}$ & Bei $180^{0}$ \\
\hline \multirow{5}{*}{$\begin{array}{c}\alpha \\
\text { Schwingungs- } \\
\text { richtung parallel } \\
\text { Axe } c\end{array}$} & $L i$ & 1,5569 & 1,5559 & 1,5544 & 1,5527 & 1,5508 \\
\hline & $C$ & 1,5573 & $1, \mathbf{5} 563$ & 1,5548 & 1,5531 & 1,5512 \\
\hline & $\mathrm{Na}$ & 1,5598 & 1,5584 & 1,5568 & 1,5554 & 1,5534 \\
\hline & $T l$ & 1,5624 & 1,5609 & 1,5590 & 1,5576 & 1,5558 \\
\hline & $F$ & 1,5660 & 1,5641 & 1,5622 & 1,5608 & 1,5590 \\
\hline \multirow{5}{*}{$\begin{array}{c}\beta \\
\text { Schwingungs- } \\
\text { richtung parallel } \\
\text { Axe } b\end{array}$} & $L i$ & 1,5615 & 1,5607 & 1,5595 & 1,5581 & 1,5566 \\
\hline & $C$ & 1,5619 & 1,5611 & 1,5599 & 1,5585 & 1,5570 \\
\hline & $N a$ & 1,5644 & 1,5634 & 1,5622 & 1,5609 & 1,5594 \\
\hline & $T l$ & 1,5672 & 1,5658 & 1,5645 & 1,5632 & 1,5619 \\
\hline & $F$ & 1,5706 & 1,5690 & 1,5677 & 1,5664 & 1,5651 \\
\hline \multirow{5}{*}{$\begin{array}{c}\gamma \\
\text { Schwingungs- } \\
\text { richtung parallel } \\
\text { Axe } a\end{array}$} & $L i$ & 1,5633 & 1,5625 & 1,5611 & 1,5599 & 1,5587 \\
\hline & $C$ & 1,5637 & 1,5629 & 1,5615 & 1,5603 & 1,5591 \\
\hline & $\mathrm{Na}$ & 1,5662 & 1,5651 & 1,5640 & 1,5626 & $1, \mathbf{5 6 1 4}$ \\
\hline & $T l$ & 1,5690 & 1,5674 & 1,5664 & 1,5649 & 1,5639 \\
\hline & $F$ & 1,5725 & 1,5706 & 1,5696 & 1,5681 & 1,5671 \\
\hline
\end{tabular}

und circa 0,0049 betragen. Es scheint auch, dass bei dem schwefelsauren Cásium eine bemerkbare Verminderung der Dispersion eintritt, wenn die Temperatur steigt; die Differenz zwischen den Exponenten fur die zwei äussersten Wellenlängen ist $0,0091-92$ bei gewöhnlicher Temperatur und $0,0082-85$ bei $180^{\circ}$, also ist die durch Temperaturerhöhung hervorgerufene Verminderung des Brechungsvermögens augenscheinlich grösser am blauen Ende des Spectrums als am rothen Ende.

Optische Elasticitätsaxen des schwefelsauren Cäsiums. Das Verhältniss der optischen Elasticität längs der drei krystallographischen Axen bei gewöhnlicher Temperatur ist:

$$
a: b: c=0,9989: 1: 1,0029 \text {. }
$$

Diese entsprechen der Orientirung $\mathfrak{c} \mathfrak{b} \mathfrak{a}$.

Das Verbältniss, aus den Brechungsexponenten furr $180^{\circ}$ berechnet, ist :

$$
a: b: c=0,9987: 1: 1,0039 .
$$

Die letzten Werthe sind also nicht weit entfernt von denjenigen fur die gewöhnliche Temperatur und zeigen dieselbe Ordnung.

Messungen des optischen Axenwinkels des schwefelsauren Casiums. Diese Messungen wurden mit sechs vortrefflichen Platten von ungefähr 2,5 mm Dicke ausgeführt. Drei waren senkrecht zur ersten 
und drei zur zweiten Mittellinie. $\mathrm{Nr}$. 1 und 2 wurden durch sehr vollkommene Flächen der Basis gebildet, breit entwickelt an ein Centimeter langen Krystallen. Die anderen Platten wurden mit Hülfe des neuen Instrumentes geschliffen und polirt, und alle wurden ungedeckt gebraucht. Die Interferenzfiguren vom schwefelsauren Gäsium sind sehr scharf definirt und mit Platten der angewandten Dicke kann man $2 E$ sehr genau bestimmen. In Bromnaphtalin sind die Figuren vortrefflich und obgleich zufällig die Dispersion der Axen, welche uber $3^{0}$ für $2 E$ beträgt, beinahe yu Null durch die hochbrechende Flussigkeit vermindert wird, kann man doch die Differenz von nur 5-6 Minuten, wenn man den neuen Beleuchtungsapparat für monochromatisches licht benutzt, deutlich bemerken und der Sinn der Dispersion wird durch schwache Färbung der Hyperbeln bei weissem Lichte bestätigt. Die Resultate sind in der folgenden Tabelle dargestellt.

Scheinbarer Axenwinkel in Luft $2 \mathrm{E}$ von $\mathrm{Cs}_{2} \mathrm{SO}_{4}$.

$\begin{array}{ccccc}\text { Nalur des Lichtes: } & \text { Platte I } & \text { Platte 2 } & \text { Platte 3 } & \text { Mittelwerthe von } 2 E \\ L i & 114^{0} 47^{\prime} & 114^{0} 33^{\prime} & 114^{0} 20^{\prime} & 114^{0} 33^{\prime} \\ C & 11453 & 11445 & 11440 & 11446 \\ N a & 11539 & 11543 & 11539 & 11540 \\ T l & 11650 & 11647 & 11641 & 11646 \\ F & 11755 & 11752 & 11734 & 11747\end{array}$

Optischer Axenwinkel $2 V_{a}$ des sobwefelsauren Cäsiums.

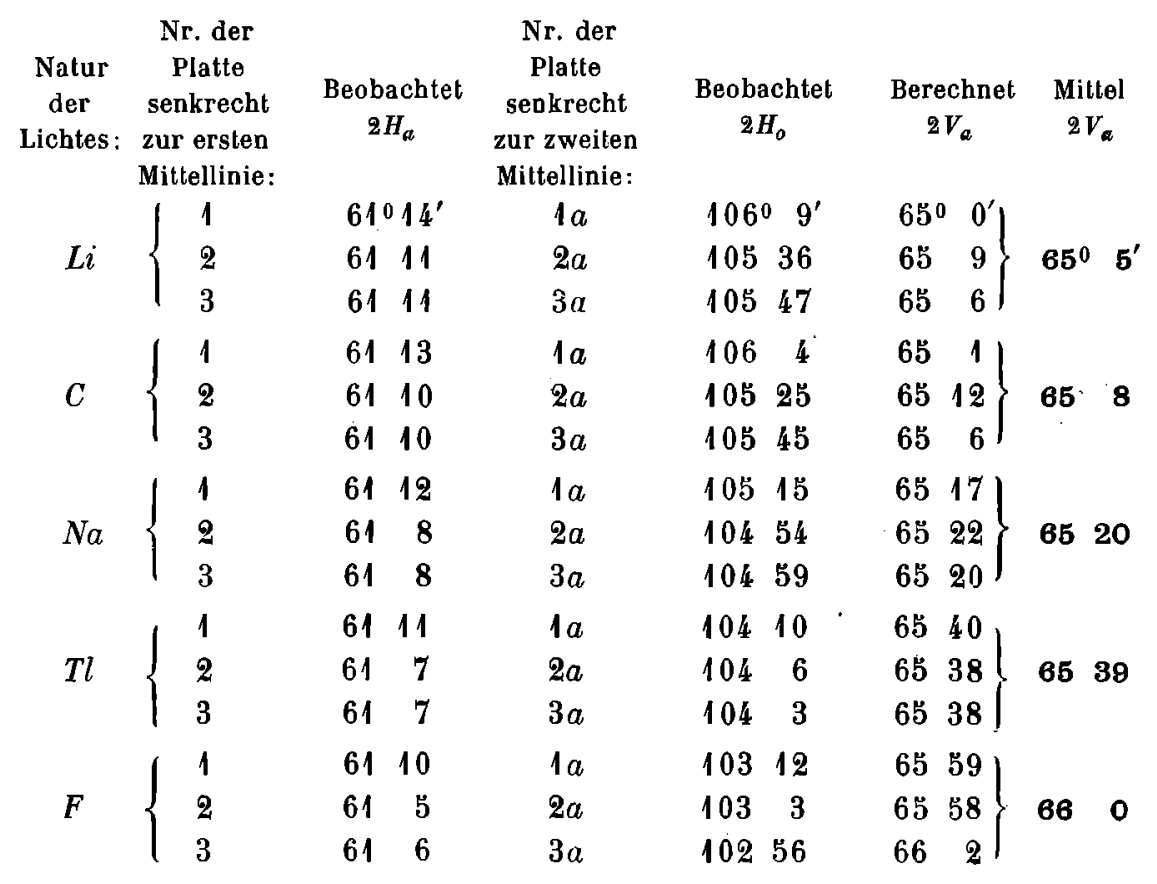


In jedem Falle sind die Beobachtungen mit den beiden Platten 1 und $1 a, 2$ und $2 a, 3$ und $3 a$ direct nach einander an demselben Tage ausgeführt worden, um Veränderung der Brechung des Bromnaphtalins zu vermeiden.

von Lang (Sitzungsber. Wien. Akad. 55, 2, 415) giebt an, dass der scheinbare Axenwinkel $2 E=114^{\circ}$ und für Roth kleiner als für Violett ist; $\varrho<v$.

Bestimmungen des optischen Axenwinkels von $\mathrm{CS}_{2} \mathrm{SO}_{4}$ bei höheren Temperaturen. Messungen von $2 E$ wurden bei Temperaturen von $60^{\circ}$ und $100^{\circ}$ ausgeführt. Die Resultate sind die folgenden, denen die Werthe fur die gewöhnliche Temperatur zur Vergleichung beigesetzt wurden.

$\begin{array}{lccc} & 2 E \text { bei } 18^{0}-20^{0} & 2 E \text { bei } 60^{\circ} & 2 E \text { bei } 100^{\circ} \\ L i & 114^{\circ} 33^{\prime} & 110^{\circ} 50^{\prime} & 108^{\circ} 30^{\prime} \\ C & 11446 & 11145 & 10842 \\ N a & 11540 & 11227 & 10910 \\ T l & 11646 & 11330 & 11056 \\ F & 11747 & 11525 & 11235\end{array}$

Die optischen Axen nähern sich also einander um ungefäbr $6^{0}$ fur eine Temperaturerhöhung von $80^{\circ}$, enisprechend einer Annäherung von $7 \frac{1}{2}{ }^{0}$ für 100\%. Dieses ist ungefähr derselbe Betrag, aber in umgekehrter Ordnung, dem negativen Zeichen der Doppelbrechung entsprechend, wie er bei dem schwefelsauren Kalium beobachtet worden ist. Der Betrag und die Richtung der Veränderung stimmen mit derjenigen tuberein, welche durch die Bestimmungen der Brechungsexponenten bei höheren Temperaturen angedeutet werden. Wie vorber bewiesen worden ist, wird der wabre optische Axenwinkel nur sebr approximativ durch die Formel $\cos V=$ $\sqrt{\frac{\frac{1}{\beta^{2}}-\frac{1}{\gamma^{2}}}{\frac{1}{\alpha^{2}}-\frac{1}{\gamma^{2}}}}$ gegeben. Doch wird der Sinn der Veränderung für ein beträchtliches Temperaturintervall dadurch klar angedeutet. Der so berechnete Axenwinkel (das Supplement von $V$, weil der Krystall negativ ist) für $\mathrm{Na}$-Licht bei der gewöbnlichen Temperatur ist $63^{\circ} 52^{\prime}$ und derjenige für $180^{\circ}$ ist $59^{\circ} 28^{\prime}$, was eine Abnahme der wahren Axenwinkel von ungefähr $4 \frac{1}{2}^{\circ}$ für $160^{\circ}$ Temperaturerhöhung andeutet. Da der mögliche Fehler des berechneten Winkels gewiss $2^{0}$ ist, so ist der Werth des angedeuteten Betrages von keiner Wichtigkeit; seine Ordnung und Richtung aber stimmen vollkommen mit den beobachteten uberein und deuten die Uebereinstimmung der Brechungs- und Axenwinkelphänomene an. 


\section{Optische Eigenschaften des schwefelsauren Rubidiums.}

Aus dem Vorhergehenden ergiebt sich, dass die Sulfate von Kalium und Cäsium zwar schwach doppeltbrechende, aber sonst ganz normale Substanzen von positivem resp. negativem Charakter sind. Die optischen Eigenschaften des schwefelsauren Rubidiums sind scheinbar ganz ausserordentlich verschieden. Wenn man einen Krystall im convergenten polarisirten Lichte untersucht, sieht man durch ein Flächenpaar des breiten Makropinakoids $a\{100\}$, wenn die so gebildete Platte ungefähr so dick ist (2-3 mm), wie es bei den beiden anderen Sulfaten als am günstigsten gefunden wurde, und wenn die Axenrichtungen mit den Schwingungsrichtungen der Nicolschen Prismen ubereinstimmen, ein breites dunkles Kreuz von sehr tiefen Farben begrenzt. Wenn man die Platte um $45^{0} \mathrm{dreht}$, bemerkt man, dass das Kreuz in zwei sebr helle hyperbolische Spectralbögen zerfällt, welche keine dunkle Mittellinie oder nur Spuren solcher besitzen. Die breite blaue Grenze ist an der Innenseite und die rothe nach aussen. Die Krystalle besitzen augenscheinlich ausserordentlich geringe Doppelbrechung und sehr starke Dispersion der optischen Axen. Wenn man eine ähnliche Platte ungefähr einen Centimeter dick bekommen kann, zeigt diese eine sehr schöne Interferenzfigur im weissen Lichte, welche an die Figur von Brookit oder anderer hoch dispergirender Substanzen erinnert; die Axen scheinen jedoch in einer Ebene parallel der Basis $c\{001\}$ zu liegen. Mit einer solchen Platte, welche dem Verf. aus der grössten und vollkommensten der erhaltenen Krystalle zu schleifen gelungen ist, sieht man, wenn die krystallographischen Axen parallel den Schwingungsrichtungen der Nicol'schen Prismen sind, das Kreuz von vier vollkommenen Gurven umgeben; die äusseren gleichen Ellipsen, symmetrisch zu den krystallographischen Axen, und die innerste liegı einwärts gegen den Mittelpunkt, beinahe eine doppelte Lemniscatenschlinge bildend. Diese Curven besitzen einen sehr grossen Durchmesser in der Richtung der Kante ac und einen sehr kleinen senkrecht zu dieser Richtung. In der Nähe des Endes des längsten Durchmessers werden die Gurven dunkel, sind aber noch mit tiefen Farben begrenzt. Der ganze Raum zwischen jedem Ende des längsten Durchmessers und dem Querarme des Kreuzes wird durch ein einziges breites Spectrum ausgefüllt, sehr ähnlich demjenigen, welches durch Brookit und Dreifachtartrat von Kalium, Natrium und Ammoniak hervorgebracht wird. Wenn man die Platte um $45^{0}$ dreht, sieht man keine dunkle Hyperbel, sondern ein Paar lebhaft spectral gefärbter Hyperbeln durch ein inneres Paar ähnlich gefärbter Ringe und drei äussere ellipsenähnliche Curven hindurchgehend; keine Dunkelheit wird bei irgend einer der Gurven beobachtet. Wenn man den monochromatischen Belichter gebraucht und den Prismenkreis des letzteren umdreht, um die Figuren fur alle Farben des Spectrums zu sehen, beob- 
achtet man, dass die Axenhyperbeln sehr scharf definirt und für Roth nur wenig getrennt sind, während für Violett ihr Abstand ein sehr grosser ist, somit eine starke Dispersion vorhanden ist. Ausserdem werden mehrere vollkommene die Axen umgebende Ringe nach einander sichtbar, wenn man sich dem Violett nähert.

Wenn man die Platte um $45^{0}$ zuruckdreht, um die Richtungen der krystallographischen Axen wieder parallel den Schwingungsrichtungen der Nicols zu bringen, mit blauem Lichte beleuchtet und eine Viertelundulationsplatte in der gowöhnlichen Stellung einschiebt, so wird die Doppelbrechung deutlich als positiv erkannt. von Lang (l. c.) giebt an, dass die Doppelbrechung des schwefelsauren Rubidiums sehr klein ist und dass das Zeichen derselben negativ ist. Wahrscheinlich aber besass er keine so dicke Platte wie die oben beschriebene; denn er sagt, dass er die optischen Axenwinkel nur: approximativ messen konnte wegen der kleinen Doppelbrechung, während Verf. keine Schwierigkeit hatte, genaue Messungen mit seiner dicken Platte zu erhalten. Es wird später festgestellt, dass das in dieser Untersuchung gebrauchle reine schwefelsaure Rubidium positive Doppelbrechung besitzt.

Die Orientirung der optischen Axen ist daher $\mathfrak{c} \mathfrak{a} \mathfrak{b}$.

Die Ursache für diese grosse Empfindlichkeit des Axenwinkels vom schwefelsauren Rubidium bei Aenderung der Wellenlänge des beleuchtenden Lichtes ist eine sehr interessante und wird später völlig erklärt werden.

Bestimmung der Brechungsexponenten des schwefelsauren Rubidiums. Zehn vortreffliche Prismen wurden mil Hülfe des neuen Instrumentes aus funf verschiedenen Krystallen geschliffen und polirt. Jedes Prisma war symmetrisch einer Ebene, und seine Kante einer Axe der optiscben Elasticität. Die Winkel wurden alle nahe an $60^{\circ}$ gemacht und ihre Flächen so gut polirt, dass keine Deckgläser nöthig waren.

Drei dieser Prismen wurden nach solchen Richtungen der Krystalle geschliffen, dass die Schwingungsrichtungen der zwei polarisirten gebrochenen Strablen parallel zu den krystallographischen Axen $b$ und $c$, identisch mit den optischen Elasticitätsaxen $\mathfrak{a}$ und $\mathfrak{b}$ waren; daher sollten sie die zwei Brechungsexponenten $\alpha$ und $\beta$ liefern. Mit diesen Prismen wurde nun die merkwürdige Beobachtung gemacht, dass sie nur ein einziges gebrochenes Bild des Websk y'schen Spaltes des Spectrometers mit irgend einer Farbe des Lichtes lieferten. Dieses Bild blieb beständig für alle Stellungen des vor das Ocular gesetzten Nicols, obgleich ein geringer Unterschied der Beleuchtung des Bildes für die Stellungen $0^{\circ}$ und $90^{\circ}$ beobachtet wurde, nicht so gross jedoch, als im Falle eines einfachen durch ein Glasprisma gelieferten Bildes. Es waren daher zwei Bilder, welche dieselbe Stellung 
besassen, wovon das eine bei $0^{0}$ und das andere bei $90^{n}$ ausgelöscht wurde. Als das Ocular angewandt wurde, welches die stärkste Vergrösserung des Bildes lieferte, konnte man zwei verschiedene, einander theilweise uberdeckende Bilder erkennen, wenn man das helle, dem $\mathrm{Na}$-Licht entsprechende Licht des monochromatischen Lichtapparates gebrauchte, und zwar war das dem $\alpha$-Index entsprechende Bild bei der Minimalablenkung um ungefähr $1^{\prime}$ näher der Richtung des einfallenden Lichtes als das $\boldsymbol{\beta}$-Bild.

Die Resultate der Messungen der Brechungsexponenten, genau wie bei den anderen Sulfaten mit Hülfe des gewöhnlichen Oculars ausgeführt, sind aus nebenstehender Tabelle zu ersehen.

Da die drei Prismen, welche die Exponenten $\alpha$ und $\beta$ lieferten, keinen bemerkbaren Unterschied zwischen den zwei Bildern zeigten, ist das Mittel der gut ubereinstimmenden Werthe fur diese Exponenten genommen worden, und dieser Mittelwerth repräsentirt die zwei Werthe so nahe als die Fehlergrenzen (ungefähr 0,0002) erlauben. Ein Unterschied von $1^{\prime}$ im Winkel der Minimalablenkung bringt einen Unterschied in den Brechungsexponenten von 0,00017 hervor. Ein solcher Unterschied ist mit dem gewöhnlichen Ocular etwas schwer zu bemerken. Die Anwendung des stärker vergrössernden Oculars aber, und entscheidend die später zu beschreibenden Messungen des optischen Axenwinkels beweisen, dass die Exponenten $\alpha$ und $\beta$ keinenfalls durch dieselben Zahlen repräsentirt werden sollten, sondern dass die Werthe von $\alpha$ um $0,0001-0,0002$ niedriger sind als die Werthe von $\beta$. Es scheint geeignet, an dieser Stelle die wirklichen Zahlen, aus den optischen Axenwinkeln berechnet, zu geben. Vollkommener Beweis ihrer Genauigkeit wird spater bei der Beschreibung der Axenwinkelmessungen gegeben werden. Diese Zahlen repräsentiren die Brechungsexponenten des schwefelsauren Rubidiums bei gewöhnlicher Temperatur genau auf vier Decimalstellen innerhalb der vorher erwähnten Fehlergrenzen, die Ordnung der drei Exponenten stimmt völlig mit den Erscheinungen der optischen Axen uberein, und die Werthe der $\alpha$-Exponenten selbst sind diejenigen, welche aus den Messungen des Axenwinkels berechnet worden sind. Es wird später bewiesen werden, dass die Differenz zwischen den Werthen $\alpha$ und $\beta$ für Roth etwas geringer als 0,0001 ist, während diejenige für Blau wahrscheinlich 0,0002 etwas uberschreitet. Diese Differenz möchte man vielleicht durch eine fünfte Decimalstelle repräsentiren, dieses ist aber in Rücksicht des möglichen Fehlers nicht zu rechtfertigen.

Wahre Brechungsexponenten des schwefelsauren Rubidiums.

$\begin{array}{lccc} & \alpha & \beta & \gamma \\ L i & 1,5108 & 1,5109 & 1,5120 \\ C & 1,5112 & 1,5113 & 1,5124 \\ N a & 1,5131 & 1,5133 & 1,5144\end{array}$


Ueber den Zusammenhang zwischen den kryslallographischen Eigenschaften elc. 49

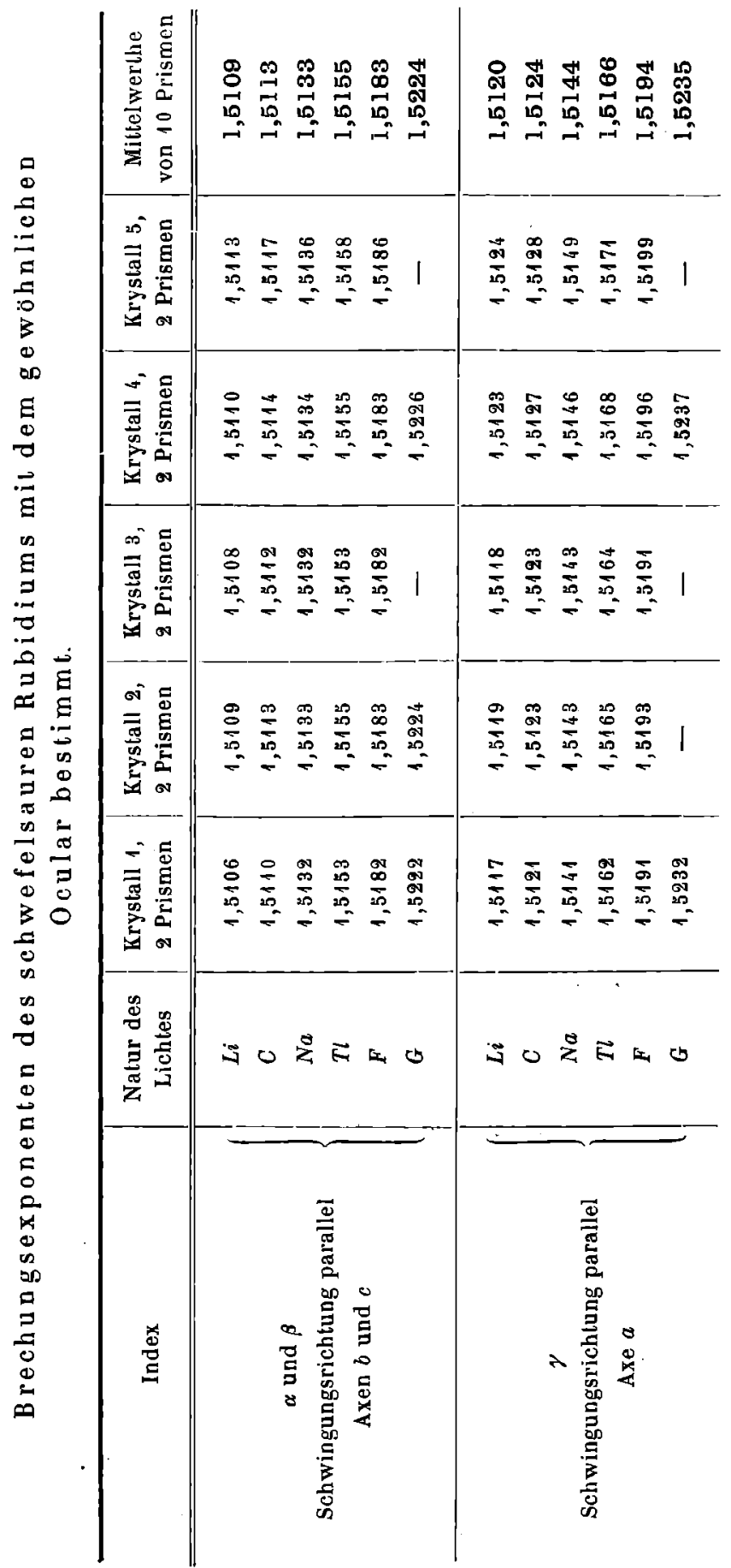

Groth, Zeitschrift f. Krystellogr. XXIV. 


$\begin{array}{cccc} & \alpha & \beta & \gamma \\ T l & 1,5153 & 1,5155 & 1,5166 \\ F & 1,5181 & 1,5183 & 1,5194 \\ G & 1,5222 & 1,5224 & 1,5235\end{array}$

Die Refraction des schwefelsauren Rubidiums für irgend eine Wellenlänge kann man wieder, wie bei den beiden anderen Sulfaten, ausdrücken durch die folgende allgemeine Formel :

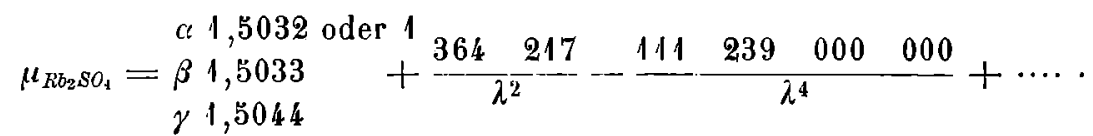

Die Constante $A$ für den $\alpha$-Index wird am genauesten zu 1,5032 für Wellenlängen von Roth bis zu gelbem $\mathrm{Na}$-Licbt und zu 1,5031 jenseit desselben angenommen. Die obige Formel reproducirt dann die Exponenten mit grosser Genauigkeit; die daraus berechneten Werthe sind identisch bis zum Thalliumlicht, die Differenzen für $F$-Licht sind nur 0,0002 und für $G$-Licht 0,0005 .

Die Thatsache, dass die $\beta$-Exponenten näher an $\alpha$ als an $\gamma$ sind, beweist die positive Natur der Doppelbrechung.

Brechung des schwefelsauren Rubidiums bei höheren Temperaturen. Diese Beobachtungen waren von besonderem Interesse, da zu erwarten war, dass der Unterschied zwischen den zwei dem $\alpha$ - und $\beta$-Exponenten entsprechenden Bildern deutlicher werden könnte, wenn man die Temperatur erhöhte. Eines der drei vorher erwähnten, diese Exponenten liefernden Prismen wurde daher erst mit dem gewöhnlichen Ocular untersucht. Bei $60^{\circ}$ wurde noch kein Unterschied beobachtet, die Stellungen der Bilder waren noch identisch. Als die Temperatur sich $100^{\circ}$ näberte, begannen die Bilder sich zu trennen, und bei $100^{\circ}$ waren sie $2^{\prime}$ entfernt und deutlich getrennt. Bei $140^{\circ}$ hatte die Differenz sich auf $3^{\prime}$ gesteigert und bei $180^{\circ}$ auf $5^{\prime}$. Ausserdem wurde festgestellt, dass das dem viedrigsten Brechungsexponent $\alpha$ entsprechende Bild erzeugt wurde durch Licht, dessen Schwingungsrichtung parallel der Verticalaxe $c$ war, während die Schwingungsrichtung des $\beta$-Bildes parallel der Axe $b$ war. Dieses ist dem Verhalten bei gewöhnlicher Temperatur entgegengesetzt. Die beiden Bilder bewegten sich auch gegen die Richtung des einfallenden Lichtes, eine regelmässige Verminderung des Brechungsvermögens durch Temperaturerhöhung andeutend. Ein zweites Prisma, dessen Schwingungsrichtungen parallel den Axen $a$ und $b$ waren, wurde ebenfalls untersucht; die zwei, diesen beiden Schwingungsrichtungen entsprechenden, Bilder behielten ihre Entfernung $\left(6^{\prime}-7^{\prime}\right)$ von einander, während sie sich der Einfallsrichtung näherten. 
Es kommt demnach die grösste Veränderung in der optischen Elasticilät für Temperaturerhöhung der Axe $c$ zu, und die Veränderungen der Elasticität längs der zwei anderen Axen $a$ und $b$ sind ungefähr gleich.

Bei gewöhnlicher Temperatur ist die Axe $c$ die mittlere optische Elasticitätsaxe $\mathfrak{b}$; ihr Werth aber ist so wenig abweichend von jenem der grösseren Elasticilăt $\mathfrak{a}$ längs der $b$-Axe, dass die zwei Exponenten für irgend eine Wellenlänge sich nur um $0,0001-0,0002$ unterscheiden. Wenn man den Krystall erwärmt, so nimmt die optische Elasticität längs der Axe $c$ zu und die Brechungsexponenten nehmen umgekehrt ab, relativ mehr als die den anderen Axen entsprechenden, năhern sich also dem Werthe längs der Axe $b$, bis fur eine Temperatur zwischen $20^{\circ}$ und $100^{\circ}$, welche fur jede Wellenlänge verschieden ist, die Werthe längs der zwei Axen $c$ und $b$ identisch werden und der Krystall augenscheinlich ein einaxiger ist, wobei die einzige optische Axe in der Axe a liegt. Nachher überschreitet die Elasticität längs der $c$-Axe diejenige längs der $b$-Axe und wird die grösste, während die Elasticität längs der $b$-Axe die mittlere wird. Die Veränderung fährt fort, bis bei $180^{\circ}$ die Werthe der $\alpha$ - und $\beta$-Exponenten ungefähr so weit entfernt sind, als diejenigen der gleichzeitig sich ändernden Werthe für die Axen $a$ und $b$.

Also ist die Orientirung der optischen Elasticitătsaxen für Temperaturen höher als diejenige, bei welcher für irgend eine besondere Wellenlänge die Elasticität längs den Axen $b$ und $c$ identisch ist ụnd bis zu etwa $180^{\circ}$, $\mathfrak{c} \mathfrak{b} \mathfrak{a}$, während gezeigt worden ist, dass sie bei gewöhnlicher Temperatur $\mathfrak{c} \mathfrak{a} \mathfrak{b}$ ist. Jenseits $180^{\circ}$ wird wahrscheinlich der Krystall negativ, weil die mittlere Elasticität der kleinsten Elasticität sich mehr nähert, und dann wird auch die Axe $c$ erste, anstatt zweite Mittellinie werden.

Die Resultate der Temperaturmessungen sind in der Tabelle auf S. 52 zusammengestellt; die Werthe fur die gewöhnliche Temperatur wurden mit denselben zwei Prismen erhalten, welche zu den Temperaturbestimmungen gebraucht wurden.

Wie fruher gezeigt wurde, gilt die bei den Sulfaten von Kalium und Cäsium angegebene Regel, dass die grösste durch Erwärmung hervorgebrachte Veränderung der optisehen Elasticität längs der $c$-Axe vorkommt und dass die Veränderungen in den Richtungen der zwei anderen Axen approximativ gleich sind, auch für das schwefelsaure Rubidium, und fübrt zu interessanten Schlüssen. Der Betrag der Differenz für $160^{\circ}$ zwischen den der $c$-Axe entsprechenden Brechungsexponenten ist $0,0059-61$, während derjenige für die $a$ - und $b$-Axen $0,0050-54$ und $0,0049-51$ ist.

Optische Elasticitätsaxen des schwefelsauren Rubidiums. Wenn man dieses Verbältniss aus den Brechungsexponenten berechnet, 
Refraction des schwefelsauren Rubidiums bei verschiedenen Temperaturen.

\begin{tabular}{|c|c|c|c|c|c|c|}
\hline Index & $\begin{array}{c}\text { Natur des } \\
\text { Lichtes }\end{array}$ & $\begin{array}{c}\text { Bei gewöhnl. } \\
\text { Temperatur } \\
\left(18^{0}-20^{0}\right)\end{array}$ & Bei $60^{\circ}$ & Bei 1000 & Bei $140^{\circ}$ & Bei $180^{\circ}$ \\
\hline $\begin{array}{c}a \\
\text { Schwing.-Ficht. } \\
\text { par. Axe } b \text { bei } \\
\text { niedrigen Temp. u. } \\
\text { par. Axe } c \text { bei höh. }\end{array}$ & $\begin{array}{l}L i \\
C \\
N a \\
T l \\
F\end{array}$ & $\begin{array}{l}1,5111 \\
1,5115 \\
1,5135 \\
1,5158 \\
1,5184\end{array}$ & $\begin{array}{l}1,5104 \\
1,5108 \\
1,5126 \\
1,5149 \\
1,5176\end{array}$ & $\begin{array}{l}1,5084 \\
1,5088 \\
1,5108 \\
1,5130 \\
1,5158\end{array}$ & $\begin{array}{l}1,5069 \\
1,5073 \\
1,5091 \\
1,5114 \\
1,5144\end{array}$ & $\begin{array}{l}1,5050 \\
1,5054 \\
1,5075 \\
1,5098 \\
1,5125\end{array}$ \\
\hline $\begin{array}{c}\beta \\
\text { Schwing.-Richt. } \\
\text { par. Axe } c \text { bei } \\
\text { niedrigen Temp. u. } \\
\text { par. Axe } b \text { bei böh. }\end{array}$ & $\begin{array}{l}\mathrm{Li} \\
\mathrm{C} \\
\mathrm{Na} \\
\mathrm{Tl} \\
\mathrm{F}\end{array}$ & $\begin{array}{c}\text { identisch } \\
\text { mit den } \\
\alpha-\text { Werthen }\end{array}$ & $\begin{array}{c}\text { identisch } \\
\text { mit den } \\
\alpha-\text { Werth. }\end{array}$ & $\begin{array}{l}1,5088 \\
1,5092 \\
1,5112 \\
1,5134 \\
1,5162\end{array}$ & $\begin{array}{l}1,5077 \\
1,5081 \\
1,5099 \\
1,5122 \\
1,5152\end{array}$ & $\begin{array}{l}1,5060 \\
1,5064 \\
1,5085 \\
1,5108 \\
1,5135\end{array}$ \\
\hline $\begin{array}{c}\gamma \\
\text { Schwingungs- } \\
\text { richlung parallel } \\
\text { Axe } a\end{array}$ & $\begin{array}{l}L i \\
C \\
N a \\
T l \\
F\end{array}$ & $\begin{array}{l}1,5124 \\
1,5128 \\
1,5149 \\
1,5170 \\
1,5195\end{array}$ & $\begin{array}{l}1,5115 \\
1,5119 \\
1,5137 \\
1,5160 \\
1,5187\end{array}$ & $\begin{array}{l}1,5098 \\
1,5102 \\
1,5124 \\
1,5146 \\
1,5174\end{array}$ & $\begin{array}{l}1,5086 \\
1,5090 \\
1,5110 \\
1,5132 \\
1,5160\end{array}$ & $\begin{array}{l}1,5070 \\
1,5074 \\
1,5096 \\
1,5117 \\
1,5145\end{array}$ \\
\hline
\end{tabular}

welche in der Tabelle gegeben sind, worin die wabre Beziehung der $\alpha$ - und $\beta$-Werthe gezeigt wird, erhält man die folgenden Zahlen :

$$
a: b: c=0,9991: 1: 0,9999 \text {. }
$$

Dieses entspricht der Orientirung $\mathfrak{c} \mathfrak{a} \mathfrak{b}$.

Das Verhältniss aus den Brechungsexponenten bei $180^{\circ}$ berechnet ist :

$$
a: b: c=0,9993: 1: 1,0006 .
$$

Dieses entspricht der Orientirung $\mathfrak{c} \mathfrak{b} \mathfrak{a}$.

Die ausserordentliche Annäherung an die Gleichheit der Elasticität parallel den drei Axen ist klar durch diese Verbältnisse ausgedrückt.

Messungen des optischen Axenwinkels des schwefelsauren Rubidiums. Die ausserordentliche Dicke einer Platte, welche nöthig ist, um eine scharf definirte Interferenzfigur im convergenten polarisirten Lichte zu erhalten, und die ungewöhnliche Dispersion der optischen Axen, welche durch die schöne Figur im weissen Lichte und die grosse Empfindlichkeit des bei monochromatischem Lichle beobachteten Axenwinkels in Bezug auf eine Veränderung der Wellenlänge des Lichtes angedeutet wird, werden völlig durch die oben beschriebenen Beziehungen der optischen Elasticităt parallel den drei Axenrichtungen erklärt.

Wenn man den Axenwinkel für $\mathrm{Na}$-Licht aus den Brechungsexponenten 
des schwefelsauren Rubidiums durch die Formel $\cos V=\sqrt{\frac{\frac{1}{\beta^{2}}-\frac{1}{\gamma^{2}}}{\frac{1}{\alpha^{2}}-\frac{1}{\gamma^{2}}}}$ berechnet und die Werthe von $\beta$ und $\gamma$ aus der ersten Tabelle der Resultate nimmt, welche mit dem gewöhnlichen Ocular erhalten wurden, und dabei eine Differenz von 0,0001 zwischen den Werthen $\operatorname{der} \alpha$ - und $\beta$-Exponenten annimmt, so findet man, dass der Winkel $34^{\circ}$ beträgt, während er natürlich $0^{0}$ ist, wenn jene Werthe identisch angenommen werden. Es scheint auf den ersten Blick erstaunlich, dass eine so kleine Differenz in dem Brechungsexponent, kaum experimentell bemerkbar, eine so grosse Veränderung des optischen Axenwinkels hervorbringen kann. Wenn man den $\alpha-W e r t h$ um 0,0002 niedriger als den $\beta$-Werth annimmt, so wird der berechnete Axenwinkel 470. Das schwefelsaure Rubidium bietet daher eine extreme Erläuterung zu der vorher erwähnten Thatsache, dass die obige Formel nur sehr approximative Werthe des optischen Axenwinkels liefern kann und dass eine wirkliche Messung desselben immer vorzuziehen ist. Es ist aber offenbar, dass umgekehrt eine experimentelle Bestimmung des Axenwinkels des schwefelsauren Rubidiums ein Mittel liefert, um die Differenz zwischen den $\alpha$ - und $\beta$-Brechungsexponenten auf vier Decimalstellen genau festzustellen. Die bestimmten wahren optischen Axenwinkel werden später für diesen Zweck benutzt werden.

Es ist jetzt gezeigt worden, dass die Differenz zwischen den Exponenten $\alpha$ und $\beta$ für Licht bis zum Blau des Spectrums 0,0002 nicht merklich uberschreiten kann, sonst würde man zwei verschiedene Bilder des Spectrometerspaltes beobachten; ferner dass eine so kleine Differenz einer Trennung der optischen Axen von ungefäbr $50^{\circ}$ entspricht, während der Winkel ungefähr $35^{0}$ sein würde, wenn die Differenz 0,0001 wäre und $0^{0}$, wenn die Exponenten identisch wären. Nun ist es kaum wahrscheinlich, dass die zwei Exponenten ganz gleich entfernt von einander für alle Wellenlängen des Lichtes sind, sondern dass kleine Differenzen vorkommen einer Ordnung, welche nur durch die funfte Decimalstelle repräsentirt werden können, sehr kleinen Differenzen in der optischen Elasticität des Krystalles parallel den krystallographischen Axen $b$ und $c$ fur verschiedene Wellenlängen des Lichtes entsprechend. Solche kleine Differenzen müssen aber in Rücksicht auf die vorhergehenden Betrachtungen verhältnissmässig sehr grosse Veränderungen des optischen Axenwinkels hervorrufen; es ist also sehr wahrscheinlich, dass das schwefelsaure Rubidium sehr beträchtliche Dispersion der optischen Axen zeigen wird.

Es ist auch zu erwarten, dass verschiedene Krystalle etwas verschiedene Axenwinkel besitzen werden. Denn die Differenzen in der vierten Decimalstelle zwischen den verschiedenen durch verschiedene Krystalle 
gelieferten Bestimmungen desselben Brecbungsexponenten können nich ganz den Versuchsfehlern zugeschrieben werden; es ist viel wahrscheinlicher, dass geringe Unterschiede der optischen Elasticität vorkommen, ebenso wie scheinbar vollkommene Krystalle kleine Differenzen (Wachsthumsfehler) in den Flächenwinkeln darbieten. Diese kleinen Abweichungen, welche gar keine Wichtigkeit in solchen Fällen besitzen, wo die Elasticitätsverhältnisse sehr verschieden sind, werden also bei dem Rubidiumsulfate relativ grosse Differenzen der optischen Axenwinkel hervorbringen.

Messungen des Axenwinkels in Luft $2 E$. Funf Platten vom schwefelsauren Rubidium senkrecht zur ersten Mittellinie (die Axe a) wurden bei den Messungen verwendet. Drei davon wurden mit Hülfe des neuen Instrumentes geschliffen und polirt und zwei wurden durch Krystalle des in Fig. 8 repräsentirten Typus gebildet, mit vorherrschenden gut ausgebildeten Makropinakoidflächen. Die ersten vier Platten hatten $3-4 \frac{1}{2} \mathrm{~mm}$ Dicke und $\mathrm{Nr}$. 5 war die vorher erwähnte $8 \mathrm{~mm}$ dicke Platte. Der mögliche Versuchsfehler für die ersten vier Platten ist nicht weniger als 20, wegen der Breite der Hyperbeln. Die fünfte sehr dicke Platte gestattete viel genauere Messungen, denn die Hyperbeln waren sehr scharf ausgeprägt. Alle fünf Platten wurden ungedeckt gebraucht. Die folgenden Werthe wurden erhalten.

Scheinbarer optischer Axenwinkel in Luft $2 E$ von $\mathrm{R}_{2} \mathrm{SO}_{4}$.

\begin{tabular}{|c|c|c|c|c|c|}
\hline Natur des Lichtes & Platte 1: & $\begin{array}{l}\text { Platte 2: } \\
35090^{\prime}\end{array}$ & Platte 3 : & $\begin{array}{l}\text { Platte 4: } \\
36045^{\prime}\end{array}$ & Platte 5 : \\
\hline$L i$ & $63^{\circ} 40^{\prime}$ & & & & \\
\hline$C$ & 6535 & 3710 & 55 & $38 \quad 45$ & 3835 \\
\hline$N a$ & 7050 & $44 \quad 45$ & $59 \quad 40$ & $46 \quad 0$ & 4620 \\
\hline$T l$ & 7635 & $\begin{array}{ll}50 & 0\end{array}$ & $\begin{array}{ll}65 & 0\end{array}$ & 5310 & $52 \quad 10$ \\
\hline$F$ & 8335 & $58 \quad 10$ & 7030 & 5840 & 6150 \\
\hline$G$ & 915 & & $\begin{array}{ll}79 & 10\end{array}$ & & \\
\hline
\end{tabular}

Die obigen Resultate stimmen völlig mit den Erwartungen uberein, welche aus den Beziehungen der optischen Elasticitätsverhältnisse abgeleitet wurden. Verschiedene Krystalle zeigen sehr beträchtliche Unterschiede zwischen den Werthen von $2 E$ und daher auch von dem wahren Axenwinkel im Krystalle, und zwar kann man sagen, dass jeder Krystall vom schwefelsauren Rubidium seinen eigenen Axenwinkel besitzt, abhängig von äusserst geringen Differenzen in der Structur, welche durch entsprechend geringe Störungen während der Bildung, oder sehr geringe Spuren von Unreinigkeiten, besonders von beigemengten isomorphen schwefelsauren Salzen von Kalium oder Cäsium, hervorgebracht werden. Es ist ganz gul denkbar, dass von Lang wirklich einen negativen Krystall des 
schwefelsauren Rubidiums hatte, welcher etwas schwefelsaures Cäsium enthielt. Er giebt $64^{\circ}$ für den approximativen Werth von $2 E$ an.

Wie die Tabelle zeigt, existirt auch eine sehr beträchtliche Dispersion der optischen Axen; dieselbe variirt zwischen $L i$ - und $F$-Licht von $18^{\circ}$ bis $23^{0}$ bei den verschiedenen beobachteten Krystallen.

Die Axenwinkelphänomene des schwefelsauren Rubidiums sind so ungewöhnlich und interessant wegen ihrer Ursache, dass eine Reihe von Photographien der durch die dicke Platte Nr. 5 gelieferten Interferenzbilder im monochromatischen Lichte angefertigt worden sind, wozu sich das neue Instrument fur monochromatisches Licht als sehr geeignet erwies. Um ein möglichst grosses Gesichtsfeld zu erbalten, wurde das Polariskop einer besonders für diesen Zweck eingerichteten Form des Axenwinkelgoniometers des Groth'schen Universalapparates, welches Fuess in der letzten Zeit für den Verf. construirt hat, benutzl; die nächste Linse jedes convergenten Systems wurde entfernt, um die Einstellung einer so dicken Platte zu gestatten, ohne das Gesichtsfeld zu vermindern. Ein sehr starkes elektrisches Bogenlicht wurde als Lichtquelle gebraucht, um den Einfallsspalt des Apparates für monochromatisches Licht eng genug stellen zu können, damit ein hoher Grad von Monochromatismus erreicht und die nothwendige Expositionszeit der photographischen Platte vermindert würde. In den Reproductionen dieser Photographien (Taf. I) wurden die ersten vier Bilder bei gewöhnlicher Temperatur erhalten. Nr. 1 ist das durch grünlichblaues

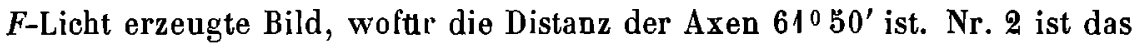
Bild für Licht der Wellenlänge der grünen Thalliumlinie, wofür der Winkel $52^{0} 10^{\prime}$ ist. $\mathrm{Nr}$. 3 wurde durch gelbes Licht der Wellenlängen der $D$-(Natrium-)Linien hervorgebracht, der Axenwinkel ist jetzt auf $46^{\circ} 20^{\prime}$ vermindert worden. Nr. 4 wurde durch rothes Licht der Wellenlänge der Wasserstofflinie $C$ dargestellt, wofür die Axen sich einander auf $38^{\circ} 35^{\prime}$ genähert baben. Die für Nr. 4 angewandte photographische Platte wurde für Roth durch Cyanin empfindlich gemacht. Diese Photographien können ungefähr eine Idee der schönen Veränderungen geben, welche vorkommen, wenn man den Dispersionsapparat des monochromatischen Belichters langsam umdreht, um das Gesichtsfeld mit verschiedenen Wellenlängen nach einander zu beleuchten.

Messungen des wahren Axenwinkels $2 V_{a}$. Es ist im Allgemeinen nicht möglich, den stumpfen Winkel der optischen Axen in Oel oder sogar in Bromnaphtalin zu beobachten wegen der grossen Dicke der Platte, welche nöthig ist, um scharfe Interferenzbilder zu erhalten und auch wegen des gewöhnlich kleinen Winkels der Axen. Ausserdem musste man wegen der Abweichungen der durch verschiedene Krystalle gelieferten Axenwinkel ein Paar Platten aus demselben Krystalle schleifen, um wahre Werthe von $2 V_{a}$ aus den Messungen von $2 H_{a}$ und $2 H_{o}$ zu erbalten. 
An dem Krystalle, aus welchem Platte 2 geschliffen war, wurde ein zweites Flächenpaar angeschliffen senkrecht zur zweiten Mittellinie (Axe b); also wurde der Krystall zu einem rechtwinkligen Block abgeschliffen. Krystall 4 in der Tabelle der Brechungsexponenten ist identisch mit diesem Krystalle; die zwei Prismen wurden an den Enden des rechtwinkligen Blockes mit ihren Kanten senkrecht zu einander geschliffen. Ein einziger Krystall ist also im Stande die sämmtlichen optischen Constanten einer schwach doppeltbrechenden Substanz zu liefern, und mit Hülfe des neuen Schleifapparates giebt es keine Schwierigkeit einen Krystall so vorzubereiten. Bei diesem Krystalle aber war der stumpfe Axenwinkel in Bromnaphtalin zu gross, um den Austritt der Axen zu erlauben.

Der wahre Axenwinkel wurde jedoch an vier Krystallen bestimml durch Messungen des Winkels der Axen, welche vier von den funf senkrecht zur ersten Mittellinie geschliffene Platten zeigten, wenn sie nacheinander in zwei Flüssigkeiten eingetaucht wurden, deren Brechungsexponenten beinahe und die Mittel derselben genau identisch mit dem mittleren Brechungsexponent $\beta$ des schwefelsauren Rubidiums sind. Diese Flussigkeiten waren Benzol $\left(\mu_{D}=1,507\right)$ und Cedernöl $\left(\mu_{D}=1,520\right)$. Die in diesen zwei Flussigkeiten beobachteten Winkel waren so gut wie identisch, daher sind die in der folgenden Tabelle gegebenen Mittelwerthe für $2 V_{a}$ genau für jeden der angewandten Krystalle.

Bestimmungen von $\mathbf{2} V_{a}$ des schwefelsauren Rubidiums durch Eintauchen in Benzol und Cedernöl.

\begin{tabular}{|c|c|c|c|c|}
\hline$L i$ & $\begin{array}{l}\text { Platte 1: } \\
40^{\circ} 25^{\prime}\end{array}$ & $\begin{array}{l}\text { Platte 2: } \\
222^{0} 55^{\prime}\end{array}$ & $\begin{array}{l}\text { Platte 3: } \\
38^{0} 40^{\prime}\end{array}$ & $\begin{array}{l}\text { Platte } 5 \\
28^{\circ} 30^{\prime}\end{array}$ \\
\hline$C$ & $41 \quad 40$ & 2350 & 3925 & $29 \quad 5$ \\
\hline$N a$ & $44 \quad 10$ & $28 \quad 25$ & 4155 & 33 \\
\hline$T l$ & 4735 & $33 \quad 5$ & 4335 & 3740 \\
\hline$F$ & 5115 & 38 & 4845 & 4435 \\
\hline$G$ & 5550 & 4435 & 5230 & 4730 \\
\hline
\end{tabular}

Man wird bemerken, dass eine beträchtliche Variation des wahren optischen Axenwinkels vorkommt, wie beim scheinbaren Winkel $2 E$. Der mögliche Versuchsfehler kann 10 nicht überschreiten, so dass diese Variation einer wirklichen Eigenschaft dieses Salzes zuzuschreiben ist.

Die obigen Bestimmungen des wahren Axenwinkels bieten ein empfindliches Mittel, die Differenzen zwischen den nahe liegenden Brechungsexponenten $\alpha$ und $\beta$ zu berechnen. Es ist nur nothwendig, in der Formel $\cos ^{2} V=\frac{\frac{1}{\beta^{2}}-\frac{1}{\gamma^{2}}}{\frac{1}{\alpha^{2}}-\frac{1}{\gamma^{2}}}$ die experimentell bestimmten Werthe von $V, \beta$ und $\gamma$ einzustellen, um direct den Werth von $\alpha$ zu erhalten. 
Aus den Maximalwerthen des Axenwinkels (Platte 1)

$$
\alpha=1,51078_{L i} \text { und } 1,51806_{F} ;
$$

aus den Minimalwerthen des Axenwinkels (Platte 2)

$$
\alpha=1,51088_{L i} \text { und } 1,51820_{F} \text {. }
$$

Die Werthe von $\beta$, welche in der Tabelle gegeben sind und bei den Rechnungen gebraucht wurden, sind

$$
\beta=1,5109_{L i} \text { und } 1,5183_{F} \text {. }
$$

Diese Zahlen deuten an, dass der $\alpha$-Index für $L i$-Iicht von $\operatorname{dem} \beta$-Index um 0,00002-0,00012 (im Miltel 0,00006) abweicht, wofür man 0,0001 nehmen kann, wenn nur vier Decimalstellen gebraucht werden; auch dass fur $F$-Licht die Abweichung 0,00010-0,00024 (im Mittel 0,00017) ist, wofur 0,0002 gesetzt werden kann. Die in der zweiten Tabelle gegebenen Werthe der Brechungsexponenten $\alpha$ repräsentiren daher genau die Beziehungen dieser zu den anderen zwei Reihen von Brechungsexponenten.

Die Axenwinkelphänomene des schwefelsauren Rubidiums bei höheren Temperaturen. Aus den Beobachtungen der Brechung bei höheren Temperaturen war, wie dies Seite 50 ausführlich erörtert wurde, zu erwarten, dass, wenn man eine Platte senkrecht zur ersten Mittellinie (Axe $a$ ) in dem mit convergenten monochromatischen Lichte beleuchteten Polariskop unter $45^{0}$ zu den Schwingungsrichtungen der gekreuzten Nicols einstellt und erwärmt, die Hyperbeln sich dem Mittelpunkte des Gesichtsfeldes nähern werden bis sie im Centrum zusammenstossen und ein Kreuz bilden, welches durch einaxige kreisförmige Ringe umgeben wird. Bei fortdauernder Erhitzung musste das Kreuz sich wieder in zwei Hyperbeln trennen, deren Mittelpunkte nun in der Ebene ac senkrecht zu ibrer vorherigen Richtung liegen wurden, und die Trennung der Axen in dieser Ebene músste mehr und mehr wachsen mit Zunahme der Temperatur, bis sie ganz aus dem Gesichtsfelde treten würden und die Axe $c$ die erste anstatt zweite Mittellinie werden würde. Ausserdem sollte die Temperatur, wobei das einaxige Bild sich einstellte, eine verschiedene für jede Wellenlänge sein, am niedrigsten für Roth und am höchsten für Blau wegen der grossen Dispersion der Axen.

Wenn man diese Voraussetzungen experimentell pruft, treten die Phänomene genau wie erwartet ein. Als die $8 \mathrm{~mm}$ dicke Platte (Nr. 5) gebraucht und mit rothem Lichte der Wellenlänge der Lithiumlinie beleuchtet wurde, beobachtete man, als die Temperatur langsam gesteigert wurde, dass die Hyperbeln sich einander ziemlich schnell längs des horizontalen Durchmessers des Gesichtsfeldes näherten, bis bei $36^{0}$ sie sich im Mittelpunkte vereinigten, um ein vollkommen einaxiges Bild darzustellen. Zunächst öffneten sie sich wieder und trennten sich längs des verticalen Durchmessers. 
Als das eiufallende Licht plötzlich zu Gelb der Wellenlängen der Natriumlinien verändert wurde, wurden die Axen wieder etwas im horizontalen Durchmesser getrennt, aber bald darauf, bei der Temperatur $38^{\circ}$, vereinigten sie sich von Neuem zu dem einaxigen Bilde und gingen dann in der Verticalebene auseinander. Ebenso wurde das einaxige Bild erhalten für grünes Licht von der Wellenlänge der Thalliumlinie bei $44^{0}$, für $F$-Licht bei $51^{\circ}$ und für $G$-Licht bei ungefähr $60^{\circ}$.

Die Platte wurde dann um $90^{\circ}$ gedreht und eine Reihe Messungen des Abstandes der optischen Axen in der Ebene $a c$ ausgefuhrt; während die Temperatur $60^{\circ}$ war. Die Resultate sind die folgenden:

\begin{tabular}{|c|c|c|}
\hline & & $\begin{array}{c}\text { Temperatur } 600 \\
\text { Axenebene } b\{010\}\end{array}$ \\
\hline Für Licht von & $L i$-Wellenlänge & $2 E=59^{\circ} \quad 0^{\prime}$ \\
\hline- & $C-\quad-$ & $57 \quad 40$ \\
\hline- & $\mathrm{Na}-$ & 520 \\
\hline- & $T l_{-}$ & 4515 \\
\hline - & $F_{-}$ & 3245 \\
\hline - & $G-$ & nur ein wenig getrennt \\
\hline
\end{tabular}

Eine andere Reihe Beobachtungen von $2 E$ wurden mit Platte 3 ausgefubrt; diese Platte zeigl einen grösseren Axenwinkel als Platte 5. Die Resultate waren :

\begin{tabular}{|c|c|c|c|c|}
\hline & \multicolumn{2}{|c|}{ Axenebene $c\{001\}$} & \multicolumn{2}{|c|}{ Axenebene $b\{010\}$} \\
\hline & Bei $18^{0}-20^{0}$ & $\widehat{\text { Bei } 40^{\circ}}$ & Bei $60^{\circ}$ & Bei 100 \\
\hline$L i$ & $52040^{\prime}$ & $20^{\circ} \quad 0^{\prime}$ & $55^{0} 45^{\prime}$ & $94^{0} 5^{\prime}$ \\
\hline$C$ & 550 & 220 & 5340 & 9115 \\
\hline $\mathrm{Na}$ & $59 \quad 40$ & 2745 & 4935 & 8745 \\
\hline$T l$ & 650 & 3620 & 3610 & 8315 \\
\hline$F$ & 7030 & 490 & 100 & 7655 \\
\hline$G$ & 7910 & 6250 & $\begin{array}{l}\text { Ein wenig getrennt } \\
\text { in der Ebene } c\{001\}\end{array}$ & 680 \\
\hline
\end{tabular}

Für $L i$-Licht war das Bild einaxig bei $42^{\circ}$, für $C$-Licht bei $44^{\circ}$, fur $N a$ Licht $48^{0}$, für $T l$-Licht $52^{0}$, für $F$-Licht $58^{0}$ und für $G$-Licht bei ungefähr $67^{\circ}$.

Um diesen ausserordentlichen Fall von Empfindlichkeit gegenuber einer Veränderung der Wellenlänge und der Temperatur völlig zu erläutern, sind zwei weitere Reihen von Photographien bei höheren Temperaluren angefertigt und auf Tafel I reproducirt worden. Die vorher beschriebenen vier Photographien wurden, nachdem die Platte in dem Erhitzungsapparate eingestellt war, bei gewöhnlicher Temperatur angefertigt, unmittelbar darnach wurde der Erhitzungsapparat mit Vorsicht langsam erwärmt vermittelst zweier sehr kleiner Bunsen'schen Brenner. Es gelang zufällig, durch Reguliren der letzten, die Temperatur während der photographischen 
Aufuahme der zweiten Reihe von Interferenzfiguren beständig auf $44^{\circ}$, bei welcher Temperatur das einaxige Bild für $T l$-Licht erzeugt wird, zu erhalten. Nr. 5 ist das Bild für grünlichblaues $F$-Licht und zeigt die Axen noch in ihrer ursprtunglichen Ebene einen kleinen Winkel bildend. Nr. 6 ist das einaxige Bild für hellgrünes Licht von der Wellenlänge der $T l$-Linie. Ein halber Grad Veränderung in der Temperatur reicht aus, um dieses schöne Bild zu zerstören. Nr. 7 gilt für gelbes Licht von $\mathrm{Na}$-Wellenlänge und zeigt die Axen in der senkrechten Ebene getrennt. Nr. 8 ist die Figur für rothes $C$-Licht, wobei die Axen noch weiter in dieser Ebene auseinanderliegen

Die dritte Reihe wurde bei der Temperatur $60^{\circ}$ aufgenommen, bei welcher das einaxige Bild für violetles $G$-Licht erzeugt wird. Nr. 9 repräsentirt dieses mit kreisförmigen Ringen, welche enger und zablreicher sind als in dem einaxigen Bilde für $T l$-Licht Nr. $6 . N$ Nr. 10 ist das Bild fur F-Licht, die Axen weit in der verticalen Ebene auseinanderliegend. Nr. 11 zeigt die Axen weiter getrennt für $\mathrm{Tl}$-Licht und $\mathrm{Nr} .12$ noch weiter für $\mathrm{Na}$-Licht.

Während die Temperatur noch bei $60^{\circ}$ blieb, wurden die Nicols um $45^{0}$ gedreht und das Zeichen der Doppelbrechung durch eine Viertelundulationsglimmerplatte gepruft. Es wurde noch positiv gefunden, was mit den Resultaten der Brechungsmessungen bei dieser Temperatur ubereinstimmt.

\section{Vergleichung der optischen Eigenschaften der drei Sulfate.}

In der folgenden Tabelle sind die Brechungsexponenten der drei Salze zusammengestellt; sie sind so geordnet, dass diejenigen, welche analogen krystallographischen Axen entsprechen, in derselben horizontalen Linie stehen.

\begin{tabular}{|c|c|c|c|c|}
\hline Axenrichtung & $\begin{array}{l}\text { Natur des } \\
\text { Lichtes }\end{array}$ & $\mathrm{K}_{2} \mathrm{SO}_{4}$ & $\mathrm{Ab} b_{2} \mathrm{SO}_{4}$ & $\mathrm{Cs}_{2} \mathrm{SO}_{4}$ \\
\hline$a$ & $\begin{array}{l}\boldsymbol{L} i \\
\mathrm{C} \\
\mathrm{Na} \\
\mathrm{Tl} \\
\mathrm{F} \\
\mathrm{G}\end{array}$ & $\begin{array}{c}\beta \\
1,4924 \\
1,4928 \\
1,4947 \\
1,4967 \\
1,4995 \\
1,5024\end{array}$ & $\begin{array}{c}\gamma \\
1,5120 \\
1,5124 \\
1,5144 \\
1,5166 \\
1,5194 \\
1,5233\end{array}$ & $\begin{array}{c}\gamma \\
1,5633 \\
1,5637 \\
1,5662 \\
1,5690 \\
1,5725 \\
1,5775\end{array}$ \\
\hline$b$ & $\begin{array}{l}\mathrm{Li} \\
\mathrm{C} \\
\mathrm{Na} \\
\mathrm{Tl} \\
\mathrm{F} \\
\mathrm{G}\end{array}$ & $\begin{array}{c}\alpha \\
1,4912 \\
1,4916 \\
1,4935 \\
1,4955 \\
1,4982 \\
1,5012\end{array}$ & $\begin{array}{c}\alpha \\
1,5108 \\
1,5112 \\
1,5131 \\
1,5153 \\
1,5181 \\
1,5222\end{array}$ & $\begin{array}{c}\beta \\
1,5615 \\
1,5619 \\
1,5644 \\
1,5672 \\
1,5706 \\
1,5756\end{array}$ \\
\hline
\end{tabular}




\begin{tabular}{c|c|c|c|c}
\hline Axenrichtung & $\begin{array}{c}\text { Natur des } \\
\text { Lichtes }\end{array}$ & $K_{2} S O_{4}$ & $R b_{2} S O_{4}$ & $C s_{2} S O_{4}$ \\
\hline \multirow{2}{*}{$c$} & & $\gamma$ & $\beta$ & $\alpha$ \\
& & 1,4950 & 1,5109 & 1,5569 \\
$C$ & 1,4954 & 1,5113 & 1,5573 \\
$N a$ & 1,4973 & 1,5133 & 1,5598 \\
$T l$ & 1,4994 & 1,5155 & 1,5624 \\
$F$ & 1,5023 & 1,5183 & 1,5660 \\
$G$ & 1,5052 & 1,5224 & 1,5705
\end{tabular}

Man sieht hieraus, dass die Brecbungsexponenten des schwefelsauren Rubidiums zwischen denjenigen der zwei anderen Salze liegen. Die wirklichen Zahlen sind beträchtlich näher denjenigen des Kaliumsalzes als denjenigen des schwefelsauren Cäsiums. Eine bundige Idee der Beziehung wird durch eine Vergleichung der Constante $A$ der allgemeinen Formeln für die Exponenten $\beta$ gegeben, denn diese Werthe sind unabhängig von der Wellenlänge.

$$
\begin{aligned}
\text { Für } \mathrm{K}_{2} \mathrm{SO}_{4} & A_{\beta}=1,4843 \\
-\quad \mathrm{Rb}_{2} \mathrm{SO}_{4} & A_{\beta}=1,5033 \text { Differenz } 0,0190 \\
-\quad \mathrm{Cs}_{2} \mathrm{SO}_{4} & A_{\beta}=1,5524 .
\end{aligned}
$$

Die Differenzen stehen ungefähr in dem Verbältnisse 2: 5 . Die erste Schlussfolgerung, was die optischen Eigenschaften betrifft, kann man daher in der folgenden Weise ausdrücken :

Die Brechungsexponenten des schwefelsauren Rubidiums liegen zwischen denjenigen der Sulfate von Kalium und Cäsium und näher denjenigen des Kaliumsalzes; die Differenzenzwischenden Exponenten der Sulfate von Kalium und Rubidium aufeiner Seite, und denjenigen der Sulfate von Rubidium und Gäsium auf der anderen, besilzen das Verhältniss 2:5. Eine Zunahme des Brechungsvermögens begleitet eine Zunahmedes Atomgewichtes des im Salzenthaltenen Metalles und die Zunabme wird verbältnissmässiggrösser, wenn das Atomgewicht steigt.

Die Beziehungen der optischen Elasticitätsverbältnisse stellen die Natur der Veränderungen in den optischeu Chärakteren in klarster Weise dar, wenn man das Kalium im schwefelsauren Kalium durch Rubidium und nachber das Rubidium durch Cäsium ersetzt. Die Veränderungen der optischen Elasticität sollten von zwei verschiedenen Gesichtspunkten angesehen werden; erstens in Rucksicht auf die mittlere Veränderung, wenn man von dem Kalium- zum Rubidiumsalz und von dem Rubidium- zum Cäsiumsalz 
übergeht, und zweitens in liücksicht auf die Wirkung der verschiedenen Betrïge der Veränderung längs der drei Axenrichtungen, um verschiedene Beziehungen zwischen den drei optischen Elasticitätsconstanten irgend eines Salzes hervorzubringen. Denn diese letzteren Beziehungen bestimmen vollständig den Betrag und das Zeichen der Doppelbrechung, die Entfernung der drei Brechungsexponenten und die Orientirung der optischen Axen.

Die optischen Elasticitätsverhältnisse der drei Salze sind hier zusammengestellt :

$$
\begin{aligned}
& \text { für } \mathrm{K}_{2} \mathrm{SO}_{4} \quad a: b: c=0,9992: 1: 0,9975 \\
& \text { - } \mathrm{Rb}_{2} \mathrm{SO}_{4} \quad a: b: c=0,9991: 1: 0,9999 \\
& \text { - } \mathrm{Cs}_{2} \mathrm{SO}_{4} \quad a: b: c=0,9989: 1: 1,0029
\end{aligned}
$$

Es wird bequem sein, bevor die Beziehungen der obigen Werthe angegeben werden, eine andere Methode des Ausdruckes der Elasticitätsverhältnisse zu betrachten, wodurch nicht allein die relativen Elasticitäten längs der Axenrichtungen irgend eines Salzes ausgedrückt werden, sondern auch die wirklichen Veränderungen der Elasticilät längs aller drei Axen, wenn man von einem Salze zu einem anderen übergeht. Dieses wird erlangt, wenn man die mittlere Elasticität des schwefelsauren Kaliums als Einheit nimmt und alle anderen Elasticitäten durch ibr Verbältniss dazu ausdruckt. Das Elasticitätsverhältniss furr Kaliumsulfat wird dann das oben angegebene. Die anderen Verbältnisse werden in ähnlicher Weise erhalten, wenn man den Brechungsexponent für $\mathrm{Na}$-Licht, entsprechend der fraglichen Axe des besonderen Salzes, durch den $\beta_{N a}$-Exponent des schwefelsauren Kaliums theilt. Solche Verhältnisse repräsentiren vollständig die Veränderungen der optischen Elasticität. Die unten angegebenen so berechneten Werthe wurden für $\mathrm{Na}$-Licht erhalten, aber identische Werthe werden auch erhalten, wenn die Rechnungen fur $C$ - oder $T l$-Licht gemacht werden.

$$
\begin{aligned}
& \text { Fur } \mathrm{K}_{2} \mathrm{SO}_{4} \quad a: b: c=0,9992: 1 \quad: 0,9975
\end{aligned}
$$

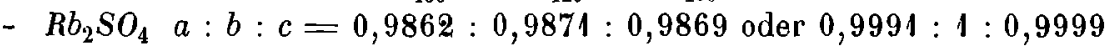

$$
\begin{aligned}
& \text { - } \mathrm{Cs}_{2} \mathrm{SO}_{4} a: b: c=0,9536: 0,9547: 0,9575 \text { - } 0,9989: 1: 1,0029
\end{aligned}
$$

Die folgenden Schlussfolgerungen gehen aus diesen Beziehungen hervor:

Die optische Elasticität der Krystalle des schwefelsauren Rubidiums liegt $\mathrm{z}$ wischen dem grösseren Werthe der Krystalle des schwefelsauren Kaliums und dem kleineren Werthederjenigen des schwefelsauren Cäsiums; dieses ist richtig, ob dieverglichenen Richtungen analog sind odernicht, weil der Unterschied zwischen dem Maximal- und dem Minimalwerthe der Elasticitätirgend eines Salzes klein ist im Vergleicbe mit den Differenzenzwischenverschiedenen Salzen. Wenn man 
dieselbe Richtung für die Vergleichung wählt, ist der Werth für das Rubidiumsalz näher demjenigen des Kaliumsalzes als demjenigen des Cäsiumsalzes, ungefährim Verhaltnis se wi e $2: 5$.

Dieses kann man noch auffallender ausdrücken wie folgt:

Die ellipsoidale Wellenoberfläche für Strablen, die von einem gemeinschaftlichen Punkte ausgehen, liegt für Rubidiumsulfat $z$ wischen den Wellenoberflächen von Kaliumsulfat und resp. Gäsiumsulfat und näherderăusseren umbällenden Wellenoberfläche des Kaliumsalzes als der inneren Wellenoberflächedes Cäsiumsulfats, approximativ in dem Verhält nisse $2: 5$.

Ferner beobachtet,man :

Der Betrag der Verminderung der optischen Elasticitä, wenn man von einem Salze zu einem anderen ubergeht, ist beinahe identisch in den Richtungen der Axen $a$ und $b$, so dass das Verhältniss der Elasticitäten zu einander in diesen zwei Richtungen praktisch constant furdiedreisalze bleibt. Die Veränderung der Elasticität längs der Axe $c$ aber wird kleiner und dies bringt eine beträchtliche Veränderungzwischen der Elasticitat längs dieser Axeund derjenigen parallel der zwei anderen Richtungen hervor.

Diese Verånderung in den Beziehungen der drei Elasticitätsaxen für irgend ein Salz wird klar ausgedrückt durch die Verhältnisse, worin $b$ als Einheit genommen ist. Die Werthe der Verhältnisse $a: b$ für die Kalium-, Rubidium- und Cäsiumsalze sind praktisch identisch, 0,9992, 0,9991 und 0,9989 , während die Verhältnisse $c: b$ sich beträchllich ändern, von 0,9975 zu 1,0029. Man beobachtet aber die interessanle Thatsache, dass Rubidium seine mitılere Stellung behält.

Diese Beziehungen können wie in Fig. 12 durch drei Curven graphisch ausgedrückt werden, welche die Elasticitälen längs der Axenrichtungen repräsentiren. Das Atomgewicht des im Salze entbaltenen Metalles isı als Ordinate und die optische Elasticität als Abscisse genommen. Zwei Reihen solcher Curven sind gegeben; die nabe liegenden punktirten Curven repräsentiren die wirklichen in der obigen Tabelle der Verhältnisse gegebenen Elasticitäten, worin die Elasticität des schwefelsauren Kaliums längs der $b$-Axe zur Einbeit genommen ist, und die ausgezogenen Curven repräsentiren die Verbältnisse, worin die Elasticitäten jedes Salzes längs der $a$ - und $c$-Axen mil der Elasticităt längs der $b$-Axe als Einheit verglichen sind. Dieselben Thatsachen werden durch beide Reihen von Curven angedeutet, aber die punktirte Linie zeigtklarer die Nähe aller drei Elasticitätswerthe jedes 
Salzes, während die ausgezogenen die Beziehungen dieser drei Werthe lür jedes Salı am besten repräsentiren.

Fig. 12.

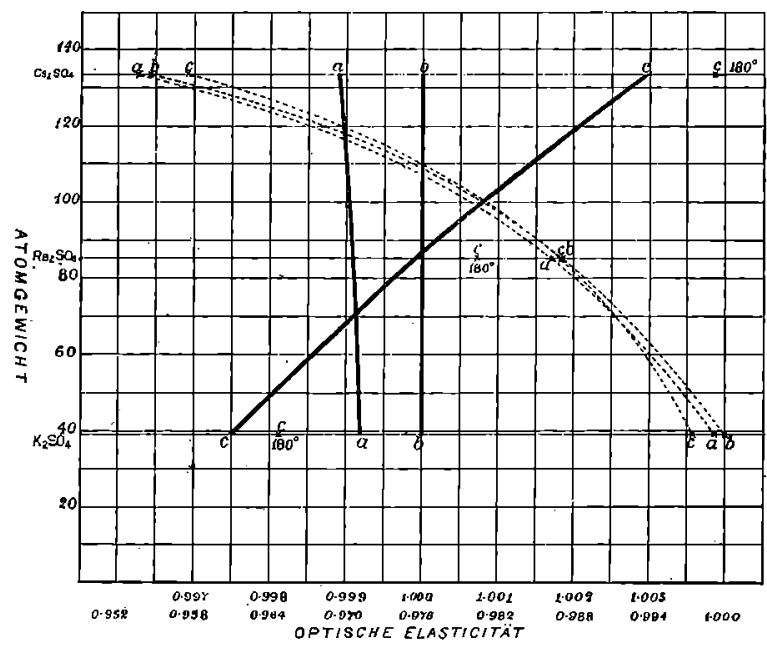

Die Natur dieser veränderten Beziehungen bei jedem Salze nebst den dadurch hervorgebrachten wichtigen Verianderungen in den optischen Eigenschaften mussen zunächst betrachtet werden.

Die praktisch gleiche Verminderung der optischen Elasticität liangs der $a$ - und $b$-Axen ist durch beinahe parallele Gurven repräsentirt; in der ausgezogenen Curve ist die Einheitselasticität längs der Axe $b$ natürlich durch eine gerade Linie repräsentirt und die Elasticitätscurve für die $a$-Axe ist beinahe auch eine gerade Linie, unbedeutend von der ersten divergirend. Dagegen wird beobachtet, dass die verhältnissmässig viel geringere Verminderung der Elasticität längs der $c$-Axe (durch grössere Steilheit in der unterbrochenen Curve für $c$ repräsentirt), welche durch Ersetzung des leichten Kaliumatoms durch das schwerere Rubidium- oder noch schwerere Cäsiumatom hervorgebracht wird, zu einem vollkommenen Umkehren des Charakters der Doppelbrechung fuhrt. Dieses ist graphisch ausgedrückt durch das Kreuzen der anderen Gurve durch die c-Curve jeder Reihe. Bei dem Kaliumsalz ist die oplische Elasticität im Minimum längs der $c$-Axe, während bei dem Cäsiumsalz sie im Maximum ist lăngs dieser Axe. Ausserdem ist der Werth der Minimal-Elasticität längs der c-Axe bei dem Kaliumalz weiter entfernt von dem mittleren Werthe längs der $a$-Axe, als der Maximalwerth längs der $b$-Axe ist; also ist diese Axe $c$ erste Mittellinie, und weil die Elasticität hier im Minimum ist, so ist die Doppelbrechung positiv. Bei dem Cäsiumsalz ist der Werth längs der c-Axe von den zwei äussersten Werthen am entferntesten von dem miltleren Werthe längs 
der $b$-Axe, so dass diese Axe wieder erste Mitlellinie ist, da jedoch die Elasticität bier ein Maximum ist, so ist das Zeichen der Doppelbrechung negativ. Es bilden also die Sulfate von Kalium und Cäsium schwach (wegen der Annäherung aller drei Werthe der optischen Elasticität), aber sonst normal positiv und resp. negativ doppeltbrechende Krystalle.

Wenn nun die krystallographischen Eigenschaften dieser drei Salze Functionen des Atomgewichtes der in ihnen enthaltenen Metalle sind, so sollte die optische Elasticität längs der $c$-Axe des schwefelsauren Rubidiums zwischen derjenigen längs derselben Axe bei den Sulfaten von Kalium und Cäsium liegen, genau wie bei den zwei anderen Axen beobachtet wird. Es ist bewiesen worden, dass dieses in der That der Fall ist. Die Wirkung aber auf die optischen Eigenschaften ist ganz ausserordentlich; denn es verursacht, dass die Elasticität längs dieser $c$-Axe beinahe identisch mit dem Werthe längs der $b$-Axe wird und zwischen den schon nahe liegenden Werthen der optischen Elasticität längs der $a$ - und $b$-Axen liegt. Daher ist schwefelsaures Rubidium eine Substanz von ausserordentlich geringer Doppelbrechung, so dass Platten von beinahe einem Centimeter Dicke nothwendig sind, um scharfe Interferenzbilder zu zeigen. Die äusserste Annäherung der mittleren und grössten Werthe der optischen Elasticilät verursacht auch, dass der optische Axenwinkel des schwefelsauren Rubidiums ausserordentlich empfindlich gegen Veränderung von Wellenlänge und Temperatur und gegenuber der Anwesenheit von Spuren der zwei anderen Salze ist.

Also wird man zu der interessanten Schlussfolgerung geführt, dass die ungewöhnlichen optischen Eigenschaften des schwefelsauren Rubidiums gerade solche sind, wie sie durch die Gültigkeit einer Regel hervorgebracht werden könnten, dass die krystallographischen Charaktere streng isomorpher Salze Functionen des Atomgewichtes der in ihnen enthaltenen Metalle sind.

Diese Thatsachen können wie folgt summarisch ausgesprochen werden :

Die geringere Verminderung der optischen Elasticität längs der Axe $c$, verglichen mit derjenigen längs der Axen $a$ und $b$, welche die Ersetzung des Kaliums durch Rubidium und des letzteren durch Cäsium begleitet, bringt eine vollständige Umkehrung der Doppelbrechung von positivzunegativhervor. Dermittlere Werth, welchendie Elasticität längs der $c$-Axe bei dem Rubidiumsalze annimmt, fällt zwischon die Werthe der Elasticität längs der Axen $a$ und $b$ und ist beinahe identisch mit demjenigen längs der Axe $b$. Da die minimalen und maximalen Werthe längs der Axen $a$ und $b$ sehr nahe zusammenliegen, zeigen die Krystalle des schwefelsauren Rubidiums so ausserordentlich geringe Doppelbrechung, dass eine Platte von beinabe einem Gentimeter Dicke nöthig ist, um ein scharfes Interferenzbildzu liefern. Die äusserste Annäherung, 
beinabe Identität, der Elasticitätswerthe für die $b$ - und $c$-Axen gestattet, dass der optische Axenwinkel des schwefelsauren Rubidiums ausnahmsweise empfindlich ist gegenuber einer Veränderung der Wellenlänge des beleuchtenden Lichtes, einer Temperaturveränderung und gegengeringe Mengen is omorpher Beimengungen. Die Dispersion der oplischen Axen dieses Salzes bei gewöhnlicher Temperaturzwischen den Wellenlängender rothen Lithiumlinie und der violetten $G$-Liniebeträgt fur $2 E$ ungefähr $35^{\circ}$ und fur $2 V_{a}$ ungefähr $20^{\circ}$. Diese ungewöhnlichen optischen Eigenschaften desschwefelsauren Rubidiums sind allein durch die Thatsache verursacht, dass diedrei Werthe der optischen Elasticität fur dieses Salz zwischen denjenigen der entgegengesetzt doppeltbrechenden Kalium-und Gäsiumsalze liegen. Also sind die optischen Eigenschaften der Krystalleder drei Salze gemeinschaftlich mit ihrergeometrischen Form Functionen der Atomgewichte der in ihnen enthaltenen Metalle.

Vergleichung der optischen Eigenschaften bei höheren Temperaturen. Es ist zunächst von Interesse zu wissen, ob die obigen Beziehungen auch bei höheren Temperaturen gültig sind.

Die folgenden Regeln sind betreffend der Brechung aller drei Salze bei Temperaturen bis zu $180^{\circ}$ beobachtet worden:

Eine regelmässige Abnahme des Brechungsvermögens, einer Zunahme der optischen Elasticität entsprechend, wird bei den Krystallen jedes der drei Salze beobachtet, wenndie Temperatur gesteigert wird.

Die Verminderung im Brechungsexponent ist am grössten fur Strahlen, deren Schwingungsrichtungen parallel zur Verticalaxe $c$ sind, und umgekebrt nimmt die optische Elasticität in dieser Richtung mit einer grösseren Schnelligkeit zu als entlang der beiden anderen Axen $a$ und $b$, in welchen Richtungen die Veränderungen approximativgleich sind. Es isl von Wichtigkeit, dass eine grössere Ausdehnung durch die Wärmeauch in der Richtung der Verticalaxe $c$ beobachtet worden ist.

Die Wirkung dieser verschiedenen Veränderung der optischen Elasticität längs der $c$-Axe, verglichen mit derjenigen längs der beiden anderen Richtungen, wird am klarsten durch die, aus den Brechungsexponenten für $180^{\circ}$ berechneten Elasticitätsverhältnisse ausgedrückt. Diese sind :

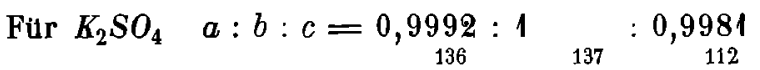

$$
\begin{aligned}
& \text { - } \mathrm{R}_{2} \mathrm{SO}_{4} a: b: c=0,9856: 0,9863: 0,9869 \text { oder } 0,9993: 1: 1,0007 \\
& \text { - } \mathrm{Cs}_{2} \mathrm{SO}_{4} a: b: c=0,9529: 0,9544: 0,9578-0,9987: 1: 1,0039 \\
& \text { Groth, Zeitschrift f. Krystallogr. XXIV. }
\end{aligned}
$$


Wenn man diese Verhältnisse mit denjenigen für gewöhnliche Temperaturen vergleicht, so bemerkt man, dass die Beziehung der optischen Elasticitäten längs irgend einer Axe bei den drei Salzen genau dieselbe bleibt innerhalb der Fehlergrenze, welch letztere natürlich bei diesen höheren Temperaturbestimmungen etwas grösser, ungefähr 0,0003 ist. Dieselbe geringere Verminderung der optischen Elasticität längs der $c$-Axe wird beobachtet, wenn man von einem Salze zu einem anderen ubergeht, während die grösseren Beträge der Verminderung längs der $a$ - und $b$-Axen approximativ gleich sind. Die Zunahme des wirklichen Werthes der optischen Elasticität, welche durch die Temperaturerböhung hervorgebracht wird, ist natürlich nicht durch diese Verhältnisse angedeutet, weil der neue Werth der Elasticităt längs der $b$-Axe des Kaliumsulfats futr $180^{\circ}$ als Einheit genommen worden ist. Sie könnte ausgedruckt werden, wenn der Werth für gewöhnlicbe Temperatur als Einbeit, genommen würde; in diesem Falle würde die $b$-Elasticität des Kaliumsulfats bei $180^{\circ} 1,0039$ anstatt 1 werden, und alle anderen Werthe würden verbältnissmässig gesteigert werden.

Die grössere Zunahme der optischen Elasticität längs der $c$-Axe irgend eines Salzes, wenn die Temperatur steigt, verglichen mit derjenigen längs der beiden anderen Axen, muss man gesondert betrachten von der geringeren Verminderung beim Uebergange von einem Salze zu einem anderen, von welcher eben erst gezeigt wurde, dass sie ähnlich derjenigen bei der gewöhnlichen Temperatur sei. Die Wirkung dieser veränderten Beziehung der c-Elasticilät zu der Elasticität längs der beiden anderen Axen, welche ihre Entfernung behalten, ist die, dass die ausgezogene $c$-Curve in Fig. 12 fast parallel mit sich selbst etwas nach rechts verschoben wird, so dass sie durch die drei mit Kreuzen bezeichneten Punkte geht. Beim Kaliumsalz nähert sich jetzt die Minimum-c-Elasticität mehr dem mittleren Werthe längs der $a$-Axe, bleibt aber noch etwas weiter davon entfernt, als die MaximumElasticität längs der $b$-Axe. Daher müsste der optische Axenwinkel des Kaliumsulfats mit der Temperatur zunehmen, was durch den Versuch auch gefunden wurde. Beim Cäsiumsalz aber verursacht Temperaturerhöhung, dass die $c$-Elasticität sich noch weiter vom mittleren Werthe längs der $b$ Axe entfernt, wodurch der optische Axenwinkel bei der Erhitzung sich vermindern müsste, was ebenfalls mit der experimentellen Beobachtung übereinstimmt. Bei dem interessanten Falle des Rubidiumsulfats liegt die neue Stellung der $c$-Axe auf der entgegengesetzten Seite der $b$-Elasticität für die gewöhnliche Temperatur und so weit auf der anderen Seite bei $180^{\circ}$, dass sie beinahe so weit entfernt von dem jetzt mittleren Werthe längs der $b$-Axe, als die Minimum-Elasticität längs der $a$-Axe ist. Es ist also bei dieser hohen Temperatur die Ordnung der $b$ - und $c$-Axen umgekehrt und die optische Axenebene von $a b$ in $a c$ ubergegangen; die Doppelbrechung ist noch positiv und die Axe $a$ erste Mittellinie, eine ganz geringe 
Temperaturerhöbung reicht indessen hin, um die Doppelbrechung negativ und die Axe $c$ zur ersten Miltellinie zu machen.

Also ist die Ueberholung der optischen Elasticität $b$ durch diejenige längs der $c$-Axe die Ursache der schönen optischen Axenwinkelphänomene des schwefelsauren Rubidiums, welche beobachtet werden, wenn man eine Platte senkrecht zur ersten Mittellinie $a$ erwärmt. Man kann jetzl völlig verstehen, warum eine so geringe Temperaturerhöhung ein Kreuzen der optischen Axenebene hervorbringen kann, denn die Elasticität $c$ bei gewöhnlicher Temperatur ist so nahe dem $b$-Werthe, dass verhältnissmässig wenige Grade Erhitzung genugen, um den $c$-Werth identisch mit dem $b$ Werthe zu machen und so die rasche Annäherung der optischen Axen aneinander bis zum Auftreten des einaxigen Bildes zu bewirken, wonach bei noch weiterer Erhitzung der $c$-Werth den $b$-Werth ubertrifft und die optischen Axen sich wieder in der senkrechten Ebene trennen. Natúrlich wird wegen der starken Dispersion der oplischen Axen die Einaxigkeit zuersı für Roth und bei etwas höheren Temperaturen für die anderen Farben nach einander eintreten.

Es giebt noch einen anderen Punkt bezüglich dieser relativ grösseren Zunahme der optischen Elasticităt längs der c-Axe, welcher bemerkenswerth ist. Die Entfernung der Curve für diese Axe bei $180^{\circ}$ von derjenigen für die gewöhnliche Temperatur ist nicht durchaus gleich, das heisst die Gurven sind nicht parallel; sie weichen von einander mit der Zunahme des Atomgewicbtes des in dem Salze enthaltenen Metalles ab und ihre Entfernung für das Rubidiumsalz liegt in der Mitte zwischen jener bei dem Kalium- und Cäsiumsalz. Die Differenz zwischen den $c$-Verhältnissen des schwefelsauren Kaliums bei gewöhnlicher Temperatur und bei $180^{\circ}$ ist 0,0006 , für das Rubidiumsalz 0,0008 und für Cäsiumsulfat 0,0010 ; und zwar ist es auffallend, wie vollkommen Rubidiumsulfat seine miltlere Stellung sogar in Rucksicht auf das geringste Delail der krystallographischen Eigenschaften behält.

Diese Thatsachen kann man wie folgt zusammenfassen:

Die Beziehungen zwischen den optischen Elasticitäten der drei Sulfate bei gewöhnlicher Temperatur werden noch bei höheren Temperaturen bewahrt; Rubidiumsulfat behält immer seine mittlere Stellung inne. Also ist die Behauptung, dass die oplischen Eigenschaften der Krystalle der drei Salze Functionen des Atomgewichtes der in ihnen enthaltenen Metalle sind, von der Temperatur unabhängig.

Die durch Temperaturerhöhung bervorgebrachtegrössere Beschleunigung der optischen Elasticität längs der c-Axe bringt eine ausserordentliche Veränderung in denoptischen Eigenschaften des Rubidiumsulfats hervor. Beim Kalium- 
sulfat bewirkt sie nur einekleine Zunahmedes optischen Axenwinkels und beim Cäsiumsulfat eine kleine Abnahme. Beidem Rubidiumsulfat aber verursacht sie, dass die optische Elasticität längs der $c-A x e$, welche bei gewöhnlicher Temperatur die mittlere Elasticitat und nur wonig geringerals das Maximum längs der $b$-Axe ist, sich dem Werth der $b$-Elasticitätnähert und fur eine sehr geringe Steigerung der Temperatur identisch damit wird, wodurch der Krystalloptisch einaxigwird. Bei weiterer Erhitzung uberschreitet die $c$-Elasticitä den $b$ Werth und wird die maximale Elasticitat. Wenn man daher einezur ersten Mittellinie $a$ sentrechte Platte erwärmt, nähern sich die den optischen Axen entsprechenden Hyperbeln in ihrer Ebene $a b$ einander, bis siesich in der Mittedes Gesichtsfeldesvereinigen, um in daseinaxige Bild uberzugeben; bei fortdauernder Erhitzungtrennensich die Axen in dersenkrechten Ebene ac wieder und ihre Entfernung nimmt immer mehrzu bis sie aus dem Gesichtsfeldetreten und die Axe cerste Mittellinie und die vorber positive Doppelbrechung negativ wird. Wegen dergrossen Dispersion der optischen Axen (uber $30^{\circ} \mathrm{zw}$ ischen roth und violelt) wird das einaxige Bild fur verschiedene Wellenlängen bei verschiedenen auf einander folgenden Temperatureneintreten, zuerst fur Rotb, zuletzt für Violett; die Mitteltemperatur für die Entstehung des einaxigen Bildes liegt bei ungefähr $50^{\circ}$. Diese ausserordentlichen optischen Eigenschaften des schwefelsauren Rubidiums sind also die naturliche Folgeder gegenseitigen Beziebungen der drei optischen Elasticitätswerthe dieses Salzes, bervorgerufen durch die Wirkung der oben festgestellten Regel, welche die optischen Eigenschaften mit dem Atomgewichte des in dem Salze enthaltenen Metalles verbindet.

Es wird zunächst interessant sein zu fragen, ob irgend ein Zusammenbang zwischen den Beziehungen der optischen Elasticität und den Volumbeziehungen $\mathrm{zu}$ beobachten ist.

Was die Volumänderungen bei der Ersetzung eines Metalles durch ein anderes anbetrifft, so wurde gezeigt, dass die topischen Axen zunehmen mit der Zunahme des Atomgewichtes des metallischen Atoms und dass die $b$-Axe am meisten und die $a$-Axe am wenigsten verlängert wird. Wenn man auf die wirklichen Werthe der topischen Axen zurückgeht, so sieht man, dass die Verlängerung längs der $b$-Axe beinahe zweimal so gross als diejenige längs der $a$-Axe ist; die Beträge sind 385 zu 216. Die Längen dieser Axen sind aber beinahe in diesem Verhältnisse, 1 zu 0,5727. Wenn die Einheitslänge sich um 385 ausdehnt, sollte 0,5727 sich ausdehnen um 220. Also 
dehnen sich diese Axen beinabe genau im Verbältniss ihrer Längen aus. Wenn man dagegen die Beziehungen der Axen $b$ und $c$ betrachtet, so bemerkt man, dass der Betrag der Ausdehnung beinahe in jeder Richtung gleich ist, während die ursprünglichen Längen sich wie 1 zu 0,7418 verhalten. Also verlängert sich die $c$-Axe verhältnissmässig zu ihrer Länge viel mehr als die $b$-Axe.

Was die optische Elasticität betrifft, so ist bewiesen worden, dass die Veränderungen durch Eintreten eines schwereren Metalles ebenfalls ähnlich sind; die Beziehungen der $a$ - und $b$-Axen bleiben beinahe dieselben, wäbrend das Verhältniss $c: b$ sehr beträchtlich zunimmt.

Also ist es klar, dass die Beziehungen der Werthe der optischen Elasticität längs der drei Axenrichtungen in ähnlicher Weise variiren wie die relativen Längen der Axen. Es ist aber scheinbar kein Zusammenhang zwischen ihren numerischen Werthen; die wirklichen Werthe sind verschiedener Ordnung, denn während die $b$-Axe die längste bei allen drei Salzen ist und die $a$-Axe die kurzeste, ist die Ordnung der optischen Elasticitäten ganz verschieden. Ausserdem ist die Zunahme in den Längen aller Axen, wenn das Atomgewicht steigt, von einer Abnahme der optischen Elasticităt längs aller Axenrichtungen begleitet.

Aus den obigen Betrachtungen kann man zum folgenden Schlusse kommen :

Ein Zusammenhang wird zwischen den Beziehungen der Werthe der optischen Elasticität längs derdrei Richtungen der krystallographischen Axen und den Beziehungen der Längen dieser Axen beobachtet; eine sehrgeringe Veränderung des Verhält $t$ isses $a: b$ findet in beiden Fällen statt und eineviel grössere in dem Verhältnisse $c: b$, und dieseVeränderungen finden nach denselben Richtungen fur diebeiden Eigenschaften statt. Die wirklichen Werthe scheinen keine Beziehung zu zeigen mit Ausnahmeder, dass die Werthe fur Rubidiumsulfat immerdazwischen liegen. Es ist daherwahrscheinlich, dass der wirkliche Werth der optischen Elasticität nichteine Function des Krystallelementes, des physikalischen Molekuls, sondern des chemischen Molekuls ist. Die Thatsache, dass die optische Elasticität in einer der Modificirung der Axenverhältnisse analogen Weise modificirt wird, scheintdie Voraussetzung zu bestätigen, dass das Krystallelement selbst mit einer äbnlichen Symmetriewie diejenige des Krystallesbegabtist in Bezug auf die innere Anordnung der chemischen Molekule, aus denen es aufgebaut ist.

\section{Molekulare optische Constanten.}

Da man annehmen kann, dass bei einer streng isumorphen Reihe solcher Salze wie die untersuchten Sulfate, die Krystallelemente aus derselben 
Anzahl von Molekülen zusammengesetzt werden, so ist es wahrscheinlich, dass die molekularen Refractionen und Dispersionen, aus den Formeln von Loren z oder von Gladstone und Dale berechnet, streng vergleichbare Werthe sein werden, ob sie Functionen des Krystallelementes, des chemischen Molekuls oder der beiden zusammen sind.

Die specifischen und molekularen Refractionen sind daher für die Wellenlängen der zwei Wasserstofflinien $C$ und $G$ dieselben Strahlen, welche auch $B r u ̈ b l$ in Betracht ziebt, berechnet worden. Die Differenz ist als die Dispersion angenommen. Die Constanten sind nach analogen Richtungen in den Krystallen der drei Salze angeordnet.

Refractionsconstante.

\begin{tabular}{|c|c|c|c|c|c|c|c|}
\hline \multirow{3}{*}{$\begin{array}{c}\text { Für } \\
\text { die Linie }\end{array}$} & \multirow{2}{*}{$\mathrm{K}_{2} \mathrm{SO}_{4}$} & \multicolumn{6}{|c|}{ Specifische Refraction $\frac{n^{2}-1}{2}$} \\
\hline & & $\begin{array}{c}\text { a. } \\
0,1092\end{array}$ & & $\begin{array}{c}\mathrm{b} . \\
0,1089\end{array}$ & & $\begin{array}{c}\text { c. } \\
0,1096\end{array}$ & Diff. \\
\hline & $\mathrm{Rb}_{2} \mathrm{SO}_{4}$ & 0,0832 & 260 & 0,0830 & 259 & 0,0831 & 265 \\
\hline$C\left(H_{\alpha}\right)$ & $\mathrm{Cs}_{2} \mathrm{SO}_{4}$ & 0,0767 & 65 & 0,0765 & 65 & 0,0759 & 72 \\
\hline
\end{tabular}

Molekulare Refraction $\frac{n^{2}-1}{n^{2}+2} \cdot \frac{M}{d}=$ m.

a. Diff.: b. $\frac{\text { biff.: } \text { c. }}{\text { Diff: }}$

\begin{tabular}{|c|c|c|c|c|c|c|}
\hline $\begin{array}{l}\text { Fur } \\
\text { die Linie }\end{array}$ & $\left\{\begin{array}{l}\mathrm{K}_{2} \mathrm{SO}_{4} \\
R b_{2} \mathrm{SO}\end{array}\right.$ & $\begin{array}{l}18,99 \\
22,16\end{array}$ & 3,17 & $\begin{array}{l}18,96 \\
22,12\end{array}$ & 3,16 & $\begin{array}{l}19,08 \\
22,13\end{array}$ \\
\hline$C\left(\boldsymbol{H}_{\boldsymbol{\alpha}}\right)$ & $\mathrm{Cs}_{2} \mathrm{SO}_{4}$ & 27,71 & 5,55 & 27,63 & 5,51 & 27,45 \\
\hline
\end{tabular}

Specifische Refraction $\frac{n^{2}-1}{\left(n^{2}+2\right) d}=\mathbb{i n}$.

a. $\quad$ Diff.: $\quad$ b. $\frac{\text { Diff.: }}{\text { c. }} \overline{\text { Diff: }}$

$\underset{G\left(H_{\gamma}\right)}{\operatorname{Fur}}\left\{\begin{array}{llrrrrr}\mathrm{K}_{2} \mathrm{SO}_{4} & 0,1110 & & 0,1107 & & 0,1115 & \\ \mathrm{Rb}_{2} \mathrm{SO}_{4} & 0,0847 & 263 & 0,0845 & 262 & 0,0846 & 269 \\ \mathrm{Cs}_{2} \mathrm{SO}_{4} & 0,0782 & 65 & 0,0780 & 65 & 0,0774 & 72\end{array}\right.$

Molekulare Refraction $\frac{n^{2}-1}{n^{2}+2} \cdot \frac{M}{d}=$ A.

\begin{tabular}{|c|c|c|c|c|c|c|c|}
\hline & & a. & Diff.: & b. & Diff: & c. & $\overline{\text { Diff: }}:$ \\
\hline Fưr & $K_{2} \mathrm{SO}_{4}$ & 19,31 & 3,26 & 19,27 & 3,25 & 19,40 & 3,13 \\
\hline die Linie & $\mathrm{Rb}_{2} \mathrm{SO}_{4}$ & 22,57 & 5,69 & 22,52 & $\begin{array}{l}5,40 \\
5,66\end{array}$ & 22,53 & 5,45 \\
\hline$G\left(H_{\gamma}\right)$ & $\mathrm{Cs}_{2} \mathrm{SO}_{4}$ & 28,26 & & 28,18 & & 27,98 & \\
\hline
\end{tabular}

Dispersionsconstante.

\begin{tabular}{|c|c|c|c|c|c|c|}
\hline \multirow[b]{2}{*}{ Axen } & \multicolumn{3}{|c|}{$\begin{array}{c}\text { Specifische Dispersion } \\
\mathbb{H}_{G}-\mathbb{H}_{\mathrm{C}}\end{array}$} & \multicolumn{3}{|c|}{$\begin{array}{c}\text { Molekulare Dispersion } \\
\mathbb{A A l}_{G}-\mathfrak{A} \mathbb{A} C\end{array}$} \\
\hline & a. & b. & c. & a. & b. & c. \\
\hline $\mathrm{K}_{2} \mathrm{SO}_{4}$ & 0,0018 & 0,0018 & 0,0019 & 0,32 & 0,31 & 0,32 \\
\hline $\mathrm{Rb}_{2} \mathrm{SO}_{4}$ & 0,0015 & 0,0015 & 0,0015 & 0,41 & 0,40 & 0,40 \\
\hline $\mathrm{Cs}_{2} \mathrm{SO}_{4}$ & 0,0015 & 0,0015 & 0,0015 & 0,55 & 0,55 & 0,53 \\
\hline
\end{tabular}


Hieraus ergeben sich die folgenden Beziehungen zwischen den Werthen für die drei Salze:

Die molekulare Refraction und Dispersion der Kryslalle der normalen Sulfate von Kalium, Rubidium und Cäsium, nach der Formel von Lorenz berechnet, nimmt mit dem Atomgewichte des in dem Salze enthaltenen Metalles zu, so dass die Werthe fur das Rubidiumsalz zwischen denjenigen für die Kalium-und Gäsiumsalze liegen. Die Zunahmesteigt mit der Steigerungdes Atomgewichtes, so dass die Differenzenzwischen den Gonstanten für die Cäsium- und Rubidiumsalze grösser als diejenigen $z$ wischen den Werthen fur die Rubidium-und Kaliumsalze sind. Diese Sätze gelten in gleicher Weise, ob analoge Richtungen für die. Vergleichung ausgewählt werden oder nicht, und im Falle der Refraction fúr irgend welche Wellenlänge die Vergleichung gemacht wird. Es wirdaber beobacbtet, dass die Zunabme längs der Richtung der Verticalaxec langsamer als entlang der Richtungender beiden seitlichen Axen fortschreitet, in welchenzwei letzteren Richtungen die Schnelligkeit der Zunabme beinahe identisch ist.

Die obigen Beziehungen stimmen völlig mit denjenigen der Elasticitätsverhältnisse überein. Man kann zunächst fragen, ob ähnliche Beziehungen erhalten werden bei den aus der Formel von Gladstone und Dale berechneten Molekularrefractionen. Die folgenden sind die Werthe von $\frac{n-1}{d} M$ für die Wellenlänge der rothen Wasserstofflinie $C$ :

\begin{tabular}{|c|c|c|c|c|c|c|}
\hline & a. & Diff.: & b. & Diff.: & c. & Diff.: \\
\hline $\mathrm{K}_{2} \mathrm{SO}_{4}$ & 32,22 & 5,61 & 32,14 & 5,60 & 32,39 & 5,36 \\
\hline $\begin{array}{l}\mathrm{R} b_{2} \mathrm{SO}_{4} \\
\mathrm{Cs} \mathrm{SO}_{4}\end{array}$ & $\begin{array}{l}37,83 \\
48,05\end{array}$ & 10,22 & $\begin{array}{r}37,74 \\
47,89\end{array}$ & 10,15 & $\begin{array}{l}37,75 \\
47,50\end{array}$ & 9,75 \\
\hline
\end{tabular}

Man wird gleich bemerken, dass ganz ähnliche Beziehungen erhalten werden, wie bei Anwendung der Lorenz'schen Formel.

Man kann jetzt weiter fragen, ob diese Beziehungen bloss zufällig für die gewöhnliche Temperatur oder gülig für alle in Betracht kommenden Temperaturen sind. Da die Veränderungen der Dichtigkeit und Refraction fur Temperaturerhöhung bestimmt worden sind, kann man die molekulare Refraction für eine höhere Temperatur gerade berechnen. Die höchste Temperatur der Refractionsversuche, $180^{\circ}$, ist für die Vergleichung ausgewählt worden.

Aus den Bestimmungen der kubischen Ausdehnung der Salze wurden ihre specifischen Gewichte bei $\frac{180^{0}}{4^{0}}$ durch Berechnung wie folgt gefunden: 


$$
\mathrm{K}_{2} \mathrm{SO}_{4} \quad 2,6080 ; \quad \mathrm{Rb}_{2} \mathrm{SO}_{4} \quad 3,5377 ; \quad \mathrm{Cs}_{2} \mathrm{SO}_{4} \quad 4,1585 .
$$

Die specifischen und die molekularen Refractionen, berechnet vermittelst der Lor enz'schen Formel aus den obigen Dichtigkeiten und den Brechungsexponenten bei $180^{\circ}$ für die Wellenlängen der $\mathrm{Na}$-Linien sind die folgenden :

Specifische Refraction.

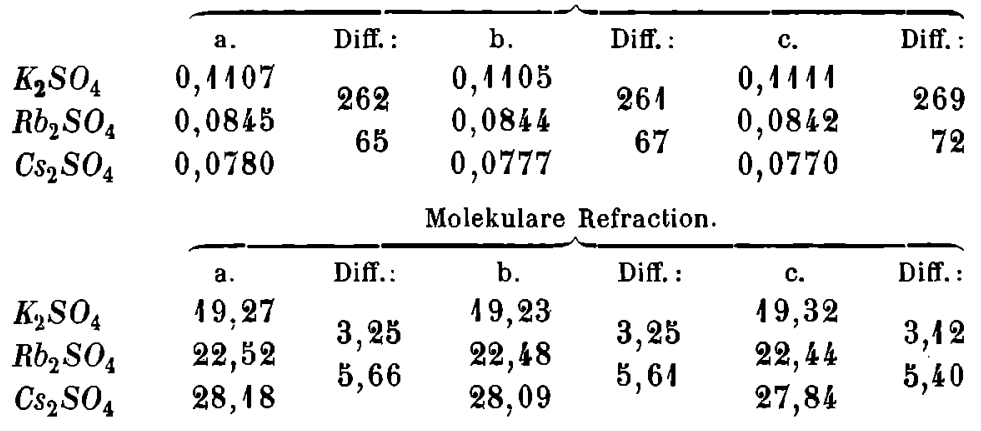

Die molekularen Refractionen für $180^{\circ}$ und die Linie $C$ nach der Formel von Gladstone und Dale berechnet sind wie nachstehend:

\begin{tabular}{|c|c|c|c|c|c|c|}
\hline & a. & Diff.: & b. & Diff.: & c. & Diff.: \\
\hline $\mathrm{K}_{2} \mathrm{SO}_{4}$ & 32,54 & & 32,44 & 572 & 32,63 & \\
\hline $\mathrm{Rb}_{2} \mathrm{SO}_{4}$ & 38,24 & $\begin{array}{r}5,70 \\
038\end{array}$ & 38,16 & $\begin{array}{r}5,72 \\
1098\end{array}$ & 38,09 & 985 \\
\hline $\mathrm{Cs}_{2} \mathrm{SO}_{4}$ & 48,62 & 10,58 & 48,44 & & 47,94 & \\
\hline
\end{tabular}

Die Werthe für die Molekularrefraction bei $180^{\circ}$, aus beiden Formeln berechnet, sind also beinahe identisch mit denjenigen fur die gewöhnliche Temperatur und ihre Beziehungen sind genau dieselben. Man kann daher betreffs der Molekularrefraction die folgende weitere Schlussfolgerung hinzufugen :

Die nach der Formel von Gladstone und Daleberechneten molekularen Refractionen zeigen genau ähnliche Beziehungen wiejenenach der Lorenz'schen Formel abgeleiteten. Ausserdem sind die Werthe der specifischen und molekularen Refraction fur die Temperatur von $180^{\circ} \mathrm{praktisch}$ identisch mit denjenigen fur diegewöhnliche Temperatur undzeigengenau dieselben Beziehungen. Die Beziehungen zwischen den Refractionsconstanten der drei Salzesind also von der Temperaturganzunabbängig.

\section{Zusammenfassung der Schlussfolgerungen.}

Die Hauptresultate dieser Untersuchung sind die folgenden.

1. Die normalen Sulfalte von Kalium, Rubidium und Gäsium weichen, was ihre Löslichkeit in Wasser anbelangt, sehr von einander ab. Schwe- 
felsaures Kalium ist schwer, schwefelsaures Rubidium ziemlich und schwefelsaures Cäsium leicht löslich in Wasser. Die mittlere Stellung des Rubidiums wird bei allen Temperaturen bewahrt.

2. Im Habitus nähern sich diese drei Salze einander mehr, als es bei den Kalium resp. Rubidium und Gäsium enthaltenden monosymmetrischen Doppelsulfaten beobachtet worden ist. Die vorherrschenden relativen Beträge der Entwickelung der primären Flächen aber deuten ein Fortschreiten an von dem Kalium- durch das Rubidium- zum Gäsiumsalz, d. h. dem Fortschreiten des Atomgewichtes des im Salz enthaltenen Metalles entsprechend.

3. Die Werthe aller Winkel des Rubidiumsalzes liegen ohne Ausnahme zwischen den Werthen der analogen Winkel der Kalium- und Cäsiumsalze. Die Differenzen zwischen den Grössen analoger Winkel sind kleiner als diejenigen, welche bei den Doppelsulfaten beobachtet worden sind und sind zu klein, um einen definitiven Schluss uber die Beziehung der Differenzen entsprechend die Ersetzung des Kaliums durch Rubidium und des Rubidiums durch Cäsium zu gewäbren.

4. Die Axenverhäl t $\mathrm{n}$ isse für Rubidiumsulfat liegen zwischen denjenigen fur Kalium- und Cäsiumsulfat. Das Verhältniss $a: b$ nimmt ab, aber nur sehr wenig, wenn Kalium durch Rubidium oder letzteres durch Cäsium ersetzt wird, während das Verhältniss $c: b$ beträchtlich zunimmt.

5. Goniometrische Messungen bei höberen Temperaturen deuten an, dass Schlussfolgerungen 3. und 4. ganzunabhängig vonder Temperatur sind.

6. Die Spaltungsrichtungen der drei Sulfate sind identisch und parallel dem Brachypinakoid und der Basis. Keine Spaltbarkeit ist sebr vollkommen, doch ist diejenige parallel dem Brachypinakoid die vollkommenste von beiden.

7. Das specifische Gewicht. und Molekularvolum des schwefelsauren Rubidiums liegen zwischen den Werthen dieser Constanten fur Kalium- und Căsiumsulfat. Eine grössere Volumzunahme begleitet die Ersetzung des Rubidiums durch Cäsium als diejenige, welche beobachtet wird, wenn Kalium durch Rubidium ersetzt wird; das Verbältniss der respectiven Veränderungen ist 11,4 zu 8,4 .

8. Die Dichtigkeiten der drei Sulfate nehmen im Verhältniss ibrer numerischen Werthe ab, wenn man ibre Temperatur erhöht, so dass die kubischen Ausdehnungscoëficienten beinahe identisch sind; die Differenzen sind ungefähr die Fehlergrenzen. Bestimmungen der linearen Ausdehnungscoefficienten deuten an, dass bei jedem Salze die grösste Ausdehnung in der Richtung der Verticalaxe stattfindet.

9. Die topischen Axenverhältnisse deuten an, dass die Ersetzung des Kaliums durch Rubidium und des Rubidiums durch Cäsium von 
einer Zunahme der Entfernung der Krystallelemente längs jeder der Axenrichtungen begleitet ist, und diese Zunahme ist relativ viel grösser, wenn Rubidium durch Cäsium, als wenn Kalium durch Ruhidium ersetzt wird. Der Betrag der Zunahme variirt in den drei Hauptrichtungen; er ist am grössten in der Richtung der $b$-Axe und am geringslen längs der $a$-Axe, während der Betrag der Zunahme in der Richtung der $c$-Axe beinahe gleich dem Maximum längs der $b$-Axe ist. Die Zunahme längs der Axen $a$ und $b$ ist beinahe genau im Verhältniss zu den Längen jener Axen, während die Zunahme längs der $c$-Axe viel grösser im Verhältniss zu ihrer Länge ist.

10. Die Spaltungsrichtungen, die Ebenen vom kleinsten Inbalte, sowie die Häufigkeil der an den Krystallen beobachteten Formen deuten an, dass d a s Elementarparallelepiped der Reihe ein rechtwinkliges rhombisches Prisma ist. Die Veränderung der topischen Axenverhältnisse kann vollständig aus der Voraussetzung erklärt werden, dass das Krystallelement der Reihe von vier chemischen Molekulen aufgebaut wird, wovon die Atome oder Gruppen symmetrisch in Bezug auf die drei Ebenen der rhombischen Symmetrie angeordnet sind.

11. Die Brechungsexponenten des schwefelsauren Rubidiums liegen zwischen denjenigen der Sulfate von Kalium und Cäsium und am nächsten denjenigen des Kaliumsalzes; die Differenzen zwischen den Exponenten der Sulfate von Kalium und Rubidium auf der einen Seite und denjenigen der Sulfate von Rubidium und Cäsium auf der anderen besitzen das Verhältniss 2: מ. Eine Zunahme des Refractionsvermögens begleitet eine Zunahme des Atomgewichtes des im Salz enthaltenen Metalles, und die Zunahme wird verhältnissmässig grösser, wenn das Atomgewicht steigt.

12. Die optische Elasticität der Krystalle des schwefelsauren Rubidiums liegt zwischen dem grösseren Werthe der Krystalle des schwefelsauren Kaliums und dem kleineren Werthe derjenigen des schwefelsauren Cäsiums; dieses gilt, ob die verglichenen Richtungen in den Krystallen analog sind oder nicht, weil der Unterschied zwischen dem Maximal- und Minimalwerthe der Elasticität irgend eines Salzes klein ist, wenn er mit den Differenzen zwischen verschiedenen Salzen verglichen wird. Wenn man dieselbe Richtung für die Vergleichung wählt, ist der Werth für das Rubidiumsalz näher demjenigen des Kaliumsalzes als demjenjgen des Cäsiumsalzes, ungefähr im Verhältnisse 2: 5 .

Oder anders ausgedruckt :

Die ellipsoidale Wellenoberfläche liegt für Rubidiumsulfat zwischen den Wellenoberflächen von Kalium- und Cäsiumsulfat und näher der äusseren umhullenden Wellenoberfläche des Kaliumsalzes als der inneren Wellenoberfläche des Cäsiumsulfats, approximativ nach dem Verhältniss $2: 5$.

13. Der Betrag der Verminderung der optischen Elasticität, wenn man 
von einem Salz zu einem anderen ubergeht, ist beinahe identisch in den Richtungen der Axen $a$ und $b$, so dass das Verhältniss der Elasticitäten zu einander in diesen zwei Richtungen praktisch constant für die drei Salze bleibt. Die Veränderung der Elasticität längs der Axe $c$ aber schreitet langsamer fort und bringt also eine beträchtliche Veränderung der Beziehungen zwischen der Elasticität längs dieser Axe und derjenigen entsprechend den beiden anderen Richtungen hervor. Diese Veränderung ist so beträchtlich, dass eine vollständige Umkehrung der D oppelbrechung, von positiv in dem Kaliumsalz zu negativ in dem Cäsiumsalz, hervorgebracht wird. Der mittlere Werth, welchen die Elasticităt längs der c-Axe bei dem Rubidiumsalz annimmt, fällt zwischen die Werthe der Elasticität längs der Axen $a$ und $b$, und ist beinabe identisch mit demjenigen längs der Axe $b$. Da die minimalen und maximalen Werthe längs der Axen $a$ und $b$ sehr nahe zusammen liegen, zeigen die Krystalle des schwefelsauren Rubidiums so ausserordentlich geringe Doppelbrechung, dass eine Platte von beinahe einem Centimeter Dicke nöthig ist, um ein scharfes Interferenzbild zu geben. Die äusserste Annuherung, beinahe Identität, der optischen Elasticitätswerthe fur die $b$ - und $c$-Axen gestattet, dass der oplische Axenwinkel des schwefelsauren Rubidiums ausnahmsweise empfindlich ist gegenưber einer Veränderung der Wellenlänge des beleuchtenden Lichtes, einer Temperaturveränderung und der Anwesenheit isomorpher Beimischungen. Die Dispersion der optischen Axen dieses Salzes bei gewöhnlicher Temperatur, zwischen den Wellenlängen der rothen Lithiumlinie und der violetten $G$-Linie, beträgt für $2 E$ ungefähr $35^{\circ}$ und für $2 V_{a}$ ungefähr $20^{\circ}$.

Diese ungewöhnlichen optischen Eigenschaften des schwefelsauren Rubidiums sind allein durch die Thatsache verursacht, dass die drei Werthe der optischen Elasticität für dieses Salz zwischen denjenigen der entgegengesetzt doppelbrechenden Kalium- und Cäsiumsalze liegen. Also sind die optischen Eigenschaften der Krystalle der drei Salze, gemeinschaftlich mit ihrer geometrischen Form, Funclionen der Atomgewichte der in ihnen enthaltenen Metalle.

14. Eine regelmässige Verminderung des Refractionsvermögens, einer Zunahme der optischen Elasticität entsprechend, wird bei den Krystallen jedes der drei Salze beobachtet, wenn die Temperatur gesteigert wird. Die Veränderung ist am grössten für Strahlen, deren Schwingungsrichtung parallel zur c-Axe ist, und die geringeren Veränderungen in den Axenrichtungen $a$ und $b$ sind approximativ gleich. Die Beziehungen aber, welche für die gewöhnliche Temperatur festgestellt wurden, bleiben auch bei böheren Temperaturen erhalten; Rubidiumsulfat bewahrt immer seine mittlere Stellung. Die wichtige Schlussfolgerung am Ende des letzten Paragraphen ist daher unabbängig von der Temperalur.

15. Die durch Tempernturerhöhung hervorgebrachte Beschleunigung. 
der optischen Elasticität längs der $c$-Axe bringt eine ausserordentliche Veränderung in den optischen Eigenschaften des Rubidiumsulfats hervor. Beim Kaliumsulfat bewirkt sie nur eine kleine Zunahme des optischen Axenwinkels, und beim Cäsiumsulfat eine kleine Abnahme. Beim Rubidiumsulfat aber verursacht sie, dass die optische Elasticität längs der $c$-Axe, bei gewöhnlicher Temperatur die mittlere Elasticität und nur wenig geringer als das Maximum längs der $b$-Axe, sich dem Werthe der $b$-Elasticilät nähert und fur eine sebr geringe Steigerung der Temperatur identisch damit wird, wodurch der Krystall optisch einaxig wird. Bei weiterer Erhitzung überschreitet die $c$-Elasticität den $b$-Werth und wird maximal. Wenn man daher eine zur ersten Miltellinié $a$ senkrechte Platte erwärmt und sie im convergenten polarisirten Lichte beobachtet, so nähern sich die den optischen Axen entsprechenden Hyperbeln in ihrer Ebene $a b$ einander, bis sie sich in der Mitte des Gesichtsfeldes vereinigen, um in das einaxige Bild uberzugehen, worauf sie sich in der dazu senkrechten Ebene ac wieder trennen. Wegen der grossen Dispersion der optischen Axen wird das einaxige Bild bei verschiedenen auf einander folgenden Temperaturen für die verschiedenen Wellenlängen eintreten, zuerst für Roth, fur $L i$-Licht bei $40^{\circ}$ und furr $G$-Licht bei $65^{\circ}$.

16. Ein Zusammenhang wird $z w i s c h e n$ den Beziehungen der Werthe der optischen Elasticität längs der drei Richtungen der krystallographischen Axen und den Beziehungen der Längen der Axen beobachtet; eine sehr geringe Veränderung des Verhältnisses $a: b$ findet in beiden Fällen statt und eine viel grössere in dem Verhältniss $c: b$, und diese Veränderungen entsprechen denselben Richtungen für die beiden Eigenschaften. Die wirklichen Werthe scheinen keine Beziehung zu besitzen, mit Ausnahme der, dass die Werthe fur Rubidiumsulfat immer dazwischen liegen. Es ist daher wabrscheinlich, dass der wirkliche Werth der optischen , Elasticilät nicht eine Function des Krystallelements, des physikalischen Molekuls, sondern des chemischen Molekuls ist. Die Thatsache, dass die optische Elasticität in einer der Modificirung der Axenverhältnisse analogen Weise modificirt wird, scheint die Voraussetzung zu bestätigen, dass die Krystallelemente selbst mit einer ähnlichen Symmetrie wie diejenige des Krystalls begabt sind in Bezug auf die innere Anordnung der chemischen Molekule, aus denen sie aufgebaut sind.

17. Die molekulare Refraction und Dispersion der Krystalle der drei Salze, ob sie nach den Formeln von Loren z oder von Gl ad st one und Da le berechnet sind, nehmen mil dem Atomgewicht des darin enthaltenen Metalles zu, so dass Rubidiumsulfat wieder in dieser Hinsicht dazwischen liegt. Die Zunabme steigt mit der Steigerung des Atomgewichtes, so dass die Differenzen zwischen den Constanten für die Gäsium- und Rubidiumsalze grösser als diejenige zwischen den Werthen für die Rubidium- und 
Kaliumsalze sind. Diese Sätze gelten ebenso, ob analoge Richtungen für die Vergleichung ausgewählt werden oder nicht, und bezuglich der Refraction, für jede Wellenlänge, für welche die Vergleichung auch gemacht wird. Es wird indessen beobachtet, dass die Zunahme längs der Richtung der Verticalaxe $c$ langsamer als entlang der Richtungen der zwei seitlichen Axen fortschreitet, in welchen zwei letzteren Richtungen die Schnelligkeit der $\mathrm{Zu}-$ nahme beinabe identisch ist.

Diese Beziehungen sind ganz unabhängig von der Temperatur.

18. Es ist jetzt bewiesen worden, dass die krystallographischen Eigenschaften der drei Sulfate ein regelmässiges Fortschreiten zeigen, demjenigen des Atomgewichtes der in ihnen enthaltenen Metalle entsprechend. In jeder Eigenschaft, ob morphologische oder physikalische, steht das Rubidiumsalz zwischen den Kalium- und Cäsiumsalzen. Die Ersetzung des Rubidiums durch Cäsium aber wird gewöhnlich von einer grösseren Modificirung der krystallographischen Eigenschaften begleitet, als wenn Kalium durch Rubidium ersetzt wird; das schwerere Atom uibt also eine Wirkung aus, welche grösser ist als sie dem Verhältniss in der Zunahme des Atomgewichtes entspricht. Die Vergleichungsresultate fur die verschiedenen Eigenschaften sind alle einander parallel; die Beziehungen der Beträge der Veränderung längs der krystallographischen Axenrichtungen sind in allen Fällen ähnlich. Ausserdem ist das Fortschreiten nach dem Atomgewichte auch im Hinblick auf die geringsten Einzelheiten der physikalischen Phänomene bemerkbar und ganz unabhängig von der Temperatur.

Aus der ganzen Untersuchung leitet sich die folgende Hauptschlussfolgerung her:

Die gesammten krystallographischen Eigenschaften der streng isomorphen rhombischen Normalsulfate von Kalium, Rubidium und Cäsium sind Functionen des Atomgewichles des in ihnen enthaltenen Metalls.

Verf. arbeitet jetzt an den physikalischen Eigenschaften der Doppelsulfate. Die Untersuchung wird auch durch eine ähnliche Arbeit über die entsprechenden einfachen und Doppelselenate derselben drei Metalle erweitert, und es ist die Absicht des Verf., eventuell die analogen einfachen und doppelten Ammonium- und Thalliumsalze der Schwefelsäure und Selensäure in diese Untersuchung einzubeziehen. 